Aus der Klinik für Innere Medizin I

mit den Schwerpunkten Gastroenterologie, Hepatologie, Pneumologie, internistische Intensivmedizin, Endokrinologie, Infektiologie, Rheumatologie, Ernährungs- und

Alterungsmedizin

(Direktor: Prof. Dr. Stefan Schreiber)

im Universitätsklinikum Schleswig-Holstein, Campus Kiel an der Christian-Albrechts-Universität zu Kiel

\title{
Variantenspezifische Wirkung des Transkriptionsfaktors ATF3 in Zusammenhang mit Nrf2-abhängiger Stressantwort in Pankreaskarzinomzellen
}

\author{
Inauguraldissertation \\ zur \\ Erlangung der Doktorwürde der Medizin \\ der Medizinischen Fakultät \\ der Christian-Albrechts-Universität zu Kiel \\ vorgelegt von \\ MY-LAN KHA \\ aus Hamburg
}

Kiel 2018 
1. Berichterstatter: Prof. Dr. Heiner Schäfer 2. Berichterstatter: Prof. Dr. Thomas Valerius Tag der mündlichen Prüfung: 03.07.2019

Zum Druck genehmigt, Kiel, den

gez.:

(Vorsitzender der Prüfungskommission) 


\section{Inhaltsverzeichnis}

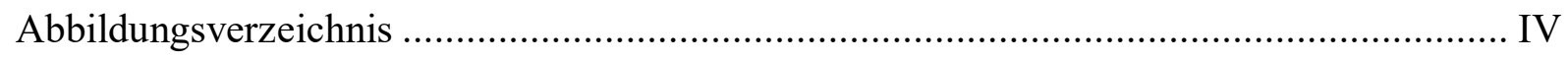

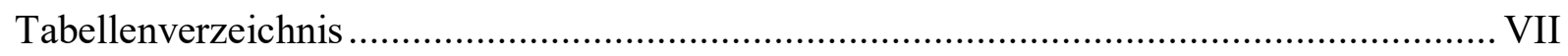

Abkürzungsverzeichnis.......................................................................................

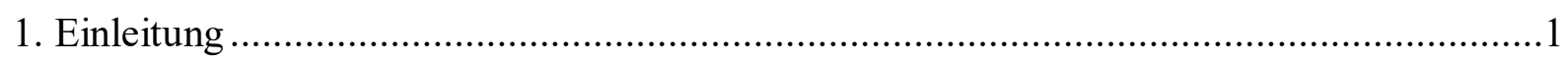

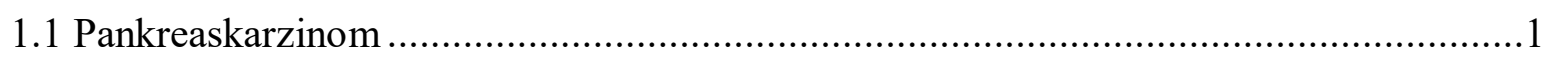

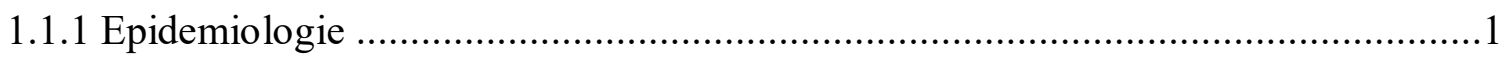

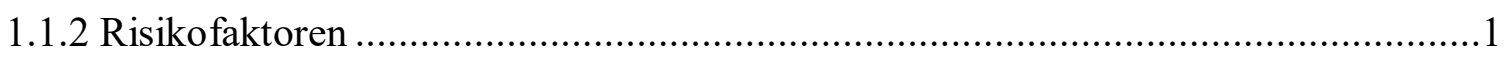

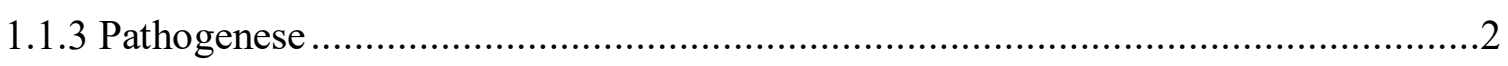

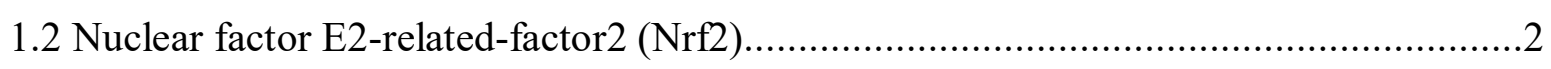

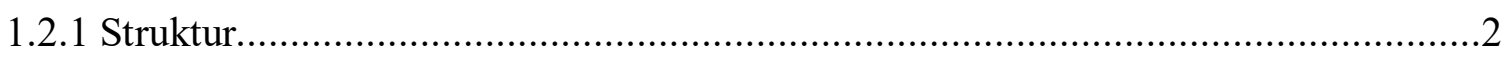

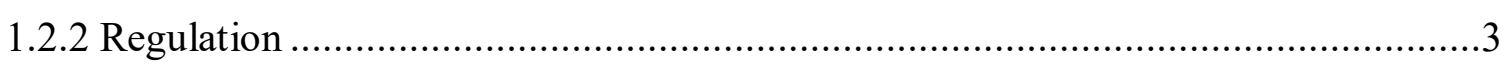

1.2 .3 Zielgene

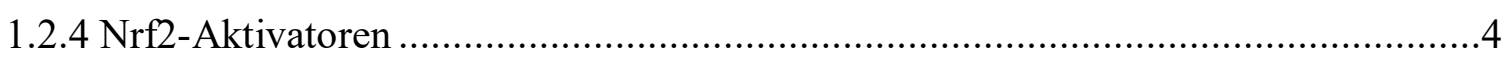

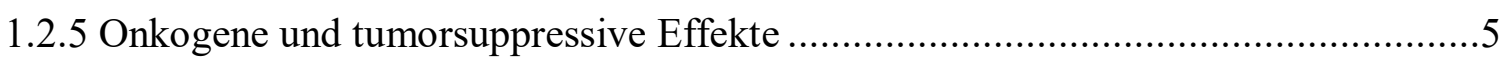

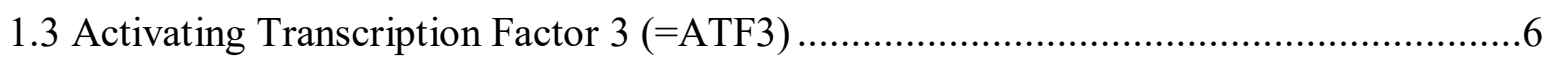

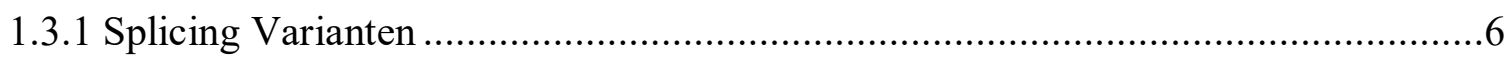

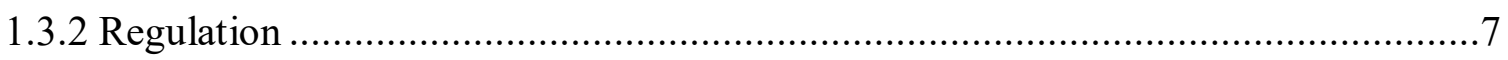

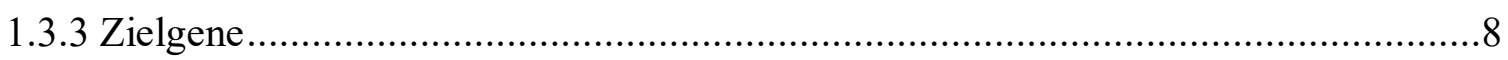

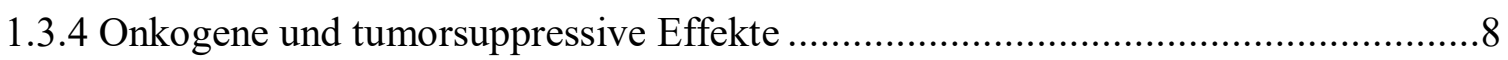

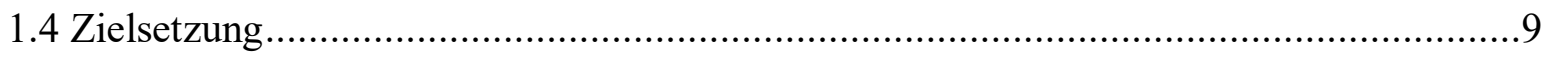

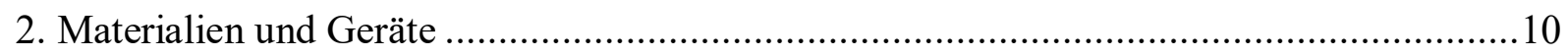

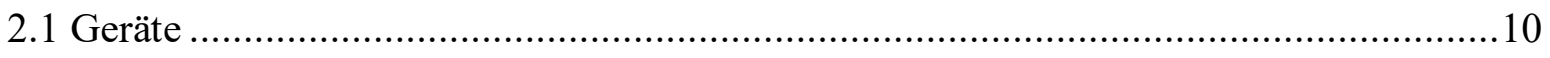

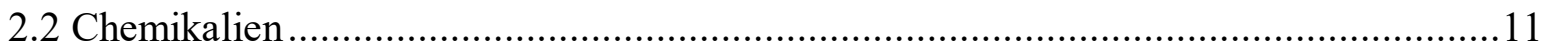

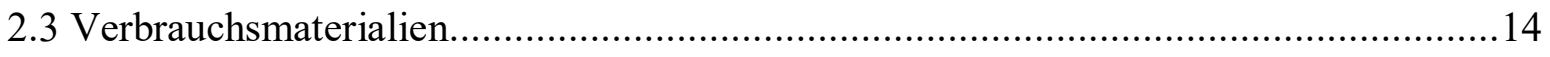

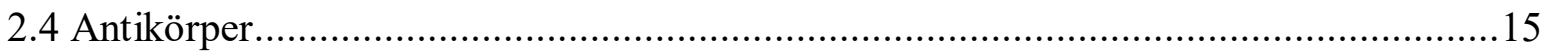

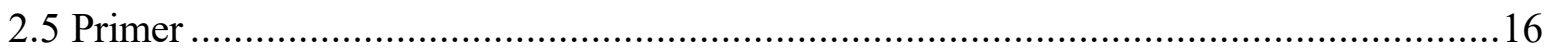

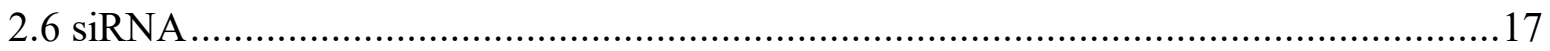

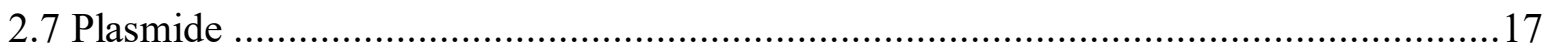

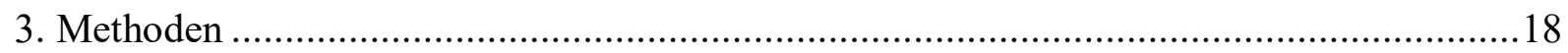

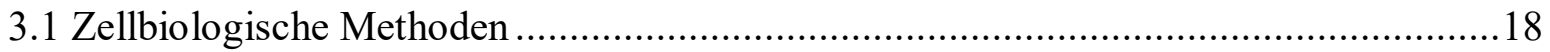


3.1.1 Zelllinien

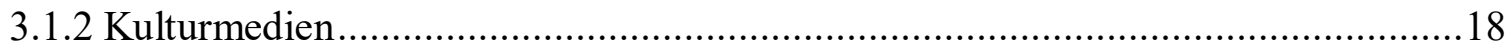

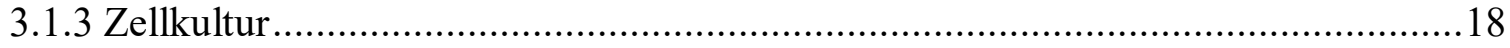

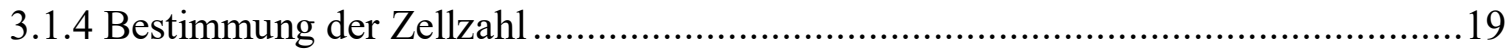

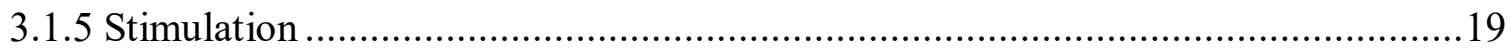

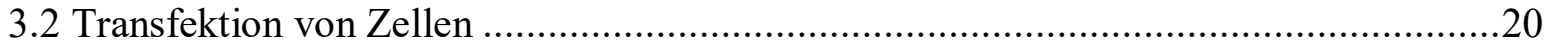

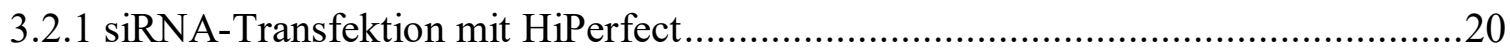

3.2.2 Plasmid-DNA Transfektion mit Lipofectamin......................................................20

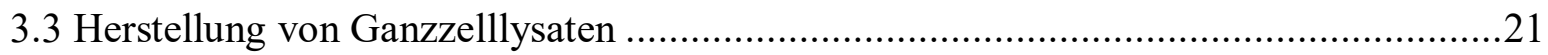

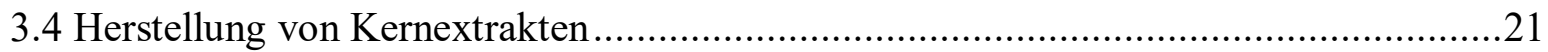

3.5 Bestimmung von Proteinkonzentrationen .............................................................22

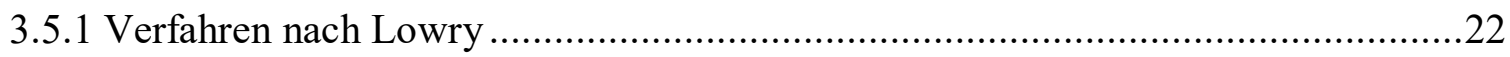

3.5.2 Verfahren nach Bradford ...........................................................................2. 23

3.6 SDS-PAGE (Natriumdodecylsulfat-Polyacrylamid-Gelelektrophorese) .....................23

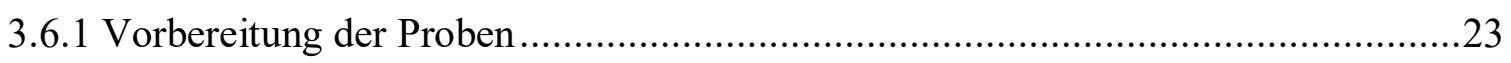

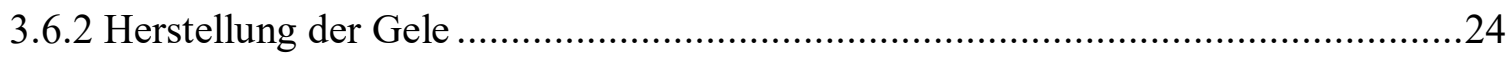

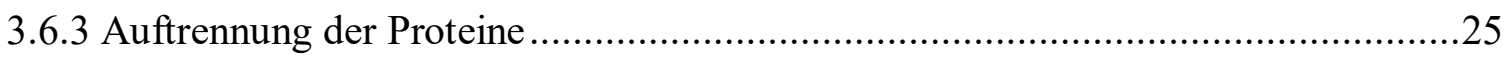

3.7 Western-Blot nach Semidry-Blotting Verfahren .................................................25

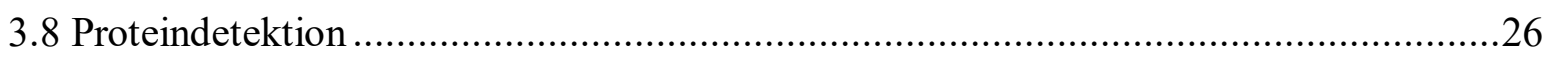

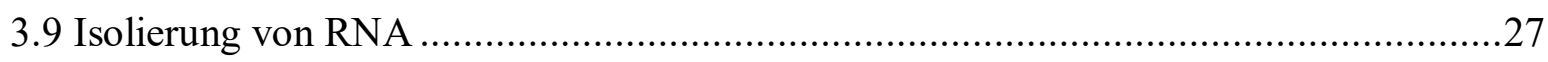

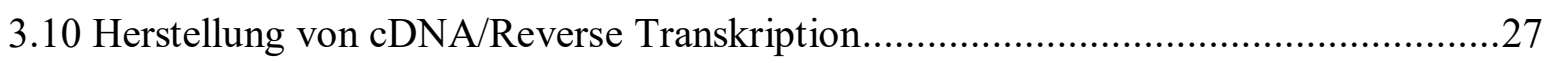

3.11 Quantitative Polymerase-Ketten-Reaktion/RealTime PCR .....................................28

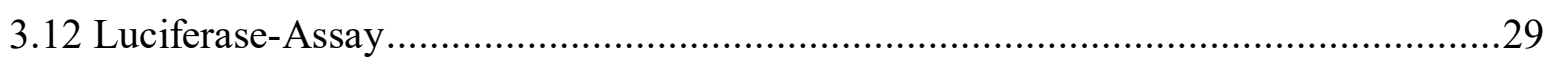

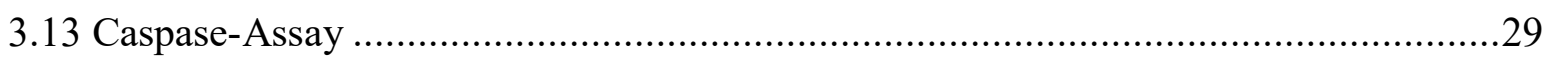

3.14 Zellzyklus-Analyse mit Propidiumiodid-Färbung ............................................. 30

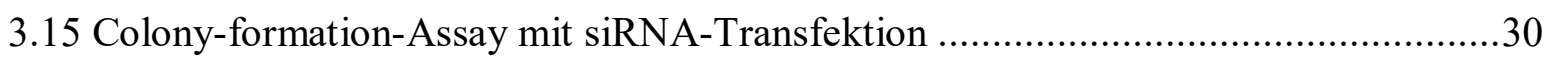

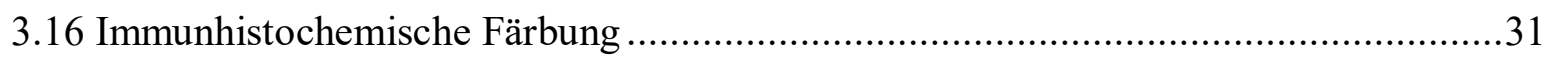

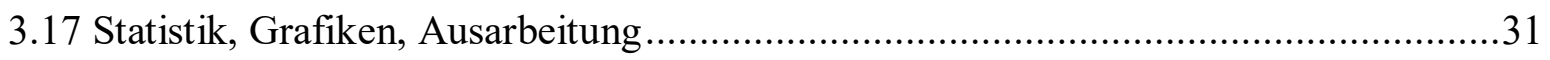

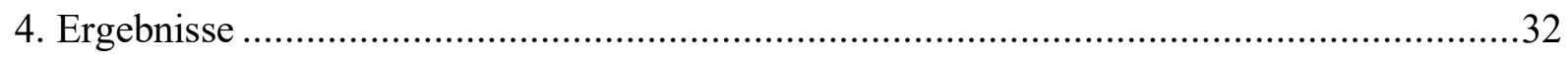

4.1 Induktion von ATF3 und $\Delta$ Zip2 durch TGF- $\beta 1$, tBHQ und Oltipraz...........................32

4.2 Rekrutierung verschiedener Promotorregionen im ATF3-Gen durch tBHQ, TGF- $\beta 1$ und

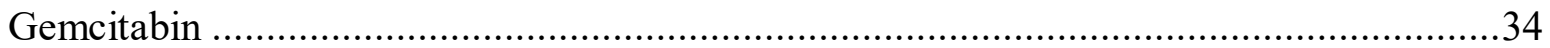

4.3 Induktion von pro- und antiapoptotischen Gene durch $\Delta$ Zip2 und ATF3 ...................37 
4.4 Wirkung des Chemotherapeutikums Gemcitabin auf die Expression von ATF3 und $\Delta$ Zip2

4.5 Einfluss von ATF3 und $\triangle$ Zip2 auf die Gemcitabin-induzierte Apoptose

4.6 Einfluss von ATF3 und $\triangle$ Zip2 auf die TRAIL-induzierte Apoptose . .43

4.7 Veränderungen im Zellzyklus und koloniales Wachstum unter ATF3 und $\Delta$ Zip2 45

4.8 Koexpression von $\triangle \mathrm{Zip} 2$ und Nrf2 in PDAC- und CP-Gewebe 47

5. Diskussion

5.1 Bedeutung der Promotor Rekrutierung für die unterschiedliche Ausprägung des ATF3Gens

5.2 Effekte von ATF3 und $\triangle$ Zip2 auf den Phänotyp von malignen und prämalignen

Pankreasgangepithelzellen

5.3 Resistenzentwicklung gegenüber Chemotherapeutika am Beispiel von Gemcitabin in Abhängigkeit von ATF3 und $\triangle$ Zip2

5.4 Rolle von $\triangle$ Zip2 in der entzündlichen Karzinogenese des Pankreas und seine

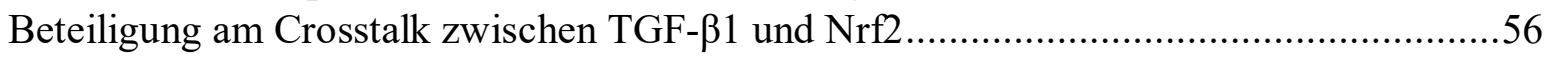

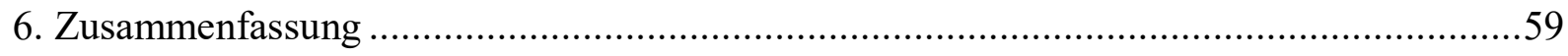

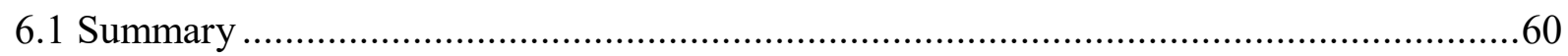

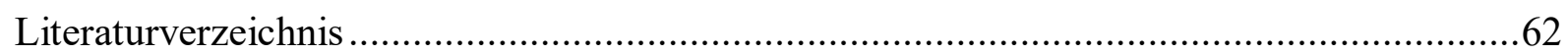

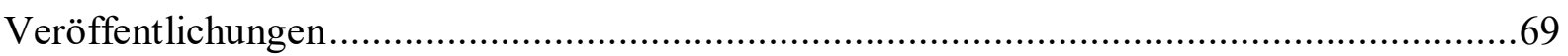

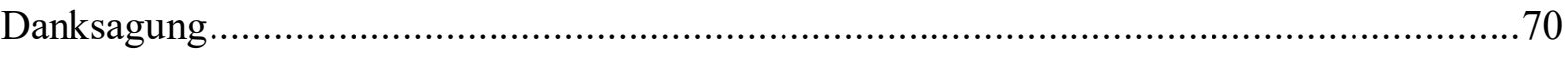

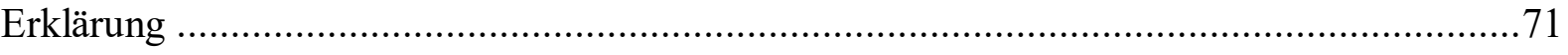




\section{Abbildungsverzeichnis}

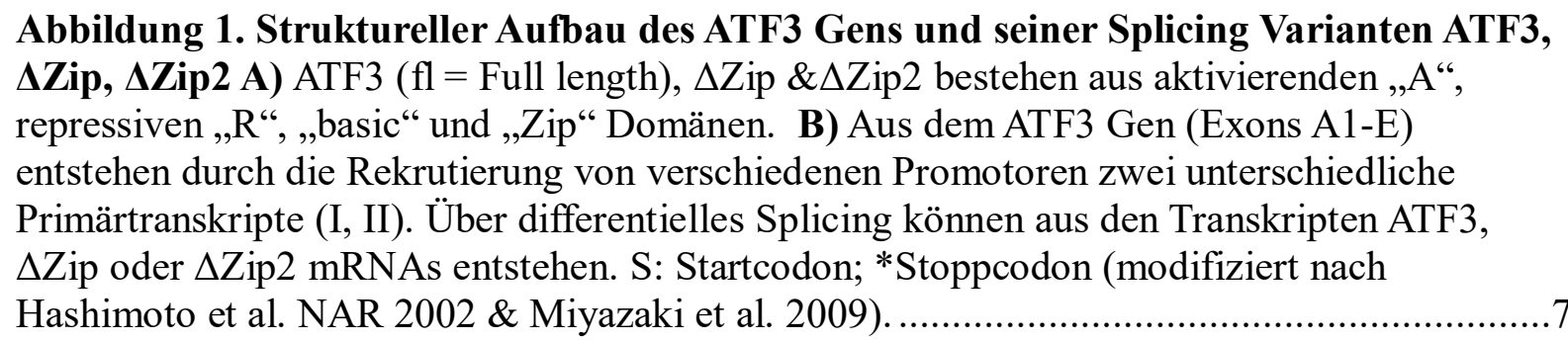

Abbildung 2. Induktion der Expression von $\triangle \mathrm{Zip2}$ und ATF3 mittels tBHQ, TGF- $\beta 1$ und Oltipraz in Panc1, T3M4 und H6c7 sowie nach Nrf2 Überexpression A) Quantitative PCR Analyse auf den Gehalt von ATF3 und $\triangle$ Zip2 in unbehandelten Zellen bzw. in Zellen nach $8 \mathrm{~h}$ Behandlung mit $50 \mu \mathrm{M}$ tBHQ oder $10 \mathrm{ng} / \mathrm{ml}$ TGF- $\beta 1$. Daten repräsentieren die Mittelwerte aus sechs unabhängigen Experimenten. ${ }^{*} p<0.02$ B) C) D) Zellkernextrakte aus B) unbehandelten Zellen bzw. aus Zellen nach Behandlung mit $50 \mu \mathrm{M}$ tBHQ oder 10ng/ml TGF$\beta 1$ für $8 \mathrm{~h}$ bzw. C) nach Behandlung mit $50 \mu \mathrm{M}$ tBHQ oder $50 \mu \mathrm{M}$ Oltipraz für $8 \mathrm{~h} \mathrm{bzw}$. D) nach Transfektion mit Nrf2-cDNA bzw. Kontroll-cDNA (mock) wurden im Westernblot auf den Gehalt von ATF3 und $\triangle$ Zip2 untersucht. Lamin A/C dient als Ladekontrolle. Der Nachweis von Nrf2 in C) dient als Kontrolle für die erfolgreiche Nrf2-cDNA Transfektion. Daten repräsentieren die Mittelwerte aus vier und drei unabhängigen Experimenten.............33

Abbildung 3. Einfluss von tBHQ, TGF- $\beta 1$ und Gemcitabin auf die Rekrutierung von unterschiedlichen Promotorregionen des ATF3-Gens Das ATF3-Gen besitzt einen distalen (P1) und einen proximalen (P2) Promotor. Die entstehenden Primärtranskripte unterscheiden sich durch den Besitz von A) Exon A1, das vom P1-Promotor entspringt und B) Exon A, das vom P2-Promotor abstammt. A) B) Panc1, T3M4 und H6c7 wurden unbehandelt oder jeweils mit $50 \mu \mathrm{M}$ tBHQ, $10 \mathrm{ng} / \mathrm{ml}$ TGF- $\beta 1$ oder $20 \mu \mathrm{g} / \mathrm{ml}$ Gemcitabin für $16 \mathrm{~h}$ behandelt.

Anschließend erfolgte eine qPCR Analyse unter Einsatz von A) Exon A1 und B) Exon A spezifischen 5' Primer in Kombination mit einem Exon B spezifischen 3' Primer. Die Daten repräsentieren den Mittelwert aus vier unabhängigen Experimenten; ${ }^{*} p<0.05,{ }^{*} p<0.01$. C) Schema des proximalen (P2) Promotors des ATF3 Gens und seiner beiden Nrf2 Bindungsstellen (ARE). Nach Kim et al. 2010.

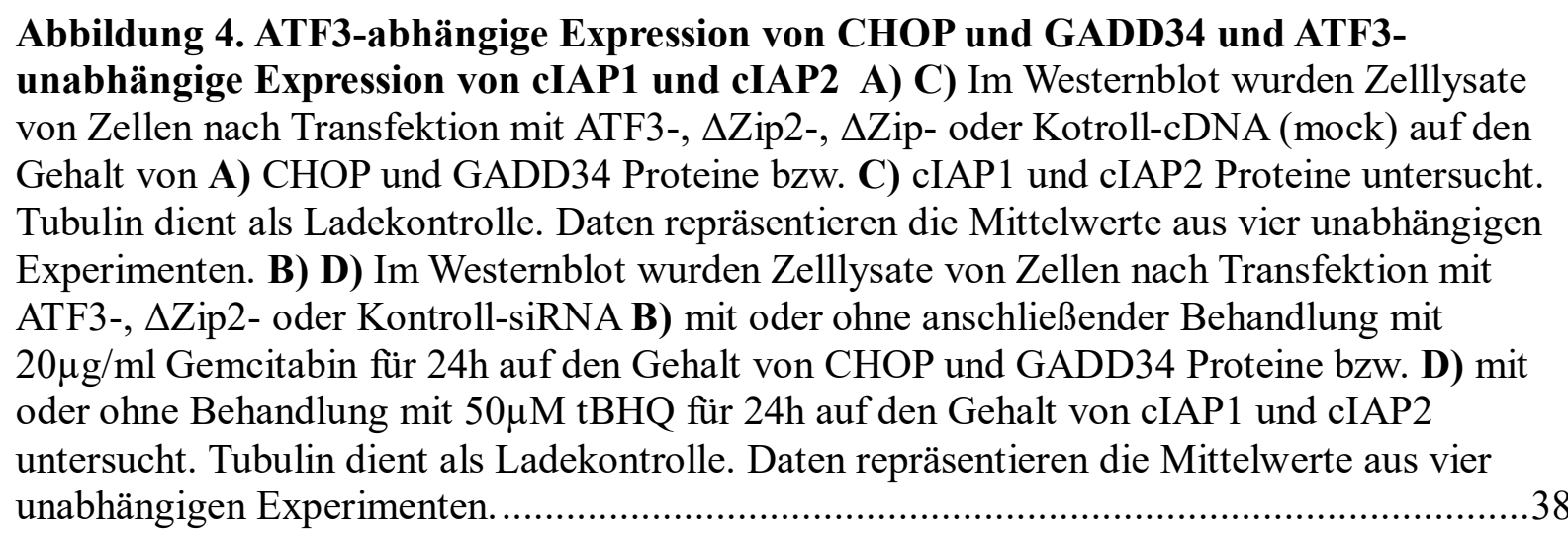


Abbildung 5. Expression von ATF3 und $\triangle \mathrm{Zip2}$ unter Gemcitabin in Panc1, T3M4 und H6c7 A) C) qPCR Analysen auf den Gehalt von $\triangle$ Zip2- bzw. ATF3-mRNA von A) unbehandelten Zellen oder Zellen nach Behandlung mit $20 \mu \mathrm{g} / \mathrm{mL}$ Gemcitabin $(\mathrm{Ge})$ für $8 \mathrm{~h}$ bzw. C) nach Transfektion mit Nrf2-siRNA oder Kontroll-siRNA mit oder ohne anschließende Behandlung mit $20 \mu \mathrm{g} / \mathrm{ml}$ Gemcitabin für $8 \mathrm{~h}$. Daten repräsentieren den Mittelwert aus 4 unabhängigen Experimenten; ${ }^{*} p<0.05,{ }^{* *} p<0.01$. B) D) Kernextrakte aus B) unbehandelten Zellen oder Zellen nach Behandlung mit $20 \mu \mathrm{g} / \mathrm{ml}$ Gemcitabin (Ge bzw. Gemz) für 8h bzw. D) nach Transfektion mit Nrf2-siRNA oder Kontroll-siRNA mit oder ohne anschließende Behandlung mit $20 \mu \mathrm{g} / \mathrm{ml}$ Gemcitabin für $8 \mathrm{~h}$ wurden im Westernblot auf den Gehalt von ATF3 und $\triangle$ Zip2 Proteine untersucht. Lamin A/C dient als Ladekontrolle. In D) dient die Untersuchung auf Nrf2 Proteine als Kontrolle für die erfolgreiche Nrf2-siRNA Transfektion. Daten repräsentieren den Mittelwert von 3 unabhängigen Experimenten.

Abbildung 6. Apoptoseverhalten von Panc1, T3M4 und H6c7 unter Gemcitabin in Abhängigkeit von ATF3, $\Delta$ Zip2 und $\Delta$ Zip A) B) Aktivität von Caspase-3/-7 (normiert an den zellulären Proteingehalt) in Zellen A) nach Transfektion mit ATF3-, $\Delta$ Zip2-, $\Delta$ Zip- oder Kontroll-cDNA (mock) mit oder ohne anschließender Behandlung mit $20 \mu \mathrm{g} / \mathrm{ml}$ Gemcitabin für 24h bzw. B) nach Transfektion mit ATF3-, $\triangle$ Zip2- oder Kontroll-siRNA mit oder ohne anschließender Behandlung mit 50 $\mathrm{M}$ tBHQ oder 10ng/ml TGF- $\beta 1$ für $16 \mathrm{~h}$ und darauffolgend eine Behandlung mit $20 \mu \mathrm{g} / \mathrm{ml}$ Gemcitabin für 24h. Die Daten repräsentieren

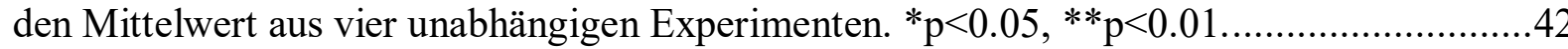

Abbildung 7. Apoptoseverhalten von T3M4 und Panc1 Zellen gegenüber TRAIL in Abhängigkeit von einer Überexpression von ATF3, $\Delta$ Zip2, $\Delta$ Zip A) B) Aktivität von Caspase-3/-7 (normiert an den zellulären Proteingehalt) in Zellen A) nach Transfektion mit ATF3-, $\Delta$ Zip2-, $\Delta$ Zip- oder Kontroll-cDNA (mock) mit oder ohne anschließender Behandlung mit $0,5 \mathrm{mg} / \mathrm{ml}$ TRAIL für $8 \mathrm{~h}$ bzw. B) nach Transfektion mit ATF3-, $\Delta Z i p 2-$ oder Kontroll-siRNA mit oder ohne anschießender Behandlung mit $50 \mu \mathrm{M}$ tBHQ oder $10 \mathrm{ng} / \mathrm{ml}$ TGF-ß1 für 16h und darauffolgend eine Behandlung mit $0,5 \mathrm{mg} / \mathrm{ml}$ TRAIL für $8 \mathrm{~h}$. Die Daten repräsentieren die Mittelwerte aus drei unabhängigen Experimenten.

Abbildung 8. Auswirkungen von ATF3 und $\triangle \mathrm{Zip2}$ auf Zellzyklus und Koloniales Wachstum A) Analyse des Zellzyklus nach Transfektion mit ATF3-, $\triangle$ Zip2- oder KontrollsiRNA mit oder ohne Behandlung mit $50 \mu \mathrm{M}$ tBHQ oder 10ng/ml TGF- $\beta 1$. Die Daten repräsentieren den Mittelwert aus sechs unabhängigen Experimenten. B) Färbung der Zellen mit Kristallviolett nach Transfektion mit ATF3-, $\triangle$ Zip2- oder Kontroll-siRNA mit oder ohne anschließende Behandlung mit 50 $\mu \mathrm{M}$ tBHQ. Für die Auswertung wurden Fotos geschossen und Kolonien $>0.25 \mathrm{~mm}$ gezählt. Die Daten repräsentieren den Mittelwert aus vier unabhängigen Versuchen. ${ }^{*} \mathrm{p}<0.05$.

Abbildung 9. Kolokalisation von aktiviertes Nrf2 mit $\triangle$ Zip2 in PDAC- und CP-Gewebe Unter Einsatz von spezifischen Antikörper gegen aktiviertes Nrf2 (p-Nrf2), $\Delta$ Zip2 und ATF3 wurden Gewebe von A) vier PDAC Patienten im G3 Stadium und B) drei CP Patienten mit PanIN1/2 Läsionen immunhistochemisch aufgearbeitet. Darstellung in 200x Vergrößerung..50 


\begin{abstract}
Abbildung 10. Hypothetisches Modell über die Induktion von ATF3 und seiner Varianten durch Nrf2 und TGF- $\beta 1$ und ihre Auswirkungen auf den Phänotyp. Die differentielle Induktion der ATF3 Varianten kann durch die Rekrutierung von unterschiedlichen transkriptio-nellen Startsequenzen (,Promotor I“ und „Promotor II“, Abb.1) ermöglicht werden. Vermutlich spielen auch epigenetische Effekte eine Rolle. Nrf2 induziert $\triangle$ Zip2 stärker als ATF3 und fördert dadurch das Zellüberleben und Zellproliferation. Dahingegen induziert TGF- $\beta 1$ ATF3 und hemmt damit das Zellüberleben bzw. Zellproliferation. $\Delta$ Zip und $\triangle$ Zip2 wirken beide hemmend auf ATF3, wobei erstere stärker hemmt (aus Kha et al. 2018)




\section{Tabellenverzeichnis}

Tabelle 1. Primär- und Sekundärantikörper für den Einsatz in Westernblot ..........................15

Tabelle 1.2 Primär- und Sekundärantikörper für den Einsatz in der Immunhistochemie ........ 15

Tabelle 2. Primer für den Einsatz in der quantitativen PCR/Realtime PCR ........................16

Tabelle 3. siRNA für die Transfektion mit HiPerfekt ....................................................... 17

Tabelle 4. cDNA/Plasmide für die Transfektion mit Lipofectamin..................................... 17

Tabelle 5: Zusammensetzung der Reagenzien für siRNA-Transfektion mit HiPerFect..........20

Tabelle 6: Zusammensetzung Plasmid-DNA-Transfektion mit EffecteneTM (Qiagen) ........21

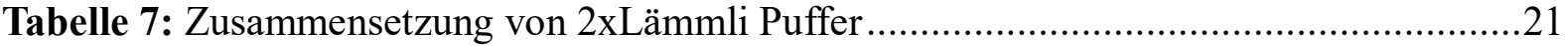

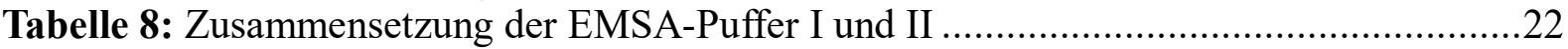

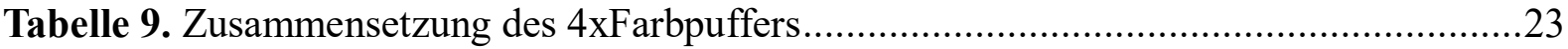

Tabelle 10. Zusammensetzung des Trenn- und Sammelgels für die Gelelektrophorese .........24

Tabelle 11. Zusammensetzung von TBS-T, Blot-Puffer-I, -II, -III .....................................25

Tabelle 12. Zusammensetzung des Mastermix für die reverse Transkription........................28

Tabelle 13. Zusammensetzung des Mastermix für die quantitative PCR ............................28 


\section{Abkürzungsverzeichnis}

AK

APS

ARE

BSA

CHOP

cIAP

$\mathrm{CP}$

dest.

DMSO

DNA

DTT

EDTA

EMT

EZM

FACS

FCS

$\mathrm{h}$

HEPES

GCLC

$\operatorname{Ig}$

IL

$\min$

$\mathrm{mM}$
Antikörper

Ammoniumpersulfat

Antioxidant response element

Bovines Serumalbumin

C/EBP homologous protein

Cellular inhibitor of apoptosis protein

Chronische Pankreatitis

destilliert

Dimethylsulfoxid

Deoxyribonucleic acid

Dithiothreitol

Ethylendiamintetraacetat

Epitheliale-mesenchymale Transition

Extrazelluläre Matrix

Fluorescence-activated cell sorting

Fötales Kälberserum

Stunde

2-(4-(2-Hydroxyethyl)-piperazinyl)ethansulfonsäure

Glutamate-cysteine ligase catalytic subunit

Immunglobulin

Interleukin

Minute

Millimol 
$\mathrm{ml}$

$N F-\kappa B$

Nrf2

NQO1

PanIN

PBS

PI

PDAC

PMSF

PVDF

ROS

rpm

RPMI

RT

SDS

SFN

tBHQ

TBS

TBS-T

TGF- $\beta 1$

TRAIL

$\mathrm{v} / \mathrm{v}$

$\mathrm{w} / \mathrm{v}$

X
Milliliter

Nuclear factor 'kappa-light-chain-enhancer' of activated Bcells

Nuclear factor E-2 related factor 2

NAD(P)H Dehydrogenase [Quinone 1]

Intraepitheliale Neoplasien des Pankreas

Phosphatgepufferte Salzlösung

Propidiumiodid

Pancreatic ductal adenocarcinoma

Phenylmethylsulfonylfluorid

Polyvinylidenfluorid

Reactive oxygen species

Revolutions per minute

Rosewell Park Memorial Institute (Medium)

Raumtemperatur

Natriumdodecylsulfat

Sulforaphan

Tertiär-Butylhydrochinon

Tris Buffered Saline

TBS-Tween

Transforming growth factor beta 1

Tumor necrosis factor related apoptosis inducing ligand

volume per volume

weight per volume

-fach 



\section{Einleitung}

\subsection{Pankreaskarzinom}

\subsubsection{Epidemiologie}

Das Pankreaskarzinom gehört $\mathrm{zu}$ den Krebsentitäten mit den niedrigsten 5-JahresÜberlebensraten $(<10 \%$ in Deutschland) und gilt als die vierthäufigste Krebstodesursache. Jährlich erkranken 10-14 von 100.000 Einwohnern in Deutschland an einem Pankreaskarzinom. Männer und Frauen sind ungefähr gleich häufig betroffen. Das durchschnittliche Erkrankungsalter liegt bei 72 Jahren für Männer und 75 Jahren für Frauen. Seit den 90er Jahren ist eine steigende Tendenz der Zahlen an Neuerkrankungen und der Todesfälle durch ein Pankreaskarzinom zu verzeichnen, die mit der Entwicklung einer immer älter werdenden Gesellschaft verbunden ist ${ }^{1}{ }^{2}$. Mittlerweile wird davon ausgegangen, dass bis 2030 das PDAC sogar die zweithäufigste Krebstodesursache darstellen wird.

\subsubsection{Risikofaktoren}

Die Ursachen für die Entstehung des Pankreaskarzinoms sind bislang noch unbekannt. Zu den Risikofaktoren zählen Rauchen, Alkohol, Diabetes mellitus, Adipositas, chronische Pankreatitis und genetische Dispositionen. Das Risiko an Pankreaskrebs zu erkranken ist bei Patienten, die mehr als ein pack pro Tag über 17 Jahre konsumiert haben, um das 2,5-fache erhöht (1). Patienten mit hereditärer Pankreatitis ${ }^{3}$ besitzen ein 53-fach erhöhtes Risiko (2) und Patienten mit chronischer Pankreatitis ein 17-fach erhöhtes Risiko an Pankreaskrebs zu erkranken als gleichaltrige Gesunde (3). Mutationen in Tumorsuppressorgenen wie z.B. p53, DPC4/SMAD, BRCA2 und in Proto-Onkogenen wie z.B. K-ras, spielen ebenfalls eine Rolle in der Entstehung des Pankreaskarzinoms (3). In einem endogenen PDAC Mausmodell konnten Mutationen im K-ras mit erhöhter Nrf2 Aktivität und Tumorzellproliferation in Verbindung gebracht werden

\footnotetext{
${ }^{1}$ Zentrum für Krebsregisterdaten - Robert-Koch-Institut unter:

https:/www.krebsdaten.de/Krebs/DE/Content/Krebsarten/Bauchspeicheldruesenkrebs/bauchspeicheldruesenkreb s_node.html (abgerufen am 14.09.2018)

${ }^{2}$ Krebs in Deutschland 2013/2014 11. Ausgabe Gemeinsame Publikation des Zentrums für Krebsregisterdaten und der Gesellschaft der epidemiologischen Krebsregister in Deutschland E.V., Robert-Koch-Institut Berlin 2017, Kapitel Bauchspeicheldrüse S.48

${ }^{3}$ Eine seltene Erkrankung, die durch eine Mutation im Trypsinogen-Gen auf dem Chromosom 7 zu einer inadäquaten Aktivierung von Trypsinogen führt. Folglich kommt es zur Autodigestion des Pankreas mit einhergehenden akuten entzündlichen Reaktionen und schließlich zu Gewebezerstörung, Fibrosierung und Chronischer Pankreatitis.
} 
(4). Außerdem ist beschrieben worden, dass K-ras Mutationen relativ früh auftreten, während p53 und DPC4/SMAD Defizite sich später in der malignen Entwicklung bilden (5).

\subsubsection{Pathogenese}

Die Mehrzahl der Malignome des Pankreas entstehen aus dem exokrinen Teil des Pankreas und sind duktale Pankreasadenokarzinome (PDAC). Bislang ist die Pathogenese noch nicht vollständig verstanden, aber es gibt Hinweise darauf, dass die Entzündung bei der Entstehung des PDAC eine wesentliche Rolle spielt, welches am Beispiel der hereditären Pankreatitis beschrieben wurde. Die Pankreatitis geht mit einer anomalen Freisetzung von proteolytischen Enzymen einher, die Zellschäden in den Azini hervorrufen und eine Entzündungskaskade in Gang setzen, an der diverse Zytokine (z.B. TNF- $\alpha$, IL-6, IL-8, INF- $\gamma$ ) und ROS beteiligt sind (3). Darauf reagieren die duktalen Epithelzellen u.a. mit einer Aktivierung des Keap1-Nrf2 Signalweges, um sich vor ROS-induzierten Zellschäden zu schützen (6), (7). Diese Entzündungsprozesse führen desweiteren zu einer starken desmoplastischen Stromareaktion ${ }^{4}$ mit Myofibroblasten, EZM und verschiedensten Immunzellen und einer Aktivierung von Pankreassternzellen (8), (9), die eine für das Tumorwachstum günstige Umgebung schaffen. Bereits in PanINs lässt sich dieses entzündliche Stroma nachweisen und im PDAC macht dieses sogar mehr als 80\% der Tumormasse aus (10), (11). Bereits frühzeitig manifestieren hierbei Malignität fördende Adapationsbedingungen epithelialer Strukturen, an denen Nrf2 wesentlich beteiligt ist.

\subsection{Nuclear factor E2-related-factor2 (Nrf2)}

\subsubsection{Struktur}

1994 klonierten und charakterisierten Moi et al. als Erste den Transkriptionsfaktor NF-E2 p45related factor 2 (Nrf2, Nfe212), der sich als essenziell für die oxidative Stressantwort bewiesen hat. Nrf2 gehört zu der Cap'n'Collar (CNC) Familie und besitzt am C-Terminus eine basic leucine zipper DNA-Bindungsdomäne (bZip) und eine acidic activation Domäne am NTerminus (12). Außerdem hat es sechs sogenannte Neh-Domänen (Neh1-6). Die Neh1-Domäne beherbergt eine CNC-type-bZip-Domäne, die für die DNA Bindung und Dimerisierung mit anderen Transkriptionsfaktoren zuständig ist (13). An die Neh2-Domäne bindet die Kelch

\footnotetext{
${ }^{4}$ Reaktive Bindegewebsvermehrung um Karzinomherde
} 
Domäne von Keap ${ }^{5}$ (14). Neh3 dient der transkriptionellen Aktivierung durch die Rekrutierung von Coaktivatoren (CHD6) (15). Neh4 und Neh5 sind reich an Säureresten und gelten als unabhängige Transaktivierungsdomänen, die synergistisch funktionieren und mit CREB-binding Proteinen (CBP) interagieren (16). Neh6 ist reich an Serin Resten und destabilisiert Nrf2 unter oxidativem Stress (17).

\subsubsection{Regulation}

Die Nrf2-Aktivität wird hauptsächlich durch Keap1 reguliert. Keap1 besitzt zwei Hauptdomänen, ein BTB (broad complex, tamtrack, bric-a-brac) und eine Kelch-Domäne und ist reich an Cystein Resten, die als Sensoren dienen. Drei Schlüsselreste (C151, C273, C288) sind bereits identifiziert worden (13). C151 wird direkt von Nrf2-Induktoren alkyliert (18) und dient der Aktivierung des Nrf2 Signalweges, während C273 oder C288 für die keap1-abhängige Ubiquitinierung $^{6}$ von Nrf2 und die keap1-gesteuerte Repression von Nrf2-abhängiger Transkription unter basalen Bedingungen sorgen (19). Bei der Regulation von Nrf2 fungiert Keap 1 als molecular switch, der Störungen der intrazellulären Redox Homöostase erkennt und die Nrf2-abhängige Stressantwort aktiviert (13). Unter basalen Bedingungen ist der molecular switch im “off” Modus. Dieses äußert sich als konstitutiver Keap1-gesteuerter Abbau von Nrf2 durch das Ubiquitin-abhängige Proteasomsystem (20), (21). Dabei bindet Keap1 an den Ubiquitin Ligase E3 Komplex und führt Nrf2 an die Ubiquitin Ligase E3. Sobald Nrf2 an Ubiquitin Ligase E3 andockt, wird Ubiquitin von Ubiquitin Conjugating Enzyme E2 an Nrf2 übertragen. An Ubiquitin gebundenes Nrf2 wird zügig durch 26S-Proteasom abgebaut. Kommt es zu einer Störung des Redox Gleichgewichts in einer Zelle, wird die Konformation von Ubiquitin Ligase E3 modifiziert, sodass die Ubiquitinierung von Nrf2 nicht mehr möglich wird. Daraus folgt eine Akkumulation von Nrf2 unter oxidativen Stressbedingungen, was zu einer Translokation von Nrf2 in den Zellkern und zu einer transkriptionellen Aktivierung seiner Zielgene durch Bindung an ARE-Sequenzen führt. Wird das Redoxgleichgewicht wiederhergestellt, wandert Keap1 in den Zellkern und bewirkt eine Dissoziation des Nrf2 von der ARE-Sequenz. Daraufhin eskortiert Keap1 Nrf2 aus dem Zellkern ins Zytoplasma zur

\footnotetext{
${ }^{5}$ Kelch-like ECH-associated protein 1, Gegenspieler von Nrf2

${ }^{6}$ Bezeichnet die Übertragung von Ubiquitin auf ein Zielmolekül. Ubiquitin ist ein kleines Protein mit 76 Aminosäuren, das andere Proteine für den proteasomalen Abbau markiert. Kovalente Bindungen von Ubiquitin an Substraten werden durch drei Enzyme ermöglicht. Ubiquitin Activating Enzyme E1, Ubiquitin Conjugating Enzyme E2 und Ubiquitin Ligase E3. Ubiquitin ist an E1 gebunden, wird von E1 zu E2 transferiert und durch E3 von $\mathrm{E} 2$ an ein Substrat übertragen.
} 
Ubiquitin Ligase E3 für den Abbau (13). Zusätzlich kann die Regulation der Nrf2-Aktivität auch über Phosphorylierung von Nrf2 durch verschiedenste Kinasen (z.B. ERK, PKC, PI3K, JNK) (22) und Koaktivatoren wie CBP und P300, erfolgen (16).

\subsubsection{Zielgene}

Die Exposition der Zellen gegenüber physikalischen oder chemischen Noxen bewirkt eine Translokation von Nrf2 in den Zellkern. Dort bildet es mit seinem obligatorischen Partner Maf ${ }^{7}$ ein Heterodimer, das in der Lage ist ARE-Sequenzen zu binden und die Transkription von verschiedenen Zielgenen anzuschalten (23). Bisher sind ca. 200 Zielgene u.a. die Gene der Phase-I- und Phase-II-Enzyme und $\mathrm{MRP}^{8}$ beschrieben worden, die antioxidative und detoxifizierende Wirkungen ausüben. $\mathrm{Zu}$ diesen gehören z.B. UDP-Glucoronosyltransferase (UGT), NAD(P)H Quinon Oxidoreduktase-1 (NQO1), Glutamatcysteine ligase catalytic subunit (GCLC) und Glutathion S-Transferase (GST) (23), (24), (25).

\subsubsection{Nrf2-Aktivatoren}

In den letzten Jahrzehnten wurde eine Vielzahl von Nrf2-Aktivatoren identifiziert. Zu diesen gehören zum einen Phytochemicals wie z.B. Sulforafan (SNF) (26), Wasabi (27), Curcumin (28) und zum anderen synthetische Antioxidantien wie z.B. Oltipraz ${ }^{9}$ (26), (29) und TertiärButylhydrochinon (tBHQ), die alle chemopräventive Eigenschaften besitzen. tBHQ findet seinen Einsatz häufig in der Lebensmittelindustrie ${ }^{10}$, während SNF natürlich in Brokkoli vorkommt (30). Diese Substanzen modifizieren die Cysteinreste von Keap1, sodass dieser von Nrf2 dissoziiert und Nrf2 somit vor dem proteasomalen Abbau bewahrt wird (31), (32). Dadurch kann Nrf2 in den Zellkern translozieren und die Expression von Phase-II-Enzymen induzieren. tBHQ und SNF können zudem noch weitere Transkriptionsfaktoren wie z.B. NF$\mathrm{kB}$ beeinflussen (33), (34).

\footnotetext{
${ }^{7}$ Musculoaponeurotic fibrosarcoma gehört zu den basic leucine zipper Transkriptionsfaktoren.

${ }^{8}$ Multidrug-resistance-associated proteins ermöglichen den Efflux von chemischen Schadstoffen nach extrazellulär.

${ }^{9}$ Ursprünglich als Mittel gegen Shistosomen entwickelt.

${ }^{10}$ Verbraucher Initiative e.V.

http://www.zusatzstoffe-online.de/zusatzstoffe/325.e319 tert butylhydrochinon tbhq.html (Zugriff am $05.02 .18)$
} 


\subsubsection{Onkogene und tumorsuppressive Effekte}

Die protektive Wirkung von Nrf2 vor zellschädigenden und mutagenen Effekten von ROS stellt einen wesentlichen Faktor in der Tumorgenese dar. In frühen Stadien wirkt Nrf2 als Tumorsuppressor und kann die Entstehung eines malignen Tumors vorbeugen (31). In vivo Studien an Nrf2-knockout Mäusen bewiesen bereits die zentrale Rolle von Nrf2 in der Krebsprävention. Unter SFN Behandlung von Wildtyp und Nrf2-knockout Mäusen, traten in den Wildtyp Mäusen deutlich weniger Hauttumore auf als in den Nrf2-knockout Mäusen (35). Eine Zeitlang bestand der Trend Nrf2-Aktivatoren präventiv gegen Krebserkrankungen einzusetzen und es folgten klinische Studien, die die Verträglichkeit von SFN und eine Vermehrung von zytoprotektiven Enzymen im menschlichen Organismus bestätigten (36), (37), (38). Diese Begeisterung legte sich wieder als Erkenntnisse darüber erschienen, dass Nrf2 in vielen verschiedenen Tumorentitäten wie z.B. Lungen-, Brust-, Ovarial-, Pankreas- und kolorektalem Karzinom überexprimiert vorliegt. Nrf2 schützt nicht nur gesunde Zellen vor der Transformation zu Krebszellen, sondern unterstützt in späten Phasen der Tumorgenese das Überleben von bereits transformierten Zellen (13). Dies wurde z.B. für das hepatozelluläre Karzinom beschrieben, bei dem die Nrf2-abhängige GSTP1 ${ }^{11}$ hochreguliert ist (39). Ursächlich für eine erhöhte Nrf2-Aktivität können loss-of-function Mutationen des Keap1 sein, die die Bindung zu Nrf2 unmöglich machen oder epigenetische Hypermethylierungen, die die Expression von Keap1 verhindern (31). Seltener führt eine gain-of-function Mutation des Nrf2 zu dessen erhöhten Aktivität. Zudem können Interaktionen von Nrf2 mit anderen onkogenen Signalwegen (z.B. K-Ras/Raf/MAPK) zu einer Überaktivität führen (4). Die Akkumulation der Zielgene von Nrf2 kann das Tumorwachstum und die Resistenz vor Chemotherapeutika begünstigen. Für chemotherapeutische Medikamente wie Cisplatin, Doxorubicin und Etoposid konnten im Neuroblastom, Bronchial-, Pankreas- und Mammakarzinom durch Einsatz von tBHQ eine positive Korrelation zwischen dem Gehalt von Nrf2 und einer Resistenz gegen diese Chemotherapeutika nachgewiesen werden (40), (41). Grund hierfür ist u.a. die Nrf2-abhängige Überexpression von Transportern wie MRP, die exogene und endogene organische Anionen inklusive konjugierte Metabolite von Phase II Enzymen aus den Zellen heraus befördern (42), (43). Diese bewirken, dass Tumorzellen eine Resistenz gegenüber Medikamenten erwerben können, da eine erhöhte Expression von diesen Transportern zu einer geringen intrazellulären Akkumulation dieser Medikamente führt (44).

\footnotetext{
${ }^{11}$ Glutathione S-transferase P1 gilt als Marker für neoplastische Läsionen, das im gesunden Gewebe abwesend und in Krebsgewebe überexprimiert ist.
} 
Der Crosstalk zwischen Nrf2 und TGF- $\beta 1$ ist ebenfalls für die Karzinogenese relevant. Bezüglich der EMT inhibiert Nrf2 in PDAC- und prämalignen H6c7 PankreasgangepithelZellen die TGF- $\beta 1$ vermittelte Aktivierung von Smad, Slug/Snail- und Vimentinexpression, sodass die invasiven Eigenschaften von Tumorzellen gefördert werden (45). Nrf2 und TGF- $\beta 1$ wirken hinsichtlich der Entwicklung einer Apoptoseresistenz additiv, während das Zellwachstum durch die Aufhebung des anti-proliferativen Effektes von TGF- $\beta 1$ durch Nrf2 gesteigert wird (46).

\subsection{Activating Transcription Factor 3 (=ATF3)}

\subsubsection{Splicing Varianten}

Als Transkriptionsfaktor gehört ATF3 zu der Familie der cAMP response element-binding proteins (CREB)/Leucine Zipper (bZIP) Proteine und zeigt unter diversen zellulären Stressbedingungen dichotome Effekte in Bezug auf die Tumorgenese. Es sind mehrere Splicingvarianten von ATF3 beschrieben worden, die die Wirkung der full length ATF3 (Isoform-1 mit 181 Aminosäuren) antagonisieren oder aber auch unabhängig von ATF3 agieren können (47), (48). Besonders von Bedeutung sind folgende 3 Varianten, die modifizierte CTermini und keine bZIP-Domänen aufweisen (Abb. 1A). Die trunkierten Proteinvarianten $\Delta$ Zip (118 Aminosäuren) und $\Delta$ Zip3 (120 Aminosäuren) entstehen aus einem differentiellen Splicing des Introns-3/Exon-D/E Übergangs mit der Beibehaltung von Exon-D oder Exon-C`. Innerhalb dieser Region können unter Beibehaltung von Exon-D‘, die Proteinvariante $\Delta$ Zip2 mit 135 Aminosäuren entstehen, die sich von den anderen Varianten durch ihre neuartigen 21 Aminosäuresequenz am C-terminus unterscheiden. Von $\Delta$ Zip2 werden auch noch zwei Proteinvarianten $\Delta$ Zip2a und $\Delta$ Zip2b mit jeweils neuem reading frame am C-Terminus unterschieden (48), (49), (50). Im ATF3 Gen wird die RNA-Polymerase II von zwei verschiedenen Startpositionen (distaler und proximaler Promotor) rekrutiert. So entstehen unterschiedlich lange Exon1-Regionen (50), die die Sekundärstruktur der ATF3 prä-RNA beeinflussen und zur unterschiedlichen Erkennung der Splicingpositionen des Exon-C' bzw. D‘ im Spleißosomkomplex führen. Daraus entstehen schließlich verschiedene mRNA Transkripte (Abb. 1B). 
A)

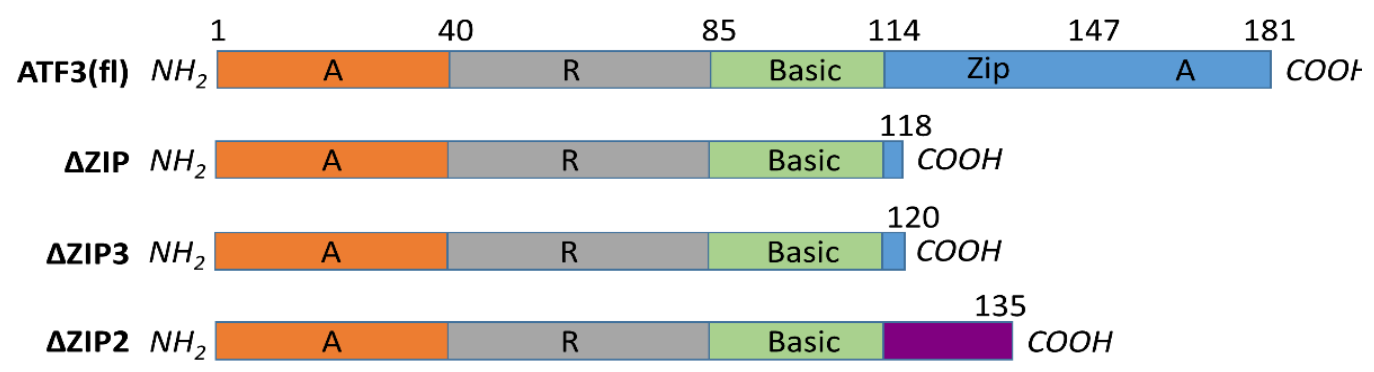

B)
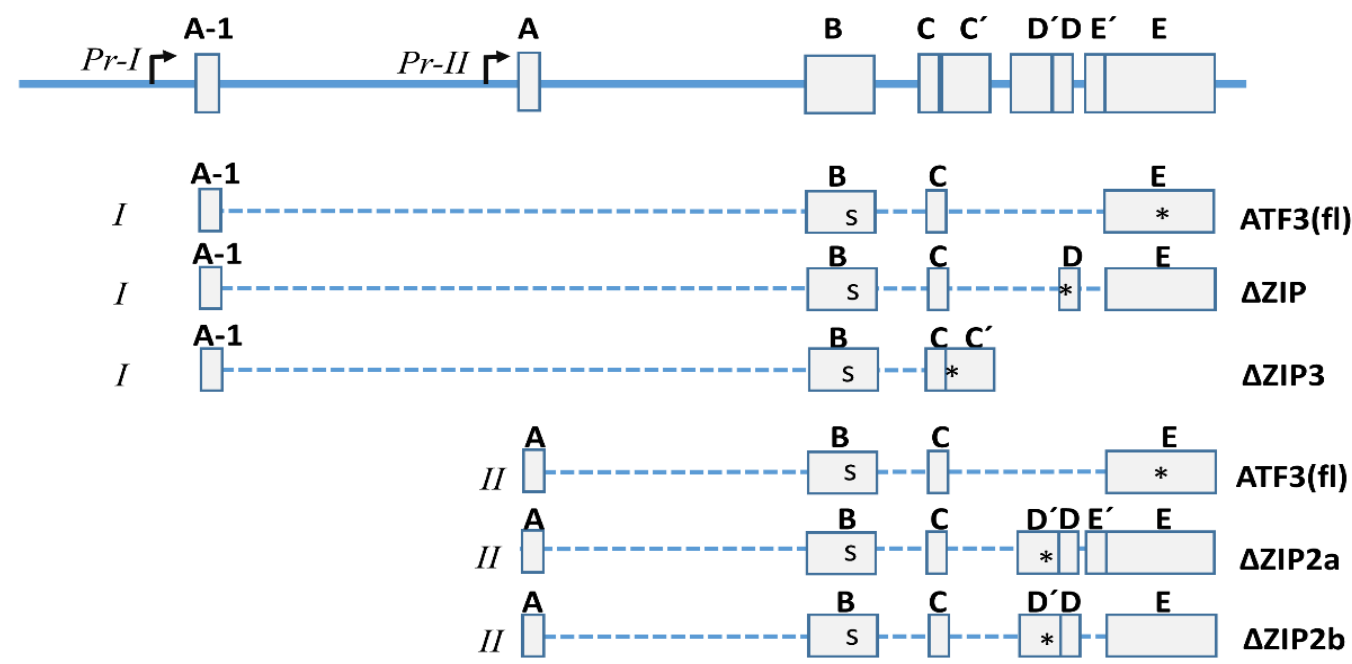

Abbildung 1. Struktureller Aufbau des ATF3 Gens und seiner Splicing Varianten ATF3, $\Delta$ Zip, $\triangle$ Zip2

A) ATF3 (fl = Full length), $\Delta$ Zip \& $\Delta$ Zip2 bestehen aus aktivierenden „A“, repressiven „R“, „basic“ und „Zip“ Domänen.

B) Aus dem ATF3 Gen (Exons A1-E) entstehen durch die Rekrutierung von verschiedenen Promotoren zwei unterschiedliche Primärtranskripte (I, II). Über differentielles Splicing können aus den Transkripten ATF3, $\Delta$ Zip oder $\triangle$ Zip2 mRNAs entstehen. S: Startcodon; *Stoppcodon (modifiziert nach Hashimoto et al. NAR 2002 \& Miyazaki et al. 2009).

\subsubsection{Regulation}

Der ubiquitär vorkommende Transkriptionsfaktor ATF3 wird unter homöostatischen Bedingungen konstitutiv sehr schwach exprimiert. Erst in Gegenwart von zellulärem Stress z.B. infolge von Hitzeschock, Hypoxie, DNA-Schäden, UV-, ROS-Exposition oder Entzündung wird die Expression von ATF3 durch diverse Stimuli (z.B. AP1, Nrf2, TGF- $\beta 1$ ) über die Aktivierung einer komplexen Wirkungskaskade induziert (49), (51), (52) (53). Für die Induktion von ATF3 befinden sich an dessen Promotor unterschiedliche Bindungsstellen. Es wurden bereits zwei ARE-Bindungsstellen am proximalen ATF3 Promotor beschrieben (Position -3541, -2975), worüber Nrf2 die Expression von ATF3 hervorruft (53). Demgegenüber induziert TGF- $\beta 1$ ATF3 u.a. über Smad-response Elemente (SRE) (54). Gleichzeitig zur Induktion von ATF3 durch proinflammatorische Faktoren wird auch die 
Splicingvariante $\Delta$ Zip induziert, das inhibierend auf die Aktivität von ATF3 wirkt (47). Über die andere Variante $\Delta$ Zip2 ist bisher bekannt, dass es nicht in der Lage ist ATF/CRE motif zu binden, sodass es erst in einer Koexpression mit ATF3 Effekte erzielen kann, die wie $\Delta$ Zip eine Hemmung von ATF3 verursacht und letztlich eine Transkription stimuliert (48).

\subsubsection{Zielgene}

Entgegen seines Namens ist ATF3 in der Lage die Transkription zu hemmen. Die ersichtliche Diskrepanz zwischen seinen Namen und seiner Funktion ist der früheren Annahme geschuldet, dass nur ein ATF existiert und dieses ein Aktivator ist (47). Die Isolation von multiplen ATF cDNA Klone entkräfteten diese Annahme. Inzwischen wurden mehrere Varianten von ATF nachgewiesen, darunter ATF3, das als Repressor der Transkription beschrieben wurde (47). Als Transkriptionsfaktor bindet ATF3 an spezifische Erkennungssequenzen von bestimmten Genpromotoren, was zu einer Rekrutierung von Korepressoren (HDACs, SMRT) oder zu einer Stabilisierung von an Promotoren gebundenen inhibitorischen Kofaktoren führt. Dafür dient die Leucine-Zipper Domäne in der C-terminalen Domäne des Proteins. Nach der Bindung kommt es zu einer Unterdrückung der Expression dieser Zielgene (49). Zu den Zielgenen, die durch ATF3 supprimiert werden, gehören p53, verschiedene Entzündungsmediatoren wie TNF$\alpha$ und IL-6, Stressmodulatoren und Oberflächenproteine wie E-Selectin (55), (56). ATF3 kann auch Heterodimere mit anderen bZIP Proteinen formieren (z.B. cJun, JunB oder Nrf2) (55), (57) oder mit anderen Transkriptionsregulatoren (z.B. Smad3) interagieren, um nach Bindung an deren Erkennungssequenzen an der DNA als Repressor oder Coaktivator zu fungieren. Als Aktivator kann ATF3 inhibitorische Faktoren an der DNA sequestieren, sodass diese nicht mehr am Promotor wirken können und die Transkription beginnen kann. $\mathrm{Zu}$ den Zielgenen, die mithilfe von ATF3 induziert werden gehören u.a. die proapoptotischen Gene CHOP/GADD153 und GADD34 (58), (59). Diese gegensätzliche Funktion von ATF3 hängt von posttranslationalen Modifikationen von ATF3 (z.B. JNK- oder ERK-abhängige Phosphorylierung) und von der Verfügbarkeit von anderen transkriptionellen Coaktivatoren (z.B. CREB-binding protein) ab.

\subsubsection{Onkogene und tumorsuppressive Effekte}

Von ATF3 gehen Effekte aus, die vor Zellschädigung schützen und zur Immunsuppression beitragen. Neben der modulierenden Wirkung auf die Immunantwort ist ATF3 auch an der 
Regulation proliferativer und apoptotischer Zellantworten beteiligt (51), (55). In verschiedenen hämatologischen Tumore, Mammakarzinom und Prostatakarzinom wurden bereits erhöhte ATF3 Expression z.B. durch eine Gen-Amplifikation auf Chromosom 1 (q32.3) in Zusammenhang mit einer proliferationsfördernden Wirkung, Apoptoseresistenz und Invasivität beschrieben (60), (61), (62). Ebenfalls konnte im transgenen Mausmodell mit epithelialer ATF3 Überexpression eine erhöhte Inzidenz von Mamma- und Plattenepithelkarzinomen beobachtet werden (63), (64). Demgegenüber gibt es auch Beobachtungen, bei denen ATF3 antitumorigene bzw. antiproliferative und Apoptose-fördernde Wirkungen zeigt, wie z.B. in Ovarial- und Prostatakarzinom (65), (66). Diese dichotome Wirkung von ATF3 auf das Tumorzellwachstum und -überleben ist das Resultat einer komplexen Interaktion mit Transkriptionsfaktoren wie p53, p65/RelA, AP1 oder Nrf2 sowie direkter Hemmung (z.B. GADD153, CyclinD1) und Induktion von ATF3-Zielgenen (z.B. Slug, Snail, Twist) (55). Beim Pankreaskarzinom induziert die entzündliche Komponente dauerhaft eine oxidative Stressantwort (11), bei der vermutlich auch ATF3 und dessen Varianten beteiligt sind. Da Nrf2 sowohl upstream als auch downstream von ATF3 an diesen Stressantworten mitwirkt (57), (52), (53), (67) unterliegt die Zellantwort durch Nrf2 den dichotomen Effekten von ATF3 und seinen Varianten und steht auch in Verbindung mit dem komplexen Zusammenspiel zwischen TGF- $\beta 1$ und Nrf2 (45), (68).

\subsection{Zielsetzung}

Aufgrund der kontroversen Befundlage zur ATF3 Expression in Tumoren, bzw. der fehlenden Befunde im PDAC, soll in der vorliegenden Arbeit der Einfluss der ATF3 Splicevariante $\Delta$ Zip2 auf Tumorzellwachstum und -überleben erstmalig gezielt untersucht und diesbezüglich mit der ATF3 full-length Variante verglichen werden. Dies soll im Kontext der Nrf2-vermittelten Stressadaption sowie vor dem Hintergrund des Nrf2-TGF- $\beta 1$ Crosstalks als wichtige Determinante der entzündlichen Karzinogenese des Pankreas erfolgen. Im Mittelpunkt stehen hierbei die Etablierung eines spezifischen PCR Protokolls zur selektiven Detektion von ATF3 und $\Delta$ Zip2 sowie deren selektiver knockdown in malignen (Panc1, T3M4) und prämalignen (H6c7) Pankreasgangepithelzellen. Des Weiteren soll ein neu etablierter, spezifischer Antiköper gegen $\Delta$ Zip2 zum Einsatz kommen, anhand dessen vor allem in immunhistochemischen Färbungen die Bedeutung dieser ATF3 Variante im pankreatischen Gewebe von PDACPatienten sowie von Patienten mit chronischer Pankreatitis validiert werden soll. 


\section{Materialien und Geräte}

\subsection{Geräte}

\section{Gerät}

Analysewaage CP124S-OCE

Autoklav Tuttnauer

Blotkammer Semi-Dry Electroblotter A

Brutschrank BBD 6220

ChemiDoc-XRS $^{\mathrm{TM}}$

Durchflusszytometer FACS-Verse

Eismaschine ZBE150

Elektrophoresekammer XCell SureLock

Gefrierschrank, $-20^{\circ} \mathrm{C}$, Premium NoFrost

Gefrierschrank, $-80^{\circ} \mathrm{C}, \mathrm{KM}-\mathrm{DU} 73 \mathrm{Y} 1 \mathrm{E}$

Kipptisch WT17

Kühlschrank Profi Line

Laborwaage PT1200

Microplate Luminometer LB96V

Mikroskop Axioplan 2 Imaging

Mikroskop Axiovert 25

Multipipette plus

Nano Drop Spectrophotometer 10-1000

pH-Meter Microprocessor pH537

Photometer Opsys MR

Pipetboy

Pipetten Pipetman classic

Plate Illuminator Piko

\section{Hersteller}

Sartorius, Göttingen

Systec, Wettenberg

Ancos, Dänemark

Kendro, Langenselbold

Bio-Rad, München

BD, Franklin Lakes, USA

Ziegra, Hannover

Invitrogen, USA

Liebherr, Biberach an der Riss

Panasonic, Japan

Biometra, Göttingen

Liebherr, Biberach an der Riss

Sartorius, Göttingen

Berthold Technologies, Bad Wildbad

Zeiss, Zaventem, Belgien

Zeiss, Zaventem, Belgien

Eppendorf AG, Hamburg

peqLab Biotechnology, Erlangen

WTW, Weilheim

Dynex Technologies, USA

Integra, Fernwald

Gilson, Limburg

Thermo Fisher Scientific, Schwerte 
Real-Time PCR System PicoReal 96

Rollenmischer roller mixer SRT6D

Schüttler MTS2

Sonicator Sonopuls

Sterilwerkbank Herasafe

Tecan Infinite-m200

Thermomixer 5436

Vakuumpumpe Laboport

Vortexer VF2

Wärmeschrank B6060

Wasserbad Precision

Zentrifuge Biofuge fresco

Zentrifuge Megafuge 1.0

Zentrifuge Varifuge 20RS

Zentrifuge 400R function line

\subsection{Chemikalien}

\section{Chemikalie}

6-Aminocapronsäure

Acrylamidlösung Rothiphorese Gel 40

AEC Peroxidase Substrat Kit

Albumin Standard

Ammoniumpersulfat (APS)

Antigen-Retrival

Aprotinin

Bromphenolblau
Thermo Fisher Scientific, Schwerte

VWR, Darmstadt

IKA $^{\circledR}$-Werke GmbH \& Co. KG, Staufen

Bandelin, Berlin

Heraeus Instruments, Hannau

Tecan Group, Hamburg

Eppendorf AG, Hamburg

KNF, Freiburg

IKA $^{\circledR}$-Werke GmbH \& Co. KG, Staufen

Heraeus Instruments, Hanau

Labcare, USA

Heraeus Instruments, Hanau

Heraeus Instruments, Hanau

Heraeus Sepatech, Osterode

Heraeus Instruments, Hanau

\section{Hersteller}

Sigma-Aldrich Chemie, München

Roth, Karlsruhe

DakoCytomation

Thermo Fisher Scientific, USA

Merck, Darmstadt

Eigenherstellung

Sigma-Aldrich Chemie, München

Serva, Heidelberg 
$\beta$-Mercaptoethanol

BSA Fraktion V

Caspase-Glo ${ }^{\circledR}$ 3/7 Assay

DMSO

DTT

Dual-Luciferase ${ }^{\circledR}$ Reporter Assay System EDTA

Effectene ${ }^{\mathrm{TM}}$ Reagenz

Essigsäure, $10 \%$

Ethanol

Fötales Kälberserum (FCS)

Gemzar

Glycerol

Glycin

HEPES

$\mathrm{H}_{2} \mathrm{O}_{2}$

HiperFect Transfection Reagent

IQ Sybr Green Supermix

Kaliumchlorid

Kaiser`s Glycerine Gelatine

Kristallviolettlösung

L-Glutamin

LumiGlo Lösung

Methanol $100 \%$

Meyers Hämalaunlösung

Milchpulver

Natriumchlorid
Biomol, Hamburg

Biomol, Hamburg

Promega, Mannheim

Sigma-Aldrich Chemie, München

Biomol, Hamburg

Promega, Mannheim

Sigma-Aldrich Chemie, München

Qiagen, Hilden

Merck, Darmstadt

Merck, Darmstadt

Biochrom, Berlin

Sigma-Aldrich Chemie, München

Sigma-Aldrich Chemie, München

Merck, Darmstadt

Sigma-Aldrich Chemie, München

Roth, Karlsruhe

Qiagen, Hilden

Bio-Rad, München

Merck, Darmstadt

Waldeck, Münster

Sigma-Aldrich Chemie, München

PAA, Pasching, Österreich

Cell Signaling, Frankfurt am Main

Merck, Darmstadt

AppliChem, Darmstadt

Roth, Karlsruhe

Mallinckrodt Baker, Niederlande 
Natriumpyruvat

Oltipraz

OptiMEM

PBS Dulbecco

PCR Auftragspuffer (5x)

PeqGOLD TOTAL RNA Kit

Phosphatase Inhibitor Cocktail 2

Phosphatase Inhibitor Cocktail 3

PMSF

Propidiumiodid

Protein Assay

Proteinbestimmungsassay DC

Proteinmarker PageRulerTM

Reverse Transkription Reagenzien

RNAse

RPMI Medium 1640

Salzsäure, 37 \%

SDS

Signal ARE Reporter Assay Kit

SuperSignal Substrate

Taq-DNA-Polymerase

tBHQ

Temed

TGF- $\beta 1$

Tris Base

Trypsin/EDTA solution
PAA Pasching, Österreich

Sigma-Aldrich, St. Louis, MO, USA

Gibco BRL, Eggenstein

Biochrom, Berlin

Qiagen, Hilden

Peqlab, Erlangen

Sigma-Aldrich Chemie, München

Sigma-Aldrich Chemie, München

Sigma-Aldrich Chemie, München

Sigma-Aldrich Chemie, München

Bio-Rad, München

Bio-Rad, München

Fermentas, St. Leon-Rot

Promega, Heidelberg

Qiagen, Hilden

Biochrom KG, Berlin

Roth, Karlsruhe

Biomol, Hamburg

Qiagen, Hilden

Thermo Scientific, Waltham, USA

Gibco BRL, Eggenstein

Sigma-Aldrich Chemie, München

Roth, Karlsruhe

BioLegend, Fell

Biomol, Hamburg

Biochrom KG, Berlin 
Trypsin/EDTA solution

Tween 20

Xylol

\subsection{Verbrauchsmaterialien}

\section{Material}

96-Well PCR Platten

96-Well Platte, weiß ummantelt

Combitips advanced ${ }^{\circledR} 1 \mathrm{ml} / 2,5 \mathrm{ml}$

Deckgläser 18 mm

FACS Röhrchen 5ml

Microtest Plate 96-Well

Multitips steril 12,5ml

Objektträger Menzel-Gläser

Parafilm

Pasteurpipetten ISO 7712

Pipettenspitzen $10 \mu 1 / 200 \mu 1 / 1000 \mu 1$

Reaktionsgefäße 1,5ml

Röhrchen 15 ml/50 ml

Roti®-PVDF, Porengröße 0,45 $\mu \mathrm{m}$

Serologische Pipette $5 \mathrm{ml} / 10 \mathrm{ml} / 25 \mathrm{ml}$

Zellkulturflaschen

Zellkulturplatten 6-Well

Zellkulturplatten 12-Well

Zellschaber
Biochrom KG, Berlin

Sigma-Aldrich Chemie, München

Merck, Darmstadt

\section{Hersteller}

Corning, Amsterdam, Niederlande

Falcon über BD Biosciences, Hamburg

Eppendorf, Hamburg

Glaswarenfabrik Hecht, Sondheim

Sarstedt, Nümbrecht

Sarstedt, Nümbrecht

Th. Geyer GmbH \& Co. KG, Hamburg

Thermo Scientific, Waltham, USA

Bemis, USA

Schleicher \& Schuell, München

Sarstedt, Nümbrecht

Eppendorf, Hamburg

Sarstedt, Nümbrecht

Roth, Karlsruhe

Sarstedt, Nümbrecht

Sarstedt, Nümbrecht

Thermo Scientific, Waltham, USA

Sarstedt, Nümbrecht

Sarstedt, Nümbrecht 


\subsection{Antikörper}

Tabelle 1. Primär- und Sekundärantikörper für den Einsatz in Westernblot

\begin{tabular}{|l|l|l|l|}
\hline Primärantikörper & Verdünnung & Spezies & Hersteller \\
\hline$\Delta$ Zip2a & $1: 200$ & Maus & Custom generated by Abmart, USA \\
\hline ATF3 & $1: 500$ & Kaninchen & PAB28450, Abnova/Biozol, Eching \\
\hline cIAP1 & $1: 500$ & Kaninchen & $\begin{array}{l}\text { \#4952 Cell Signaling Technology, } \\
\text { Frankfurt }\end{array}$ \\
\hline cIAP2 & $1: 500$ & Kaninchen & $\begin{array}{l}\text { \#3130 Cell Signaling Technology, } \\
\text { Frankfurt }\end{array}$ \\
\hline CHOP/GADD153 & $1: 200$ & Maus & $\begin{array}{l}\text { Sc-7351 Santa Cruz Biotechnology, } \\
\text { Heidelberg }\end{array}$ \\
\hline GADD34 & $1: 200$ & Maus & $\begin{array}{l}\text { Sc-373815 Santa Cruz Biotechnology, } \\
\text { Heidelberg }\end{array}$ \\
\hline Lamin A/C & $1: 1000$ & Maus & $\begin{array}{l}\text { Sc-7293 Santa Cruz Biotechnology, } \\
\text { Heidelberg }\end{array}$ \\
\hline Nrf2 & $1: 200$ & Kaninchen & Ab62352 Abcam, UK \\
\hline Tubulin & $1: 5000$ & Maus & T5168 Sigma Aldrich, Deisenhofen \\
\hline
\end{tabular}

\begin{tabular}{|l|l|l|}
\hline Sekundärantikörper & Verdünnung & Hersteller \\
\hline $\begin{array}{l}\text { Anti-Maus IgG, } \\
\text { HRP-linked Antibody }\end{array}$ & $1: 1000$ & $\# 7076$ Cell Signaling, Frankfurt am Main \\
\hline $\begin{array}{l}\text { Anti-Kaninchen IgG, } \\
\text { HRP-linked Antibody }\end{array}$ & $1: 1000$ & $\# 7074$ Cell Signaling, Frankfurt am Main \\
\hline
\end{tabular}

Tabelle 1.2. Primär- und Sekundärantikörper für den Einsatz in der Immunhistochemie

\begin{tabular}{|l|l|l|l|}
\hline Primärantikörper & Verdünnung & Spezies & Hersteller \\
\hline Ser40-P-Nrf2 & $\begin{array}{l}1: 2001 \% \text { BSA/0.3\% } \\
\text { Triton-X in PBS }\end{array}$ & Kaninchen & Abcam \\
\hline ATF3 & $\begin{array}{l}1: 751 \% \text { BSA/0.3\% } \\
\text { Triton-X in PBS }\end{array}$ & Kaninchen & $\begin{array}{l}\text { Abnova/Biozol, } \\
\text { Eching (PAB28450) }\end{array}$ \\
\hline
\end{tabular}




\begin{tabular}{|l|l|l|l|}
\hline$\Delta$ Zip2a & $\begin{array}{l}1: 2001 \% \mathrm{BSA} / 0.3 \% \\
\text { Triton-X in PBS }\end{array}$ & Maus & $\begin{array}{l}\text { Custom generated by } \\
\text { Abmart }\end{array}$ \\
\hline
\end{tabular}

\begin{tabular}{|l|l|l|}
\hline Sekundärantikörper & Verdünnung & Hersteller \\
\hline $\begin{array}{l}\text { Envision+HRP-Anti } \\
\text { Rabbit-Reagent }\end{array}$ & & Dako, Hamburg, FRG \\
\hline $\begin{array}{l}\text { Biotin-konjugiertes } \\
\text { Anti-Maus IgG }\end{array}$ & $\begin{array}{l}\text { PBS/0.3\%Triton- } \\
\text { X100 }\end{array}$ & $\begin{array}{l}\text { Jackson ImmunoResearch, Dianova, Ham- } \\
\text { burg, FRG }\end{array}$ \\
\hline $\begin{array}{l}\text { Peroxidase-konjugiertes } \\
\text { Streptavidin }\end{array}$ & $\begin{array}{l}1: 500 \text { in } \\
\text { PBS/0.3\%Triton- } \\
\text { X100 }\end{array}$ & $\begin{array}{l}\text { Jackson ImmunoResearch, Dianova, Ham- } \\
\text { burg, FRG }\end{array}$ \\
\hline
\end{tabular}

\subsection{Primer}

Tabelle 2. Primer für den Einsatz in der quantitativen PCR/Realtime PCR

\begin{tabular}{|l|l|l|}
\hline Primer & Vorwärts- und Rückwärtssequenzen & Hersteller \\
\hline$\Delta$ Zip2a/b & $\begin{array}{l}\text { 5'-CGCTGGAATCAGTCACTGTCAG- } \\
\text { 3'(Fw) }\end{array}$ & Eurofins Genomics, \\
& $\begin{array}{l}\text { 5'-CTGCA GAAACTCCCAAGGCCCT- } \\
\text { 3'(Rv) }\end{array}$ & \\
\hline ATF3 & $\begin{array}{l}5^{\prime}-\text { CGCTGGAATCAGTCACTGTCAG - } \\
\text { 3' (Fw) }\end{array}$ & Eurofins Genomics, \\
& $\begin{array}{l}\text { 5'- } \\
\text { CCTGCAGAAAGAGTCGGAGAAG- } \\
\text { 3'(Rv) }\end{array}$ & \\
\hline ATF3 P1 & $\begin{array}{l}\text { 5'-AGGATGCTCTGCTGTTTCCT-3'(Fw) }) \\
\text { 5'-TTAGCTCTGCAATGTTCCTTC- } \\
\text { 3'(Rv) }\end{array}$ & Eurofins Genomics, \\
\hline ATF3 P2 & $\begin{array}{l}\text { 5'-TGATGCAACGCTCTCCAAGC- } \\
\text { 3'(Fw) } \\
\text { 5'- } \\
\text { TTAGCTCTGCAATGTTCCTTC-3'(Rv) }\end{array}$ & Eurofins Genomics, \\
\hline
\end{tabular}




\begin{tabular}{|l|l|l|}
\hline TBP & 5'-TATAATCCCAAGCGGTTTGC-3' $^{\prime}$ & Eurofins Genomics, \\
& (Fw) & Ebersberg \\
& $\begin{array}{l}5^{\prime} \text {-GCTGGAAAA CCCAACTTCTG-3' } \\
(\mathrm{Rv})\end{array}$ & \\
\hline
\end{tabular}

\section{6 siRNA}

Tabelle 3. siRNA für die Transfektion mit HiPerfekt

\begin{tabular}{|l|l|}
\hline siRNA & Hersteller \\
\hline$\Delta$ Zip2 & Custom-designed by Thermo-Fisher-Scientific \\
\hline ATF3 & $\begin{array}{l}\text { Qiagen, Hilden } \\
\text { no. SI04191180 }\end{array}$ \\
\hline Kontroll-siRNA & Qiagen, Hilden \\
\hline Nrf2 & $\begin{array}{l}\text { Qiagen, Hilden } \\
\text { no. SI03246614 }\end{array}$ \\
\hline
\end{tabular}

\subsection{Plasmide}

Tabelle 4. cDNA/Plasmide für die Transfektion mit Lipofectamin

\begin{tabular}{|l|l|}
\hline Plasmide & Hersteller \\
\hline$\Delta$ Zip & Thermo-Fisher \\
\hline$\Delta$ Zip2 & Thermo-Fisher \\
\hline ATF3 & Thermo-Fisher \\
\hline pcDNA.3.1 (mock, Kontroll-cDNA) & Thermo-Fisher \\
\hline
\end{tabular}




\section{Methoden}

\subsection{Zellbiologische Methoden ${ }^{12}$}

3.1.1 Zelllinien ${ }^{13}$

\section{Zelllinie}

Panc1

T3M4

H6c 7

\section{Vertreiber}

DSZM, Braunschweig

Prof. Dr. H. Friess, Heidelberg, Germany

M.S. Tsao; Ontario Cancer Institue, Toronto, Canada

\subsubsection{Kulturmedien}

\section{Zelllinie}

Panc1

T3M4

H6c7

\section{Medium}

RPMI 1640 mit 2mmol/1 L-Glutamin, $10 \%$ FCS, 1\% Sodiumpyruvat

RPMI 1640 mit 2mmol/1 L-Glutamin, 10 \%

FCS, 1\% Sodiumpyruvat

KSF-Medium mit 0.5\% L-Glutamin, $50 \mu \mathrm{g} / \mathrm{ml}$ bovine pituitary extract, $5 \mathrm{ng} / \mathrm{ml}$

EGF

\subsubsection{Zellkultur}

Die Konservierung der Zelllinien erfolgte in mit 10\% DMSO versetztem FCS mit darauffolgender Lagerung in flüssigem Stickstoff. Für das Anlegen einer Kultur wurden Aliquots im Wasserbad bei $37^{\circ} \mathrm{C}$ aufgetaut und mit Kulturmedium versetzt. Nach einer 5- bis

\footnotetext{
${ }^{12}$ Alle aufgeführten zellbiologischen Arbeiten wurden unter der Sterilwerkbank und unter der Verwendung von autoklaviertem oder desinfiziertem Material und sterilen Lösungen durchgeführt. Ebenfalls wurde regelmäßig auf Kontaminationen mit Mykoplasmen untersucht.

${ }^{13}$ Die Authentizität der Zelllinien wurden durch STR-Profiling überprüft.
} 
10-minütigen Zentrifugation bei 1000 rpm wurde der Überstand abgenommen und das Pellet in $10 \mathrm{ml}$ Kulturmedium resuspendiert. Die Zellsuspension wurde in eine $250 \mathrm{ml}$

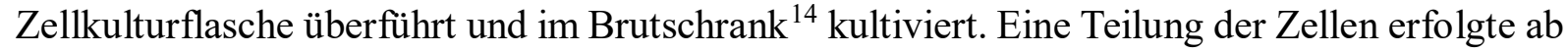
einer Konfluenz von ca. 80\% entsprechend ihrer Wachstumsraten zweimal pro Woche (max. bis zur 16. Passage). Hierzu wurde das verbrauchte Medium aus der Flasche abgesaugt und die Zellen durch die Zugabe von $5 \mathrm{ml}$ 1xTrypsin/EDTA mit einer Inkubationszeit von 5-15 min abgelöst. Um den Prozess der Ablösung mechanisch zu unterstützen, wurde die Flasche sanft beklopft. Anschließend wurde die Ablösung der Zellen unter dem Lichtmikroskop bestätigt. Die Wirkung des 1xTrypsin/EDTA wurde mit Einsatz von $5 \mathrm{ml}$ Medium neutralisiert und die entstandene Suspension in ein 50ml Röhrchen überführt. Darauf folgte eine 5-minütige Zentrifugation bei $1200 \mathrm{rpm}$. Der Überstand wurde verworfen, das Pellet in $10 \mathrm{ml}$ frisches Medium aufgenommen und in eine neue Flasche mit je $10 \mathrm{ml}$ Medium weiterkultiviert oder für Versuche auf 6- bzw. 12-well Platten ausgesät.

\subsubsection{Bestimmung der Zellzahl}

Die Bestimmung der Zellzahl erfolgte mithilfe einer Neubauer-Zählkammer. Es wurden $10 \mu 1$ der Zellsuspension unter das Deckglas der Zählkammer pipettiert und unter mikroskopischer Sicht die Zellzahl aller vier Quadranten manuell ermittelt. Der Mittelwert der Zellzahlen der Quadranten wurde mit dem Kammerfaktor $10.000\left(10^{4}\right)$ multipliziert. Versuche in 12-well

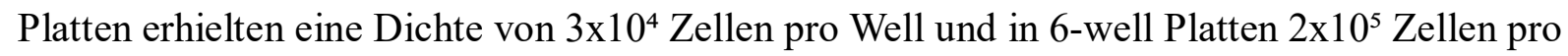
Well.

\subsubsection{Stimulation}

Zur Stimulation wurden 50 $\mu \mathrm{M}$ tBHQ, 50 $\mu \mathrm{M}$ Oltipraz, 10ng/ml TGF- $\beta 1,20 \mu \mathrm{g} / \mathrm{ml}$ Gemcitabin und $0,5 \mathrm{mg} / \mathrm{ml}$ TRAIL eingesetzt.

${ }^{14} 37{ }^{\circ} \mathrm{C}, 5 \% \mathrm{CO}_{2}$ und $85 \%$ Luftfeuchtigkeit 


\subsection{Transfektion von Zellen}

\subsection{1 siRNA-Transfektion mit HiPerfect}

24h nach Aussaat der Zellen in 6- bzw. 12-well Platten wurden siRNA ${ }^{15}$ Transfektionen mit HiPerFect Transfektionsreagenz durchgeführt. In Tab. 5 sind die entsprechenden Mengen der Reagenzien aufgeführt. Warmes OptiMEM ${ }^{16}$, siRNA (Tab. 3) und HiPerFect wurden miteinander versetzt und für 10 min bei RT inkubiert. Anschließend wurde in 12-well Platten je $53 \mu 1$ bzw. in 6-well Platten je 106 $\mu 1$ vom Ansatz tröpfchenweise in jedes Well gegeben. Es vergingen mind. $24 \mathrm{~h}$ bevor die transfizierten Zellen weiterverarbeitet wurden.

Tabelle 5: Zusammensetzung der Reagenzien für siRNA-Transfektion mit HiPerFect

\begin{tabular}{|l|l|l|l|}
\hline Platte & OptiMEM & HiPerFect & siRNA \\
\hline 12-Well & $50 \mu 1$ & $6 \mu 1$ & $0,6 \mu l(20 \mathrm{mM})$ \\
\hline $6-$ Well & $100 \mu 1$ & $12 \mu 1$ & $1,2 \mu 1$ \\
\hline
\end{tabular}

\subsubsection{Plasmid-DNA Transfektion mit Lipofectamin}

Die Transfektion von Plasmiden ${ }^{17}$ in die Zellen erfolgte unter der Verwendung von Lipofectamin Effectene Transfektionsreagenz. $\mathrm{Zu}$ Beginn wurde ein Mediumwechsel durchgeführt, bei dem die Zellen in 12-well Platten $750 \mu 1$ frisches Medium pro Well vorgelegt bekamen. EC-Puffer, Plasmid (Tab. 4) und Enhancer wurden in einem $50 \mathrm{ml}$ Röhrchen miteinander versetzt und für 5 min bei RT inkubiert. Anschließend wurde Effectene beigefügt und der Ansatz für weitere 10 min bei RT inkubiert, bevor dieser mit Kulturmedium versetzt und auf die Zellen geträufelt wurde. In 12-well Platten wurden je $350 \mu 1$ bzw. in 6-well Platten je $700 \mu 1$ vom Ansatz in jedes Well gegeben. Nach 8-10h wurde das Medium gewechselt und bis zur weiteren Bearbeitung 24h abgewartet.

\footnotetext{
${ }^{15}$ siRNA werden verwendet, um die Expression spezifischer Zielgene durch RNA-Interferenz zu vermindern. Hierzu binden siRNA an komplementäre Sequenzen der mRNA, die dann abgebaut werden.

${ }^{16}$ Serumfreies Medium

${ }^{17}$ Plasmide werden als Vektoren zur Integration von Fremdgen in ein Wirtsgenom verwendet.
} 
Tabelle 6: Zusammensetzung Plasmid-DNA-Transfektion mit EffecteneTM (Qiagen)

\begin{tabular}{|l|l|l|l|l|l|}
\hline Platte & EC-Puffer & Plasmid & Enhancer & Effectene & Medium \\
\hline 12-well & $50 \mu \mathrm{l}$ & $0,4 \mu \mathrm{g}$ & $3,2 \mu \mathrm{l}$ & $8 \mu \mathrm{l}$ & $315 \mu 1$ \\
\hline 6-well & $100 \mu \mathrm{l}$ & $0,8 \mu \mathrm{g}$ & $6,4 \mu \mathrm{l}$ & $16 \mu \mathrm{l}$ & $730 \mu \mathrm{l}$ \\
\hline
\end{tabular}

\subsection{Herstellung von Ganzzelllysaten}

In einer 12-well Platte wurden Zellen ausgesät. Bei einer Konfluenz von ca. 70\% erfolgte die Aufarbeitung der Zelllysate. Zunächst wurde das Medium abgesaugt, die Zellen mit 1ml PBS gewaschen und je nach Zelldichte mit 100-150 $\mu 1$ 2x Lämmli-Puffer pro Well versetzt. Mit einem Zellschaber wurden die Zellen anschließend vom Boden gelöst und in Eppendorfer Reagenzgefäße überführt. Danach erfolgte eine Ultraschallbehandlung mittels Sonificator mit 4 Zyklen je 1 sec. Die fertigen Zelllysate wurden bei $-20^{\circ} \mathrm{C}$ für eine Weiterverarbeitung gelagert.

Tabelle 7: Zusammensetzung von 2xLämmli Puffer

\begin{tabular}{|c|c|}
\hline 2x Lämmli Puffer: & $\begin{array}{l}128 \mathrm{mM} \text { Tris Base } \\
4,6 \%(\mathrm{w} / \mathrm{v}) \mathrm{SDS} \\
10 \%(\mathrm{v} / \mathrm{v}) \text { Glycerol } \\
\text { ad } 1000 \mathrm{ml} \mathrm{H}_{2} \mathrm{O} \text { bidest. } \\
\mathrm{pH} \mathrm{7,6}\end{array}$ \\
\hline
\end{tabular}

\subsection{Herstellung von Kernextrakten}

Zellen wurden in 6-well Platten ausgesät und für die jeweilige Fragestellung entsprechend wie in Kapitel 3.1.5 und 3.2. behandelt. Für die Herstellung von Kernextrakten wurde zunächst das Medium abgesaugt, die Zellen mit kaltem PBS gewaschen und mit 200 $\mu 1$ EMSA-I-Puffer pro Well versetzt. Unter Verwendung eines Zellschabers wurden die Zellen vom Boden gelöst und in Eppendorf-Cups überführt. Nach einer 5-minütigen Zentrifugation bei $3500 \mathrm{rpm}$ und $4^{\circ} \mathrm{C}$ wurde der Überstand (=zytoplasmatischen Fraktion) verworfen oder für weitere Untersuchungen bei $-20^{\circ} \mathrm{C}$ gelagert. Das verbleibende Pellet wurde in $500 \mu 1$ EMSA-I-Puffer 
resuspendiert und für 1 min bei $4^{\circ} \mathrm{C}$ und 3500rpm zentrifugiert. Anschließend wurde der Überstand verworfen. Zum Pellet wurden je nach Pelletgröße 50-80 $\mu 1$ EMSA-II-Puffer hinzugegeben und für 30 min bei $4^{\circ} \mathrm{C}$ auf einem Schüttler inkubiert. Danach erfolgte eine weitere Zentrifugation für $10 \mathrm{~min}$ bei $4^{\circ} \mathrm{C}$ und $13000 \mathrm{rpm}$. Der Überstand (=Kernextrakt) wurde abgenommen und für weitere Untersuchungen bei $-80^{\circ} \mathrm{C}$ aufbewahrt.

Tabelle 8: Zusammensetzung der EMSA-Puffer I und II

\begin{tabular}{|l|l|}
\hline EMSA-I-Puffer & $10 \mathrm{mM}$ HEPES pH 7,9 \\
& $10 \mathrm{mM}$ KCL \\
& $0,2 \mathrm{mM}$ EDTA \\
& $1 \mathrm{mM}$ DTT \\
& $10 \mu \mathrm{g} / \mathrm{ml}$ Aprotinin \\
& $0,5 \mathrm{mM}$ PMSF \\
& Phosphatase-Inhibitor Cocktail $210 \mu 1 / \mathrm{ml}$ \\
& Phosphatase-Inhibitor Cocktail $310 \mu 1 / \mathrm{ml}$ \\
\hline EMSA-II-Puffer & $20 \mathrm{mM}$ HEPES pH 7,9 \\
& $0,4 \mathrm{M}$ NaCl \\
& $0,2 \mathrm{mM}$ EDTA \\
& $1 \mathrm{mM}$ DTT \\
& $10 \mu \mathrm{g} / \mathrm{ml}$ Aprotinin \\
& $0,5 \mathrm{mM}$ PMSF \\
\hline
\end{tabular}

\subsection{Bestimmung von Proteinkonzentrationen}

\subsubsection{Verfahren nach Lowry}

Unter der Verwendung des DC-Proteinassay von Bio-Rad wurden die Proteinkonzentrationen von Ganzzelllysaten quantitativ ermittelt. Auf 96-well Microtest-Platten wurden je $5 \mu 1$ von den Proben in die Wells vorgelegt, wobei von jeder Probe zwei Bestimmungen gemacht wurden.

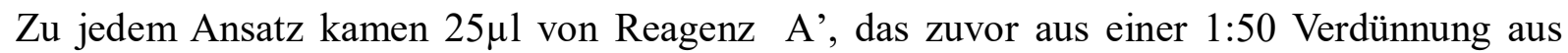
Reagenz A und Reagenz S' hergestellt wurde, hinzu. Anschließend erfolgte die Zugabe von $200 \mu 1$ von Reagenz B zu jedem Ansatz. Nach 20 min Inkubationszeit im Dunkeln wurde die Proteinkonzentration mittels Photometer Opsys MR und der Software Revelation QuickLink 
bei einer Wellenlänge von 630nm gemessen und ausgewertet. Für die Eichung diente eine Verdünnungsreihe aus Proteinstandard BSA und Lämmli-Puffer $(1: 1 ; 1: 2 ; 1: 4 ; 1: 8,0)$.

\subsubsection{Verfahren nach Bradford}

Für die quantitative Bestimmung der Proteinkonzentrationen von Kern- und zytoplasmatischen Extrakten wurden im doppelten Ansatz je $5 \mu 1$ Probe auf die Mikrotitierplatten vorgelegt und mit 200 $\mu 1$ Biorad-Reagenz, das zuvor 1:5 mit Aqua dest. verdünnt wurde, inkubiert. Nach 10 min Inkubationszeit bei RT in Dunkelheit erfolgte die photometrische Messung mittels Photometer Opsys MR5000 bei einer Wellenlänge von 630nm und der Revelation QuickLink Software. Als Standardkurve diente eine Verdünnungsreihe mit BSA und EMSA-II-Puffer (1:1, $1: 2,1: 4,1: 8,0)$.

\subsection{SDS-PAGE (Natriumdodecylsulfat-Polyacrylamid-}

\section{Gelelektrophorese ${ }^{18}$ )}

\subsubsection{Vorbereitung der Proben}

Die Ganzzell- bzw. Kernlysate (Kapitel 3.3 bzw. 3.4) wurden entsprechend ihrer Proteinkonzentrationen auf eine einheitliche Proteinmenge (8-12 $\mu \mathrm{g}$ Protein) eingestellt. Dabei wurden die Probenvolumina mit 2xLämmli- bzw. EMSA-I-Puffer aufgefüllt und mit 4xFarbpuffer versetzt. Zur weiteren Denaturierung der Proteine, wurden die Proben bei $95^{\circ} \mathrm{C}$ auf dem Thermoblock für 5 min erhitzt und danach abgekühlt und kurz zentrifugiert.

Tabelle 9. Zusammensetzung des 4xFarbpuffers

4xFarbpuffer

$0,005 \%(w / v)$ Bromphenolblau

$2,5 \%(\mathrm{v} / \mathrm{v})$ Mercaptoethanol

\footnotetext{
${ }^{18}$ Die Gelelektrophorese ist eine Methode, die zur Trennung von verschiedenen Molekülen verwendet wird. Dabei wandern die Moleküle, in einem elektrischen Feld durch ein Gel, das als Netz fungiert und die Moleküle entsprechend ihrer Größe und relativen Molekülmasse bei ihrer Bewegung aufhält. Natriumdodecylsulfat (SDS) trägt als anionisches Detergenz zur Denaturierung der Proteine bei und verleiht den Proteinen durch Komplexbildung eine negative Ladung, sodass die Auftrennung eines Proteingemisches durch SDS-PAGE unabhängig von der Eigenladung der Proteine erfolgt.
} 


\subsubsection{Herstellung der Gele}

In der Herstellung von Polyacrylamid-Gele ${ }^{19}$ werden die Komponenten Trenngel und Sammelgel unterschieden. In Tab. 10 sind die jeweiligen Zusammensetzungen aufgeführt. Das Trenngel wurde in den Zwischenraum einer Konstruktion, bestehend aus zwei Glasplatten und einer Dichtung zwischen den beiden Platten, gefüllt. Anschließend wurde eine Schicht Isopropanol auf das Trenngel gegeben. Sobald das Gel vollständig polymerisiert war, wurde das Isopropanol mit Aqua dest. entfernt und das Sammelgel darauf gegossen, sowie ein Kamm zur Bildung von Taschen für die Proben eingelegt. Nachdem sich das Sammelgel verfestigt hatte, war das Gel für seinen Einsatz bereit.

Tabelle 10. Zusammensetzung des Trenn- und Sammelgels für die Gelelektrophorese

\begin{tabular}{|l|l|}
\hline Trenngel 12,5\% & 5,4 ml Aqua dest. \\
& 3 ml Trenngelpuffer $\mathrm{pH} 8,8$ \\
& $3,6 \mathrm{ml} 40 \%$ PAA \\
& $44 \mu 110 \%$ APS \\
& $8,8 \mu 1$ Temed \\
\hline Sammelgel & $1575 \mu 1$ Aqua dest. \\
& $625 \mu 1$ Sammelgelpuffer pH 6,8 \\
& $250 \mu 140 \%$ PAA \\
& $13 \mu 110 \%$ APS \\
& $2,5 \mu 1$ Temed \\
\hline Trenngelpuffer & $1,5 \mathrm{M}$ Tris \\
& $0,4 \%$ SDS \\
& pH-Wert mit HCl auf 8,8 eingestellt \\
\hline
\end{tabular}

${ }^{19}$ Polyacrylamid Gele sind geeignet zur Trennung kleiner Proteine. Der Vernetzungsgrad des Gels wird in Abhängigkeit von der Größe des zu trennenden Moleküls gewählt. 


\begin{tabular}{|l|l|}
\hline Sammelgelpuffer & $1,5 \mathrm{M}$ Tris \\
& $0,4 \%$ SDS \\
& pH-Wert mit $\mathrm{HCl}$ auf 6,8 eingestellt \\
\hline
\end{tabular}

\subsubsection{Auftrennung der Proteine}

Für die elektrophoretische Auftrennung von Proteinen wurde das Gel in eine Gelkammer eingespannt und mit 1xSDS-Laufpuffer befüllt. In die Taschen wurden die Proben (Kapitel 3.3 bzw. 3.4) hinein pipettiert, wobei eine Tasche mit dem PageRuler ${ }^{20}$ beladen wurde. Die Auftrennung beginnt, sobald elektrische Spannung an die Gelkammer angelegt wurde. $\mathrm{Zu}$ Beginn wurden 30mA eingestellt bis die Proben das Sammelgel überbrückt haben und dann auf 40mA erhöht. Die Auftrennung der Moleküle wurde erst beendet, wenn die kleinsten Moleküle bzw. der letzte Marker des PageRuler das Ende des Gels erreicht hatte.

\subsection{Western-Blot ${ }^{21}$ nach Semidry-Blotting Verfahren}

Für den Proteintransfer nach dem Semidry-Blotting Verfahren wurden 6 Whatman Paper in Blot-Puffer I und 3 in Blot-Puffer II getränkt und übereinandergeschichtet. Die PVDF-Membran wurde in 100\% Methanol für 1 min gelegt, anschließend mit Aqua dest. gewaschen und auf den Stapel Whatman Paper gelegt. Behutsam wurde das mit Proben beladene Gel von den Glasplatten gelöst und auf die Membran gebracht. Es wurde darauf geachtet, das Gel möglichst luftblasenfrei auf die Membran zu legen. Darauf folgten 6 Whatman Paper, die in Blot-Puffer III getränkt wurden. Anschließend wurde der Stapel in einer Blotkammer platziert. Der Transfer erfolgte bei $70 \mathrm{~mA}^{22}$ für $1 \mathrm{~h}$.

Tabelle 11. Zusammensetzung von TBS-T, Blot-Puffer-I, -II, -III

\begin{tabular}{|l|l|}
\hline $1 \mathrm{xTBS}$ & $20 \mathrm{mM}$ Tris-Base \\
\hline
\end{tabular}

\footnotetext{
${ }^{20}$ Marker für den Größenstandard von Molekülen

${ }^{21}$ Ein Verfahren zum Transfer von Proteinen auf eine Membran, um im Anschluss eine Identifizierung und Quantifizierung von Proteinen durchführen zu können. Es gibt unterschiedliche Varianten, die alle nach dem gleichen Prinzip funktionieren: Proteine wandern durch das Anlegen einer Spannung in einem elektrischen Feld vom Gel zur Membran.

${ }^{22} 1,2 \mathrm{~mA} / \mathrm{cm}^{2}$, bei einem Blot der Größe $6,5 \mathrm{~cm} \times 9,0 \mathrm{~cm} 70 \mathrm{~mA}$
} 


\begin{tabular}{|l|l|}
\hline & $\begin{array}{l}140 \mathrm{mM} \mathrm{NaCl} \\
\mathrm{pH} 7,6\end{array}$ \\
\hline TBS-T & $\begin{array}{l}100 \mathrm{ml} 10 \mathrm{xTBS} \\
500 \mu \mathrm{T} \text { Tween-20 } \\
\text { ad } 1000 \mathrm{ml} \text { Aqua dest. }\end{array}$ \\
\hline Blot-Puffer-I & $\begin{array}{l}300 \mathrm{mM} \text { Tris-Base } \\
20 \%(\mathrm{v} / \mathrm{v}) \text { Methanol }\end{array}$ \\
\hline Blot-Puffer-II & $\begin{array}{l}25 \mathrm{mM} \text { Tris-Base } \\
20 \%(\mathrm{v} / \mathrm{v}) \text { Methanol }\end{array}$ \\
\hline Blot-Puffer-III & $\begin{array}{l}25 \mathrm{mM} \text { Tris-Base } \\
20 \% \text { (v/v) Methanol } \\
0,04 \mathrm{M} \text { Aminocapronsäure } \\
\mathrm{pH} 10,6\end{array}$ \\
\hline
\end{tabular}

\subsection{Proteindetektion}

Im Anschluss an den Westernblot wurden für die Detektion der Proteine Primär- und Sekundärantikörper ${ }^{23}$ (Tab. 1) eingesetzt. Die mit den Proben beladene Membran wurde zunächst mit TBS-T gewaschen und in 5\% Magermilch/TBS-T für $1 \mathrm{~h}$ inkubiert, um unspezifische Bindungen von Antikörpern an die Membran zu verhindern. Die Primärantikörper wurden nach Herstellerangaben mit 5\%Magermilch/TBST-T oder 5\% BSA verdünnt und mit der Membran in einem $50 \mathrm{ml}$ Röhrchen bei $4^{\circ} \mathrm{C}$ über Nacht auf einem Rollmischer inkubiert. Dann wurde die Membran 3 Mal je 10 min in TBS-T gewaschen, bevor diese in ein weiteres Röhrchen überführt, welches den Sekundärantikörper enthält und für $1 \mathrm{~h}$ bei RT inkubiert wurde. Anschließend wurde die Membran erneut 3 Mal je 10 min in TBS-T

\footnotetext{
${ }^{23}$ Der Primärantikörper bindet spezifisch an das zu detektierende Protein und der Sekundärantikörper bindet wiederum spezifisch an den Primärantikörper. Der Sekundärantikörper trägt eine Horseradish-Peroxidase, das bei einer Substratreaktion Chemilumineszenz emittiert.
} 
gewaschen. Für die Entwicklung des Blots wurde Dura Detection Kit (Perbio Sciences, Bonn)/SuperSignal Substrat oder LumiGlo Chemiluminescent Substrate verwendet und die entstandene Lichtreaktion mit ChemiDoc-XRS ${ }^{\top M}$ (Quantity One ${ }^{\circledR}$ Software von BioRad) gemessen. Um die gleichmäßige Beladung der Proben auf das SDS-Gel zu bestätigen, wurde auf der Membran zusätzlich Lamin $\mathrm{A} / \mathrm{C}^{24}$ oder Tubulin ${ }^{25}$ detektiert.

\subsection{Isolierung von RNA}

Die Isolierung der RNA erfolgte mit Einsatz des Qiagen RNeasy Total RNA Kits. Hierbei wurde zuerst das Medium abgesaugt und die Zellen mit PBS gewaschen. Mit der Zugabe von $400 \mu 1$ RNA-Lysis Buffer wurden die Zellen lysiert und in Eppendorfer Reagenzgefäße überführt. $400 \mu 1$ von 70\%-igem Ethanol wurden zu jedem Ansatz beigemischt und in speziellen Säulen mit einer RNA-auffangenden Membran überführt. Nach der Zentrifugation bei $11000 \mathrm{rpm}$ für 1 min wurde die in der Membran liegenden RNA nacheinander mit Washing Buffer I und II gewaschen und zentrifugiert. Durch die Zugabe von $40 \mu 1$ RNAse-freies Wasser und einer 1minütigen Zentrifugation bei $8000 \mathrm{rpm}$ wurde die RNA aus der Membran gelöst. Die photometrische Bestimmung zur Ermittlung der RNA-Konzentration erfolgte mittels Nano Drop Spectrophotometer $10-1000$ bei $250 / 280 \mathrm{~nm}$. Die Proben wurden bei $-80^{\circ} \mathrm{C}$ gelagert.

\subsection{Herstellung von cDNA/Reverse Transkription ${ }^{26}$}

Für diesen Vorgang wurden 1,5 $\mu$ g der RNA-Probe in ein Eppendorf Reaktionsgefäß überführt, mit RNAse-freies Wasser auf ein Volumen von 11,4 $\mu$ l aufgefüllt und je $1 \mu 1$ Oligo-dT-Primer hinzugegeben. Die Proben wurden bei $65^{\circ} \mathrm{C}$ für $5 \mathrm{~min}$ in einem Thermoblock unter schüttelnder Bewegung erhitzt. Sobald die Proben abgekühlt waren, wurden je 11,6 $\mu 1$ Mastermix (Tab. 12) hinzugefügt und bei $42^{\circ} \mathrm{C}$ für 60 min erneut erhitzt. Anschließend wurden die Proben bei $70^{\circ} \mathrm{C}$ für 5 min inkubiert und die entstandene cDNA bis zur weiteren Untersuchung bei $-20^{\circ} \mathrm{C}$ gelagert.

\footnotetext{
${ }^{24}$ Ladekontrolle für Kernextrakten in Westernblot

${ }^{25}$ Ladekontrolle für Ganzzelllysate in Westernblot

${ }^{26}$ Bei der reversen Transkription wird am RNA-Strang ein komplementärer DNA-Strang synthetisiert. Dann wird der RNA-Strang abgebaut und die bestehende DNA zu einem Doppelstrang Molekül ergänzt, was dann die cDNA ergibt.
} 
Tabelle 12. Zusammensetzung des Mastermix für die reverse Transkription

\begin{tabular}{|l|l|}
\hline Mastermix pro Ansatz & $\begin{array}{l}4 \mu 15 \mathrm{x} \text { Reaction buffer } \\
2 \mu 1 \mathrm{dNTP}(10 \mathrm{mM})\end{array}$ \\
$0,5 \mu 1$ RiboLock RNAse Inhibitor \\
$1 \mu 1$ Revert Aid M-MLV Reverse Transkriptase
\end{tabular}

\subsection{Quantitative Polymerase-Ketten-Reaktion/RealTime PCR}

Die Durchführung einer quantitativen PCR dient der Ermittlung der Menge an DNA in einer Probe. Zum Einsatz kam der interkalierende Farbstoff SYBR Green Mix ${ }^{27}$. Die in Kapitel 3.10 hergestellten cDNA wurden zunächst 1:5 mit RNAse-freies Wasser verdünnt. In einer 96-well PCR-Platte wurden je $2 \mu 1$ der verdünnten cDNA für eine Doppelbestimmung in die Wells pipettiert. Dazu wurden je 10 $\mu 1$ des Mastermix pro Well (Tab. 13) hinzugefügt. Anschließend wurde eine Folie auf die Platte geklebt und für $15 \mathrm{sec}$ bei $1200 \mathrm{rpm}$ zentrifugiert. Die Messung erfolgte mittels PicoReal 96 mit der PikoReal-2.1 Software. Für die Kontrolle der gleichmäßigen Beladung der Proben in den Wells wurde die Menge von TBP oder $\beta$-Aktin detektiert.

Tabelle 13. Zusammensetzung des Mastermix für die quantitative PCR

\begin{tabular}{|l|l|}
\hline Mastermix pro Ansatz & $6 \mu 1$ SYBR Green Mix \\
& $0,04 \mu 1$ Forward Primer \\
& $0,04 \mu 1$ Reverse Primer \\
$3,92 \mu 1$ Aqua dest
\end{tabular}

\footnotetext{
${ }^{27}$ Solche Farbstoffe interkalieren in doppelsträngiger DNA und können durch Anregung mit Licht fluoreszieren. An jedem Zyklusende wird die Fluoreszenz gemessen. Die Zunahme der Fluoreszenz ist direkt proportional zur Zunahme der zu amplifizierenden DNA.
} 


\subsection{Luciferase-Assay}

Für die Untersuchung der Promotor- bzw. Gen-Aktivität wurde Luciferase ${ }^{28}$ eingesetzt. Das Medium wurde abgesaugt und mit PBS gewaschen. Je 200 $\mu 1$ Passive Lysis Puffer wurden in die Wells gebracht. Mit einem Zellschaber wurden die Zellen von den Wells gelöst und in ein Eppendorf Reaktionsgefäß überführt. Anschließend erfolgte eine Zentrifugation bei $13000 \mathrm{rpm}$ für $30 \mathrm{sec}$. Der Überstand wird in ein neues Eppendorf Reaktionsgefäß überführt und das Pellet wurde verworfen. In einer weißen 96-well-Platte wurden je $20 \mu 1$ von der Probe doppelt aufgetragen und je $25 \mu 1$ Luciferase-Assay-Reagenz hinzugegeben und mittels Luminometer die Firefly Aktivität über die Dauer von $20 \mathrm{sec}$ gemessen. In einer weiteren 96-well Platte wurden $20 \mu 1$ der gleichen Proben mit $25 \mu 1$ Renilla-Reagenz doppelt aufgetragen und die Lumineszenz bestimmt. Die Messwerte der Firefly Luciferase wurden mit denen der Renilla Luciferase normiert.

\subsection{Caspase-Assay}

Zur Ermittlung der Aktivität der Effektorcaspasen -3 und -7 wurde der Caspase Glo®3/7 Assay $^{29}$ verwendet. Dabei wurde der Mediumüberstand der Zellen, nach Behandlung mit Apoptose-induzierenden Stimulanzien wie TRAIL oder Gemcitabin, in ein FACS-Röhrchen überführt. Die in den Wells verbliebenden adhärenten Zellen wurden mit Trypsin gelöst und zu ihren jeweiligen Überständen in die FACS-Röhrchen hinzugefügt. Danach erfolgte eine Zentrifugation bei $1400 \mathrm{rpm}$ für $10 \mathrm{~min}$. Anschließend wurde der Überstand abgesaugt, das Pellet mit $1 \mathrm{ml}$ PBS versetzt, die Suspension in Eppendorfer Reagenzgefäße überführt und erneut für 5 min bei $1200 \mathrm{rpm}$ zentrifugiert. Der entstandene Überstand wurde verworfen und das Pellet in $500 \mu 1$ PBS resuspendiert. Danach wurden je $25 \mu 1$ der Zellsuspension doppelt in eine weiße 96-well-Platte pipettiert und mit jeweils $25 \mu 1$ Caspase-Reagenz versetzt und für 30 min bei RT in Dunkelheit inkubiert. Die Messung der Caspase-Aktivität erfolgte mit Microplate Lumino-

\footnotetext{
${ }^{28}$ Enzym, das aus dem Leuchtkäfer stammt. Luciferase wandelt Luciferol um, dabei entsteht ATP, das zu einer Lichreaktion umgesetzt wird. Die Stärke der Lichtreaktion ist proportional zur Höhe der Promotor- bzw. GenAktivität.

${ }^{29}$ Das eingesetzte Caspase-Substrat lysiert die Zellen und wird anschließend gespalten. Dabei wird Aminoluciferin freigesetzt, das von der Luciferase in ein Lumineszenz-Signal umgesetzt wird. Die Stärke des Signals ist proportional zur Höhe der Caspase-3,-7-Aktivität.
} 
meter LB96V. Zum Schluss wurden die restlichen Zellsuspensionen zu Ganzzelllysaten weiterverarbeitet und der Proteingehalt wie in Kapitel 3.5.1 bestimmt, um die Caspase-Aktivität auf den Proteingehalt normieren zu können.

\subsection{Zellzyklus-Analyse mit Propidiumiodid-Färbung}

Nach der Aussaat von Zellen in Wells wurde der Mediumüberstand abgenommen und in ein $15 \mathrm{ml}$ Röhrchen überführt. Die in den Wells verbliebenden adhärenten Zellen wurden trypsiniert und in die Röhrchen zu ihrem jeweiligen Überstand hinzugegeben. Danach folgte eine Zentrifugation bei $4^{\circ} \mathrm{C}$ und $1500 \mathrm{rpm}$ für $10 \mathrm{~min}$. Der Überstand wurde verworfen und das Pellet mit $2 \mathrm{ml}$ kaltem PBS resuspendiert und erneut unter den gleichen Bedingungen wie zuvor zentrifugiert. Der Überstand wurde wieder verworfen und der gleiche Vorgang mit $2 \mathrm{ml}$ PBS wiederholt. Anschließend wurde das Pellet mit $1 \mathrm{ml}$ kaltem PBS resuspendiert, mit $1 \mathrm{ml} \mathrm{100 \% -}$ igem Ethanol versetzt und für 10 min auf Eis inkubiert. Nach einer erneuten Zentrifugation für $10 \mathrm{~min}$ bei $4^{\circ} \mathrm{C}$ und $1500 \mathrm{rpm}$ wurde der Überstand verworfen und das Pellet mit $500 \mu 1 \mathrm{kaltem}$ PBS resuspendiert. Je $200 \mu 1$ dieser Zellsuspensionen wurden in ein FACS-Röhrchen überführt und mit $10 \mu 1$ RNAse $(10 \mathrm{mg} / \mathrm{ml})$ für $15 \mathrm{~min}$ bei RT inkubiert. Zum Schluss erfolgte die Zugabe von je $200 \mu 1$ Propidium-Iodid $(100 \mu \mathrm{g} / \mathrm{ml})$. Die Proben wurden mittels Durchflusszytometer FACS-Verse gemessen.

\subsection{Colony-formation-Assay mit siRNA-Transfektion}

Es wurden Zellen in 6-Well-Platten ausgesät und eine Transfektion mit siRNA (Kapitel 3.2.1) durchgeführt, die nach 4 Tagen wiederholt wurde. Nach einer Inkubation der Zellen für 3-6 Tage im Brutschrank wurden die Zellen zweimal in PBS gewaschen und mit einer Methano1/Essigsäure-Lösung (3:1) für 5 min behandelt. Anschließend wurden die Zellen mit $0.1 \%(w / v)$ Kristallviolett-Lösung gefärbt. Mithilfe des Chemidoc-XRSTM Transilluminator wurden Fotos von den Wells gemacht. Kolonien, die größer als 0.5mm Durchmesser waren, wurden gezählt und die Plating Efficiency ${ }^{30}$ errechnet.

\footnotetext{
${ }^{30} \mathrm{PE}=\frac{\text { colonies counted }}{\text { cells inoculated }} \times 100$
} 


\subsection{Immunhistochemische Färbung}

Für die nachfolgende Verwendung und Verarbeitung von Geweben liegt eine Genehmigung der Ethikkommission der Medizinischen Fakultät der CAU zu Kiel (D 400/14) vor. Eine schriftliche Einverständniserklärung aller Patienten wurde eingeholt.

Aus 20 PDAC- und 6 CP-Patienten wurden Pankreasgewebe (11) gewonnen, die zunächst in Formalin fixiert und in Paraffin eingebettet wurden. Daraus wurden konsekutive $3 \mu \mathrm{m}$ dünne Gewebeschnitte erstellt, die dann mit Xylol, einer absteigenden Alkoholreihe und Aqua dest. entparaffinisiert wurden. Die Zugabe von $0,3 \% \mathrm{H}_{2} \mathrm{O}_{2}$ diente der Neutralisierung der endogenen Peroxidasen. Anschließend erfolgte ein Antigen-Retrieval in Tris-EDTA Puffer (pH 9,0) für 20 min und Sub-Siedetemperatur. Dann wurden die Gewebeschnitte in 4\% BSA/PBS für 1h gewaschen und für die Immunhistochemische Färbung mit monoklonalen Antikörpern (Tab. 1.2) gegen aktiviertes Nrf2 (P-Nrf2), ATF3 und $\Delta$ Zip2 über Nacht bei $4{ }^{\circ} \mathrm{C}$ inkubiert. In einer Feuchtkammer wurden die Gewebeschnitte 3 Mal in PBS gewaschen. Für die Detektion von P-Nrf2 wurden die Gewebeschnitte 30 min bei RT mit dem EnVision+HRP-Anti Kanninchen Antikörper-Komplex inkubiert. Für die Detektion von ATF3 und $\Delta$ Zip2 wurden die Gewebeschnitte 30 min bei RT mit einem Biotin-konjugierten Anti-Maus IgG Antikörper inkubiert und dann dreimal in PBS gewaschen und mit Peroxidase-konjugiertes Streptavidin für 30 min bei RT reinkubiert. Entsprechend den Herstellerangaben wurde mit dem AEC Peroxidase Substrat Kit die Substratreaktion durchgeführt. Die Gewebeschnitte wurden anschließend mit Wasser gewaschen, für $1 \mathrm{~min}$ in 50\% Meyers Hämalaunlösung getaucht, für $10 \mathrm{~min}$ in Wasser gelegt und zum Schluss mit Kaisers Glyceringelatine bedeckt. Gemäß den vorgenannten Arbeitsschritten wurde eine Negativkontrolle erstellt, bei der IgG-Kontroll-Antikörper eingesetzt wurde. Mit dem Axioplan 2 Imaging Mikroskop wurden die Gewebeschnitte unter 200x Vergrößerung beurteilt.

\subsection{Statistik, Grafiken, Ausarbeitung}

Für die statistischen Berechnungen, die Erstellung der graphischen Abbildungen und die Bearbeitung von Bildmaterial wurden Microsoft Excel 2013 (Microsoft, München), Photoshop 7.0 (Adobe Systems Inc., San Jose, USA) und Powerpoint 2010 (Microsoft, München) verwendet. Das Verfassen der Dissertation erfolgte mit Word 2016 (Microsoft). Anhand des doppelseitigen Student's t-Test wurden die Signifikanzen beurteilt $\left({ }^{*} p<0.05\right.$ gilt als signifikant). 


\section{Ergebnisse}

\subsection{Induktion von ATF3 und $\Delta$ Zip2 durch TGF- $\beta 1$, tBHQ und Oltipraz}

Die Zelllinien Panc1, T3M4 und H6c7 wurden mittels qPCR und Westernblot auf die Expression von ATF3 und $\triangle$ Zip2 sowie deren Abhängigkeit von Nrf2 und TGF- $\beta 1$ untersucht. Als Nrf2 Aktivatoren wurden hierbei tBHQ und Oltipraz eingesetzt. In Panc1 zeigte sich basal eine geringe $\Delta$ Zip2 Expression und praktisch keine ATF3 Expression, während sich in T3M4 und H6c7 basal hohe Spiegel von ATF3, jedoch nicht von $\triangle$ Zip2 nachweisen ließen (Abb. 2A, B). Unter dem Einsatz von tBHQ erhöhte sich die Expression von ATF3 in Panc1 und H6c7, sowie die Expression von $\Delta$ Zip2 in allen drei Ziellinien. Am stärksten ausgeprägt war die tBHQinduzierte $\Delta$ Zip2 Expression in T3M4. Demgegenüber bewirkte die Behandlung mit Oltipraz eine im Vergleich mit tBHQ nur geringe Induktion der $\triangle$ Zip2 Expression, wie in Panc1 und T3M4 gezeigt (Abb. 2C). Dies kann in der deutlich schwächeren Aktivierung von Nrf2 durch Oltipraz begründet sein, wie ebenfalls in Panc1 und T3M4 Zellen beobachtet wurde (Abb. 2C). In diesen beiden Zelllinien war jedoch ein induzierender Effekt durch Oltipraz auf die ATF3 Expression festzustellen, der in vergleichbarer Größenordnung lag wie der Effekt von tBHQ. Eine ähnlich ausgeprägte Induktion der ATF3 Expression trat auch unter einer Behandlung mit TGF- $\beta 1$ auf, wie in Panc1, T3M4 und H6c7 gezeigt werden konnte (Abb. 2A,B), wobei in diesen drei Zelllinien kein Effekt von TGF- $\beta 1$ auf die $\Delta$ Zip2 Expression zu beobachten war. Um die Nrf2-Abhängigkeit der Induktion von $\Delta$ Zip2 zu überprüfen, wurde nachfolgend ein Versuch mit Panc1, T3M4 und H6c7 Zellen unternommen, bei dem diese mit einem Nrf2 Expressionsplasmid transfiziert wurden. Im Westernblot konnte entsprechend eine deutlich erhöhte Expression von $\Delta$ Zip2 Protein nachgewiesen werden, wenn Nrf2 überexprimiert war (Abb. 2D). Ähnlich der tBHQ Behandlung war auch eine Induktion der ATF3 Expression durch überexprimiertes Nrf2 nachzuweisen. 


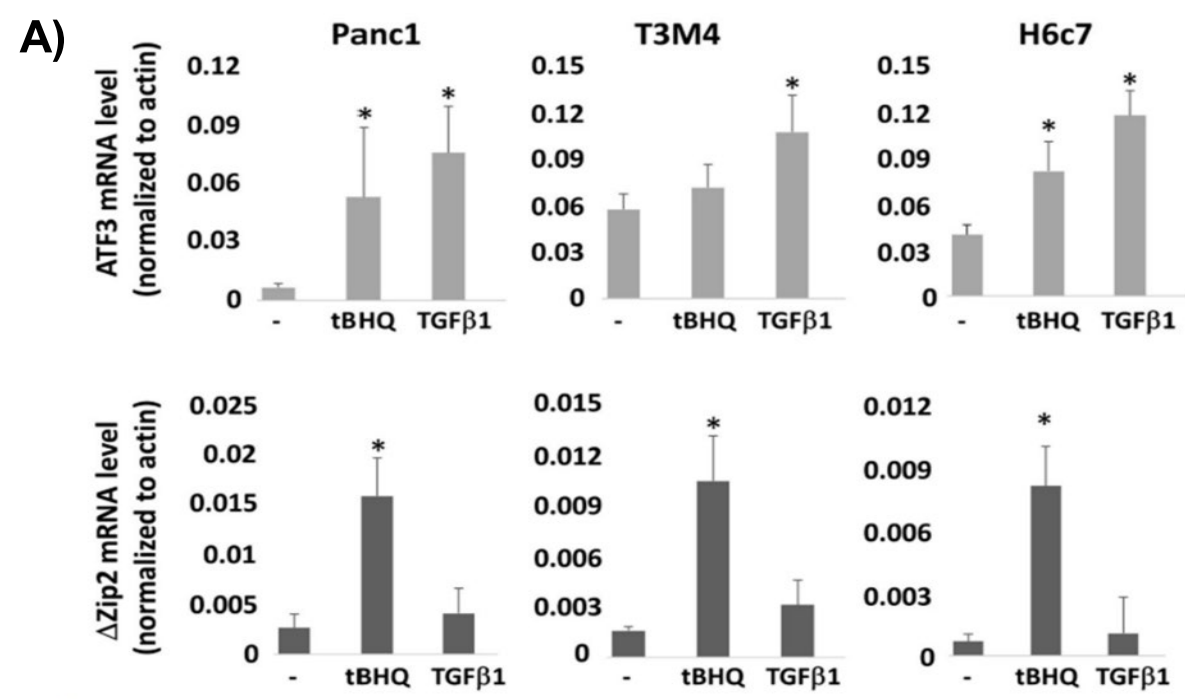

B)

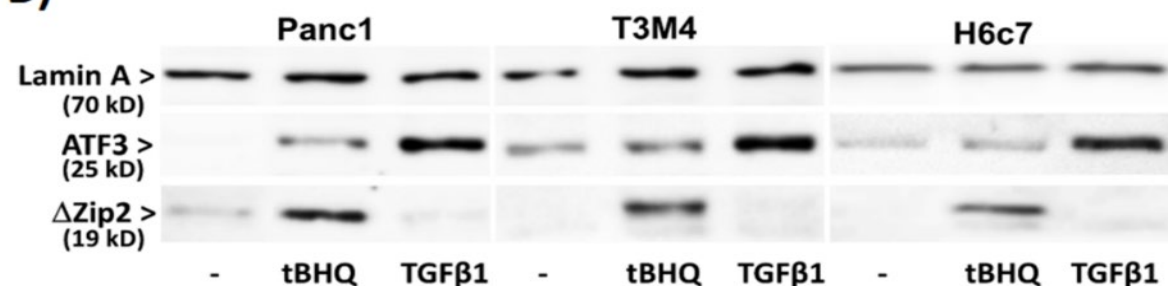

C)

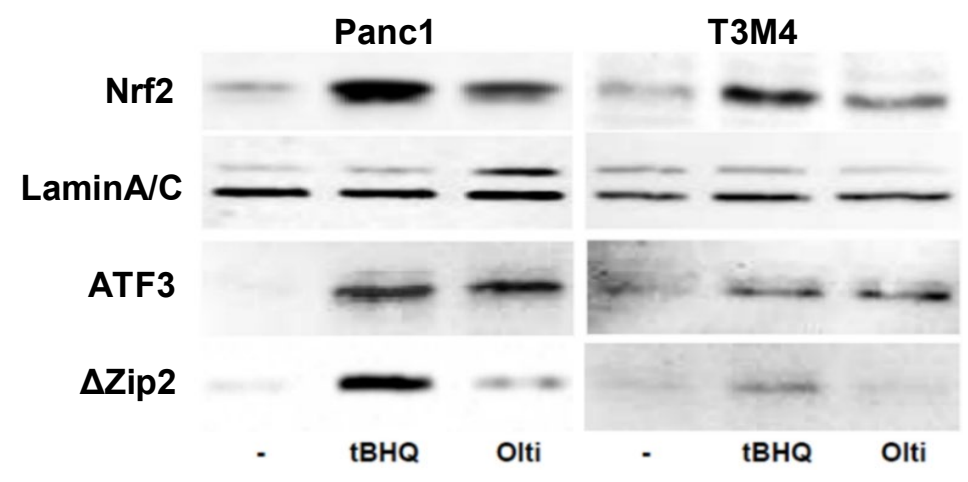

D)

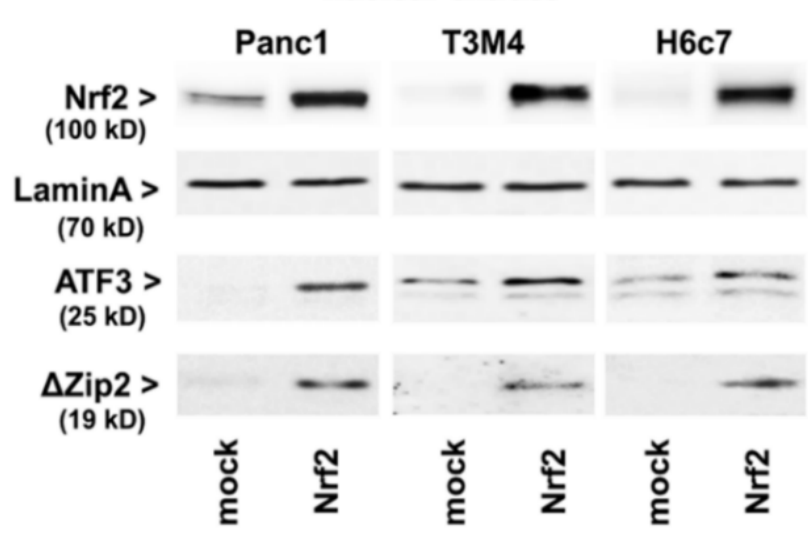

Abbildung 2. Induktion der Expression von $\triangle$ Zip2 und ATF3 mittels tBHQ, TGF-ß1 und Oltipraz in Panc1, T3M4 und H6c7 sowie nach Nrf2 Überexpression

A) Quantitative PCR Analyse auf den Gehalt von ATF3 und $\triangle$ Zip2 in unbehandelten Zellen bzw. in Zellen nach 
8h Behandlung mit 50 $\mu \mathrm{M}$ tBHQ oder 10ng/ml TGF- $\beta 1$. Daten repräsentieren die Mittelwerte aus sechs unabhängigen Experimenten. ${ }^{*} \mathrm{p}<0.02$

B) C) D) Zellkernextrakte aus B) unbehandelten Zellen bzw. aus Zellen nach Behandlung mit 50 $\mu \mathrm{M}$ tBHQ oder $10 \mathrm{ng} / \mathrm{ml}$ TGF- $\beta 1$ für $8 \mathrm{~h}$ bzw. C) nach Behandlung mit 50 $\mu \mathrm{M}$ tBHQ oder 50 $\mu \mathrm{M}$ Oltipraz für 8h bzw. D) nach Transfektion mit Nrf2-cDNA bzw. Kontroll-cDNA (mock) wurden im Westernblot auf den Gehalt von ATF3 und $\Delta$ Zip2 untersucht. Lamin A/C dient als Ladekontrolle. Der Nachweis von Nrf2 in C) dient als Kontrolle für die erfolgreiche Nrf2-cDNA Transfektion. Daten repräsentieren die Mittelwerte aus vier und drei unabhängigen Experimenten.

\subsection{Rekrutierung verschiedener Promotorregionen im ATF3-Gen durch tBHQ, TGF- $\beta 1$ und Gemcitabin}

Die Entstehung der ATF3 Varianten ist auf das Splicing verschiedener primärer mRNA Transkripte zurückzuführen, die durch differenzielle Rekrutierung der RNA-Polymerase an verschiedenen Promotorregionen des ATF3 Gens synthetisiert werden (50). Diese primären Transkripte wurden analysiert und es zeigte sich, dass Transkripte mit Exon-A1, die für ATF3 kodieren, von einer Transkription vom distalen (P1) Promotor des ATF3 Gens abstammen, während Transkripte mit Exon-A, aus denen über ein spezielles Splicing Transkripte für $\Delta$ Zip2 entstehen (69), (48) vom proximalen Promotor (P2) ausgehen (Abb. 3A,B). Die Expression dieser Primärtranskripte konnte unter Einsatz von tBHQ, TGF- $\beta 1$ und Gemcitabin induziert werden. In Panc1 wurde unter tBHQ eine Zunahme von P2-zugehörigen Transkripten beobachtet (Abb. 3B), die sich auf die Existenz von zwei Nrf2-Bindungsstellen (anti-oxidant response element, ARE) (53), (52) zurückführen lassen (Abb. 3C). Demgegenüber kam es in T3M4 und H6c7 unter tBHQ sowohl zur Expression P2-zugehöriger als auch P1-zugehöriger Transkripte. Gemcitabin induziert in Panc1 ebenfalls beide Transkripte, während in T3M4 und H6c7 nur die P1-zugehörigen Transkripte verstärkt exprimiert wurden. Eine TGF- $\beta 1$ Behandlung zeigte in allen drei Zelllinien eine schwache Induktion der P2-zugehörigen Transkripte, aber eine deutliche Vermehrung der P1-zugehörigen Transkripte, die zu einer erhöhten Expression von ATF3 führten.

Diese Ergebnisse konnten auch mittels Luciferase-Assay bestätigt werden. Dafür wurden je zwei Fragmente mit unterschiedlichen Basenlängen von der distalen (P1-1502 und P1-845) und proximalen (P2-3572 und P2-2997) Promotorregion kloniert (Abb. 3C) und in Panc1 und T3M4 transfiziert. Beide Zelllinien zeigten nach Transfektion mit dem distalen Promotorkonstrukt P11502 oder P1-845 eine hohe basale Promotoraktivität, wobei dies in T3M4 am deutlichsten zu verzeichnen ist. Wurde anschließend eine Behandlung mit TGF- $\beta 1$ durchgeführt, erhöhte sich die P1-Promotoraktivität in Panc1 stärker als in T3M4. Unter tBHQ war hingegen nur eine sehr 
schwache Induktion der P1-Promotorkonstrukte zu erzielen. Im Gegensatz dazu konnte in beiden Zelllinien mit tBHQ eine starke Aktivität an den proximalen Promotorkonstrukten P2-3570 und P2-2997 erreicht werden, während mit TGF- $\beta 1$ keine Effekte zu detektieren waren. Dies steht im Einklang mit der Präsenz von zwei funktionellen Nrf2 Bindungsstellen im proximalen ATF3 Genpromotor (53). Diese Beobachtungen bestätigen die unterschiedliche Rekrutierung von P1- und P2-Promotoren des ATF3 Gens durch verschiedene Stimulanzien, die für die Expression von ATF3 und $\triangle$ Zip2 verantwortlich sind.
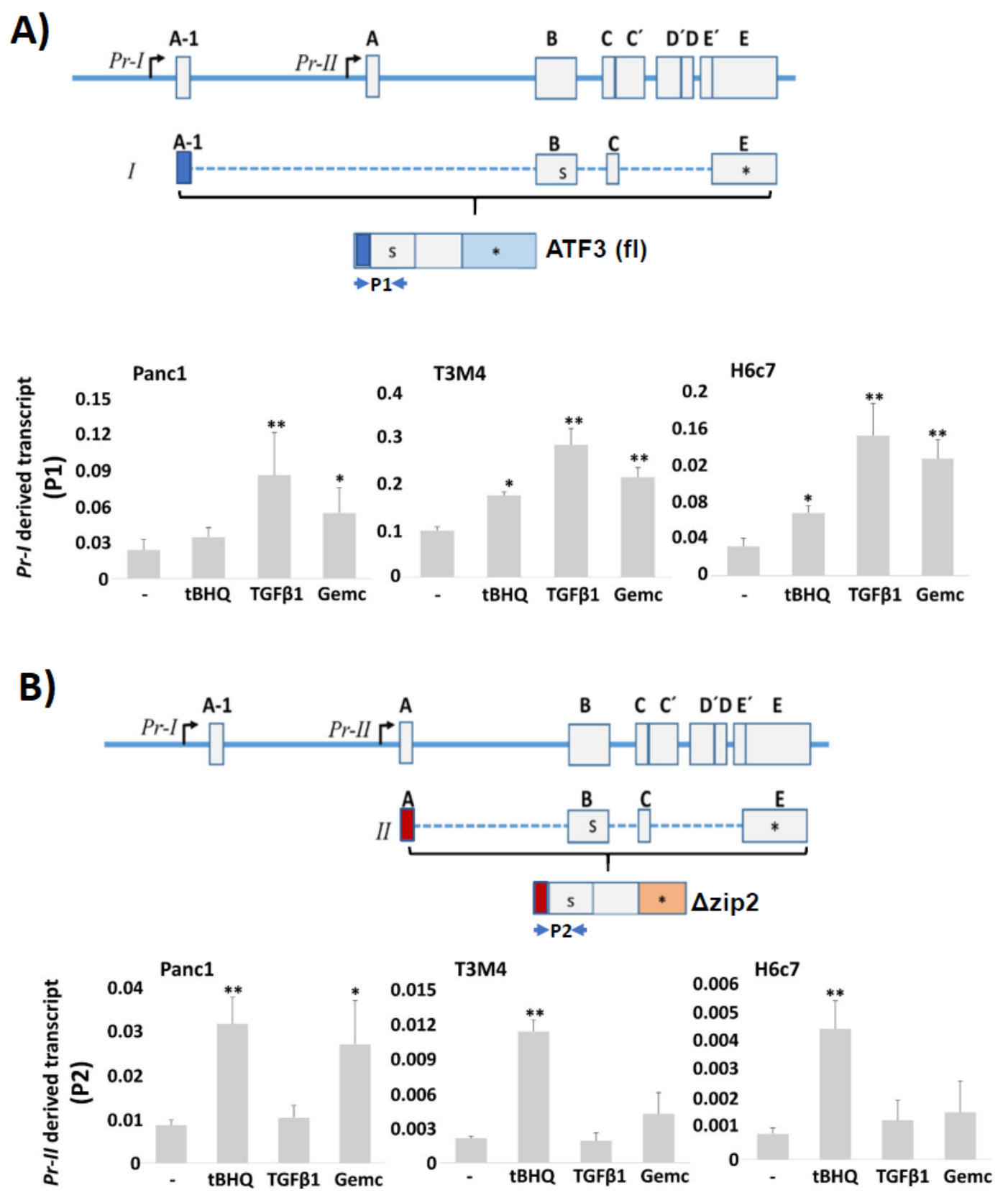
C)

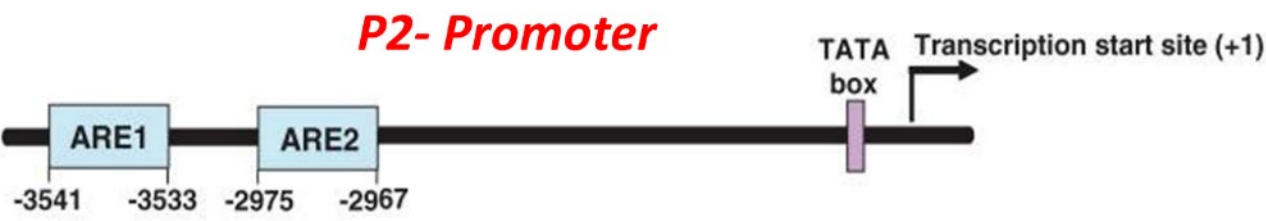

Antioxidant response element : $5^{\prime}-\mathrm{T}$

ARE1 $(-3541 \sim-3533)+$ strand : $5^{\prime}-\frac{1}{T}$

ARE2 $(-2975 \sim-2967)+$ strand : $5^{\prime}-\frac{1}{\mathrm{~T}}$

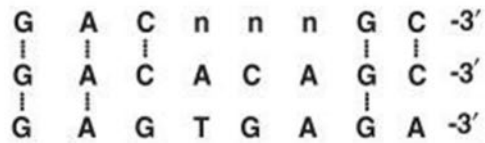

D)

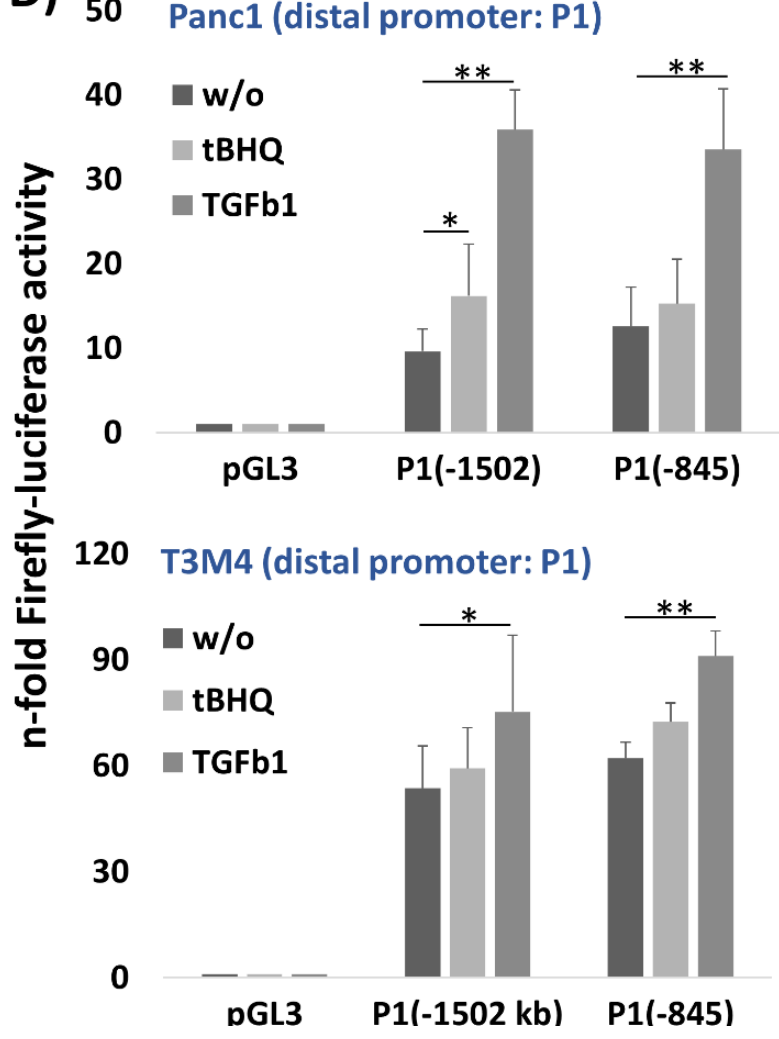

100 Panc1 (proximal promoter: P2)

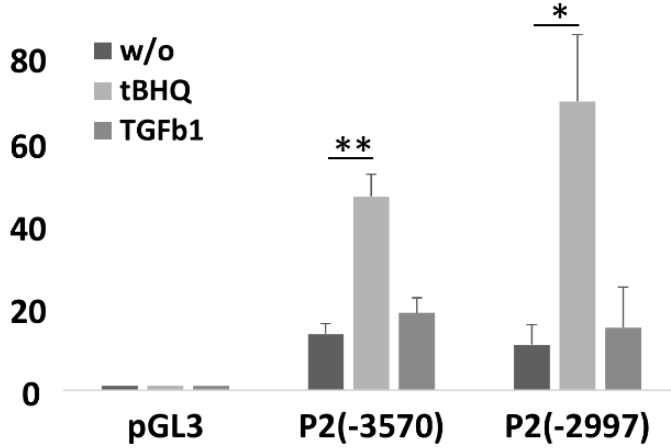

75 T3M4 (proximal promoter) w/o

$60 \quad \mathrm{tBHQ}$ - TGFb1

45

30

15

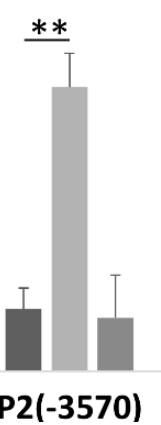

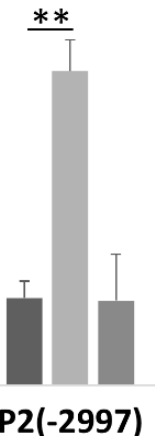

\section{Abbildung 3. Einfluss von tBHQ, TGF- $\beta 1$ und Gemcitabin auf die Rekrutierung von unterschiedlichen Promotorregionen des ATF3-Gens}

Das ATF3-Gen besitzt einen distalen (P1) und einen proximalen (P2) Promotor. Die entstehenden Primärtranskripte unterscheiden sich durch den Besitz von A) Exon A1, das vom P1-Promotor entspringt und B) Exon A, das vom P2-Promotor abstammt.

A) B) Panc1, T3M4 und H6c7 wurden unbehandelt oder jeweils mit 50 $\mu \mathrm{M}$ tBHQ, $10 \mathrm{ng} / \mathrm{ml}$ TGF- $\beta 1$ oder $20 \mu \mathrm{g} / \mathrm{ml}$ Gemcitabin für 16h behandelt. Anschließend erfolgte eine qPCR Analyse unter Einsatz von A) Exon A1 und B) Exon A spezifischen 5' Primer in Kombination mit einem Exon B spezifischen 3' Primer. Die Daten repräsentieren den Mittelwert aus vier unabhängigen Experimenten; ${ }^{*} \mathrm{p}<0.05,{ }^{* *} \mathrm{p}<0.01$.

C) Schema des proximalen (P2) Promotors des ATF3 Gens und seiner beiden Nrf2 Bindungsstellen (ARE). Nach Kim et al. 2010.

D) Panc1 und T3M4 wurden mit Kontrollvektor (pGL3), an Luciferase-gekoppeltem Plasmid mit 1-1502 bp und 1-845 bp Fragmente des P1-Transkriptes oder 1-3570 bp und 1-2997 bp des P2-Transkriptes transfiziert.

Anschließend erfolgte eine Behandlung mit 50 $\mu \mathrm{M}$ tBHQ oder 10ng/ml TGF- $\beta 1$ für 16h, sowie eine Messung der Luciferaseaktivität. Die Ergebnisse wurden an die Messungen der Renilla Luciferase normiert. Daten repräsentieren den Mittelwert aus 6 unabhängigen Experimenten, ${ }^{*} \mathrm{p}<0.05,{ }^{* *} \mathrm{p}<0.01$. 


\subsection{Induktion von pro- und antiapoptotischen Gene durch $\Delta$ Zip2 und}

\section{ATF3}

Die proapoptotischen Gene CHOP/GADD153 und GADD34, die durch ATF3 induziert werden, wurden in Panc1, T3M4 und H6c7 analysiert. Es konnte beobachtet werden, dass eine Überexpression von ATF3 zu einer erhöhten Expression von CHOP und GADD34 führte (Abb. 4A). Wurden $\triangle$ Zip2- und ATF3-cDNA gemeinsam transfiziert, so waren deutlich weniger CHOP und GADD34 Proteine zu verzeichnen als bei alleiniger Überexpression von ATF3. Obwohl $\Delta$ Zip2 in den vorherigen Versuchen einen großen Apoptoseschutz lieferte, erreichte es bei einer Koexpression mit ATF3 nur eine mäßige Inhibition der Expression von CHOP und GADD34. In Knockdown Versuchen mit Einsatz von Gemcitabin wurde beobachtet, dass Gemcitabin allein eine Zunahme von CHOP und GADD34 Proteinen in allen drei Zelllinien bewirkte. Bei zusätzlichem Knockdown von $\Delta$ Zip2 war in T3M4 und H6c7, aber nicht in Panc1, eine minimal stärkere Zunahme der Proteine zu verzeichnen (Abb. 4B). Ein Knockdown von ATF3 verringerte hingegen die Expression von CHOP und GADD34. Es ist somit naheliegend, dass die $\Delta$ Zip2-induzierte Resistenz gegenüber Gemcitabin nur zum Teil an der Aufhebung der ATF3-induzierten CHOP und GADD34 Expression liegt und ein weitaus stärkerer antiapoptotischer Effekt durch $\Delta$ Zip2 existiert. Des Weiteren wurde die Expression von den antiapoptotischen Proteinen cIAP1 und cIAP2 in Abhängigkeit von ATF3 und $\triangle$ Zip2 analysiert. In Abbildung 4C wird deutlich, dass ein selektiver Knockdown von $\Delta$ Zip2 die Wirkung von tBHQ-induzierter Expression von cIAP1 und cIAP2 in Panc1, T3M4 und H6c7 verringerte. Bei einem Knockdown von ATF3 stieg die basale und tBHQ-induzierte Expression von cIAP1 und cIAP2 kaum oder nur gering an. Dies führt zu der Annahme, dass ATF3 an der Expression von cIAP1 und cIAP2 größtenteils unbeteiligt ist. Außerdem ist $\mathrm{zu}$ erkennen, dass die Überexpression von $\Delta$ Zip2 zu einer Erhöhung von cIAP1 und cIAP2 in allen drei Ziellinien führte, dieser Effekt jedoch nicht durch eine Überexpression von $\Delta$ Zip erzielt werden konnte (Abb. 4D). 
A)

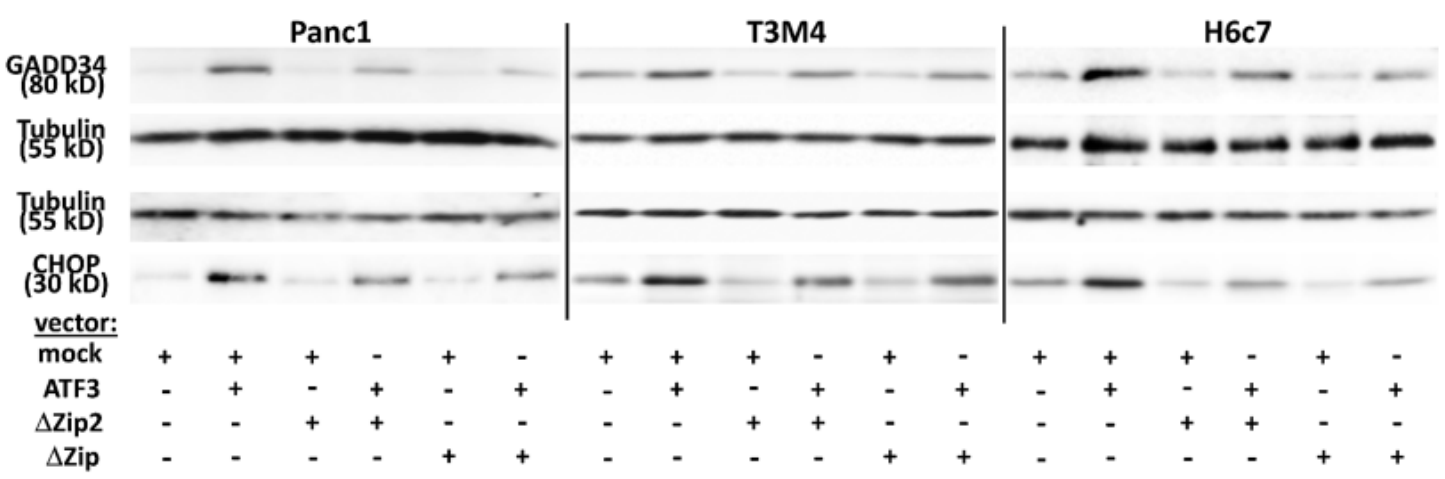

B)

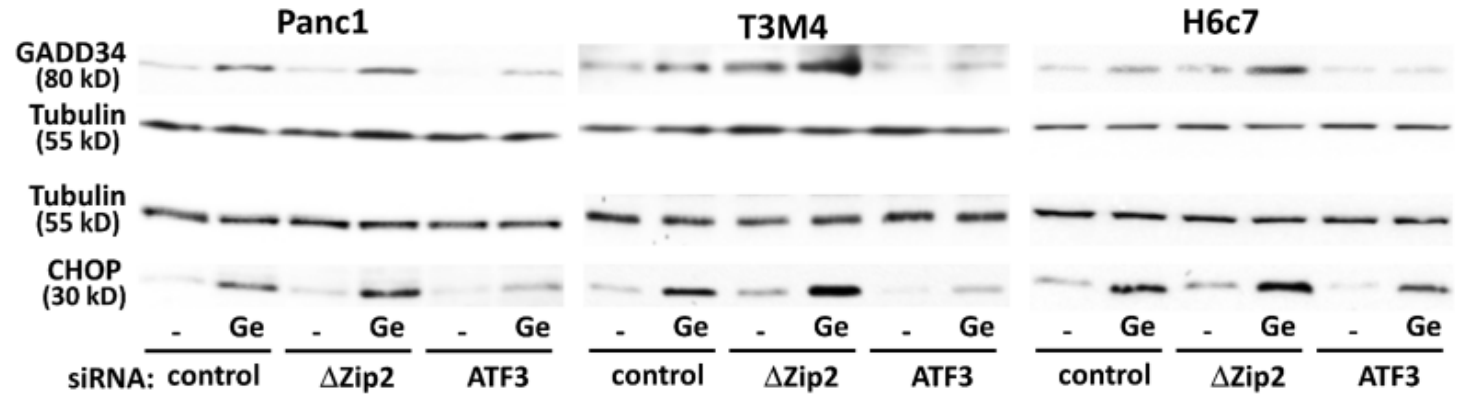

C)

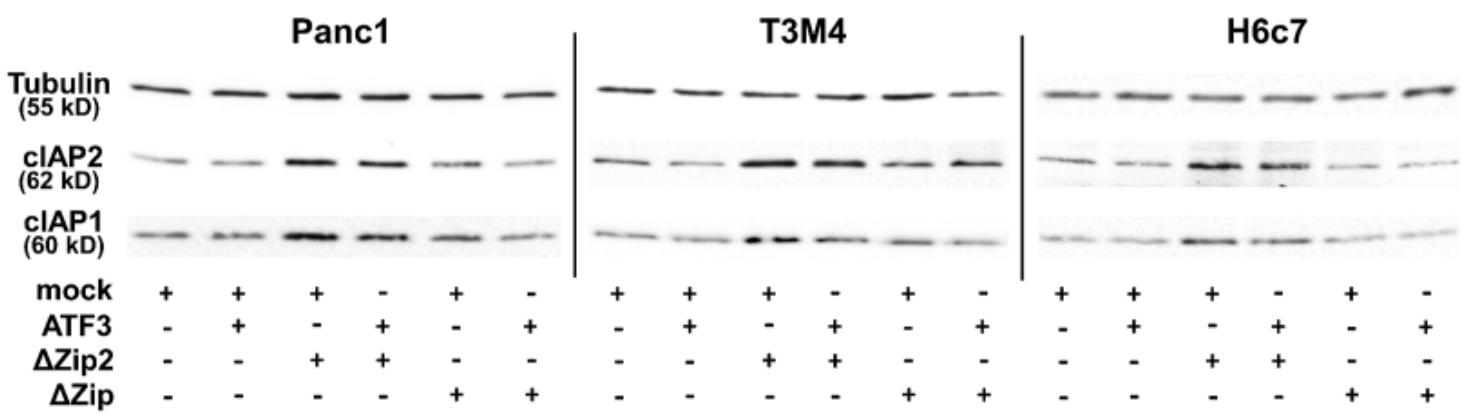

D)

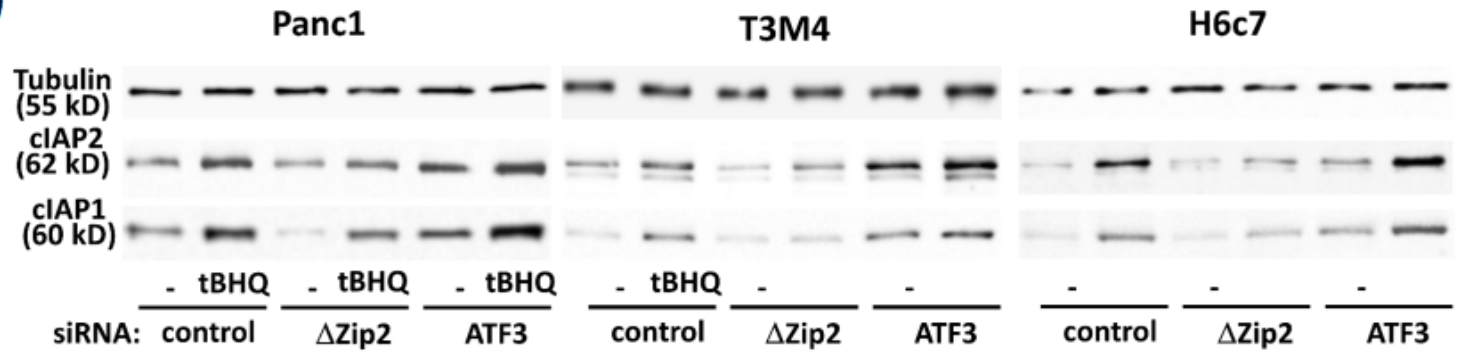

Abbildung 4. ATF3-abhängige Expression von CHOP und GADD34 und ATF3-unabhängige Expression von cIAP1 und cIAP2

A) C) Im Westernblot wurden Zelllysate von Zellen nach Transfektion mit ATF3-, $\Delta$ Zip2-, $\Delta$ Zip- oder KotrollcDNA (mock) auf den Gehalt von A) CHOP und GADD34 Proteine bzw. C) cIAP1 und cIAP2 Proteine untersucht. Tubulin dient als Ladekontrolle. Daten repräsentieren die Mittelwerte aus vier unabhängigen Experimenten.

B) D) Im Westernblot wurden Zelllysate von Zellen nach Transfektion mit ATF3-, $\triangle$ Zip2- oder Kontroll-siRNA B) mit oder ohne anschließender Behandlung mit $20 \mu \mathrm{g} / \mathrm{ml} \mathrm{Gemcitabin} \mathrm{für} 24 \mathrm{~h}$ auf den Gehalt von CHOP und GADD34 Proteine bzw. D) mit oder ohne Behandlung mit 50 $\mu \mathrm{M}$ tBHQ für 24h auf den Gehalt von cIAP1 und 
cIAP2 untersucht. Tubulin dient als Ladekontrolle. Daten repräsentieren die Mittelwerte aus vier unabhängigen Experimenten.

\subsection{Wirkung des Chemotherapeutikums Gemcitabin auf die}

\section{Expression von ATF3 und $\Delta$ Zip2}

Wie bereits gezeigt wurde, induziert Gemcitabin in unterschiedlicher Weise die Expression der P1- bzw. P2-Promoter zugehörigen Transkripte in Panc1, T3M4 und H6c7 Zellen. In Abbildung 5 A und B ist ersichtlich, dass eine Behandlung mit Gemcitabin zu einer signifikanten Erhöhung der ATF3-Expression in allen drei Zelllinien führt. Demgegenüber kommt es nach Gemcitabin Behandlung nur in Panc1 Zellen auch zu einem signifikanten Anstieg der $\Delta$ Zip2 Expression sowie einer starken Aktivierung von Nrf2. In T3M4 und H6c7 sind diese Effekte hingegen kaum bzw. deutlich geringer ausgeprägt.

Die Vermutung, dass die Expression von ATF3 und $\Delta$ Zip2 durch Gemcitabin Nrf2-abhängig verläuft, wurde durch ein Nrf2-Knockdown Versuch überprüft. Mittels siRNA wurden in allen drei Zelllinien ein Knockdown von Nrf2 herbeigeführt, woraus ein Wegfall der Gemcitabininduzierten Expression von $\triangle$ Zip2 und ATF3 resultierte (Abb. 5C, D). Dieser Effekt war besonders in Panc1 ausgeprägt.
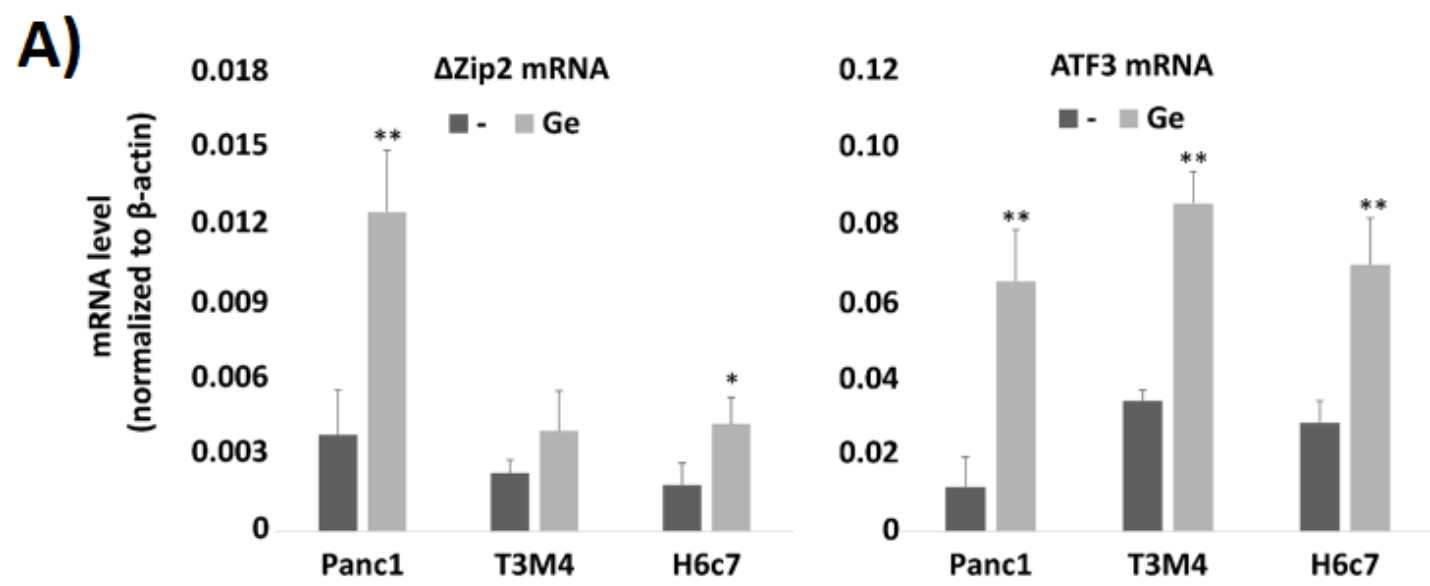


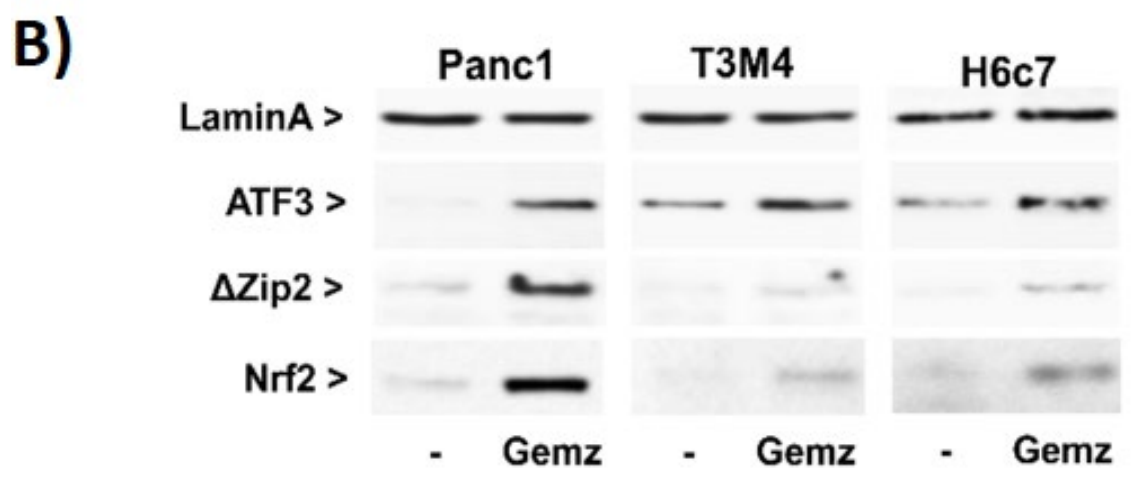

C)
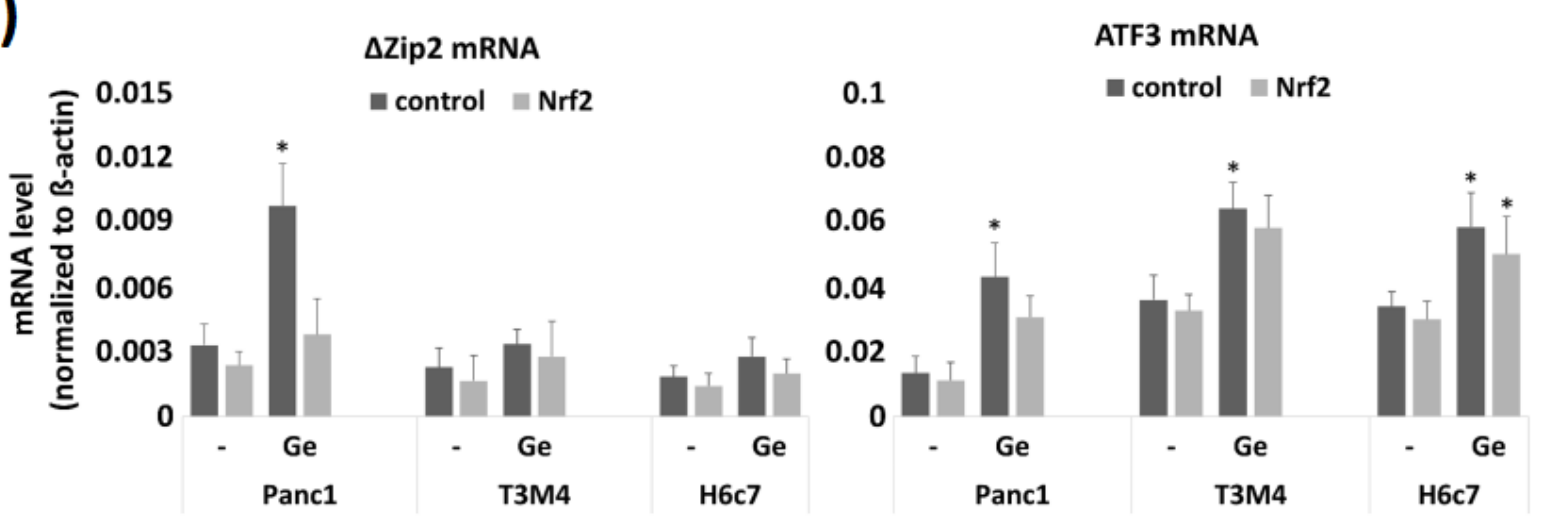

D)

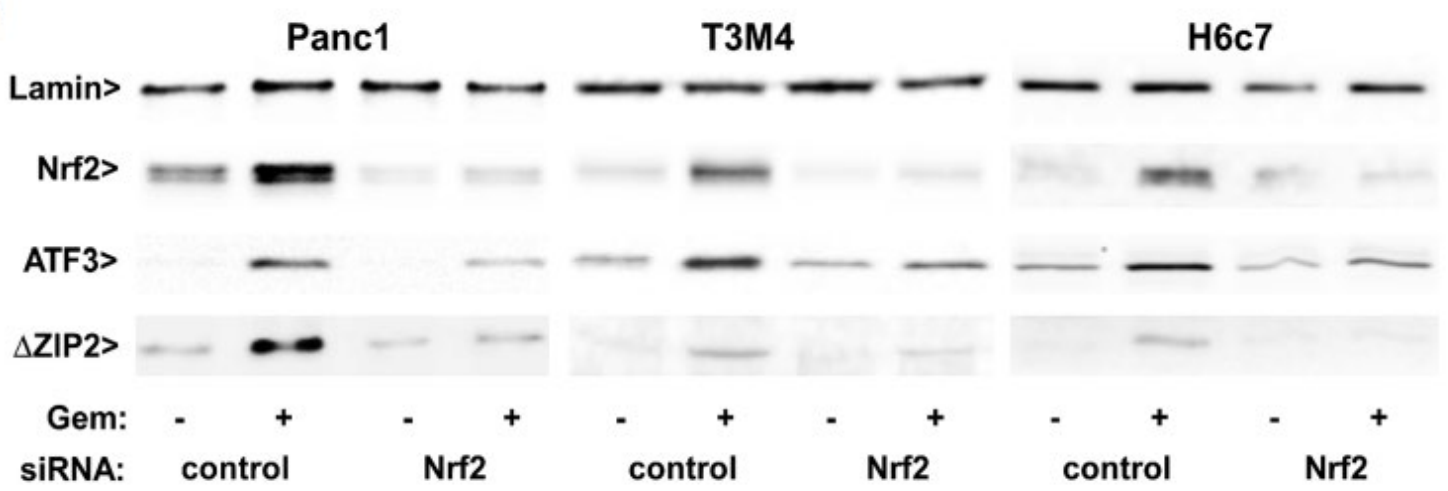

Abbildung 5. Expression von ATF3 und $\Delta$ Zip2 unter Gemcitabin in Panc1, T3M4 und H6c7

A) C) qPCR Analysen auf den Gehalt von $\triangle$ Zip2- bzw. ATF3-mRNA von A) unbehandelten Zellen oder Zellen nach Behandlung mit $20 \mu \mathrm{g} / \mathrm{mL}$ Gemcitabin (Ge) für 8h bzw. C) nach Transfektion mit Nrf2-siRNA oder Kontroll-siRNA mit oder ohne anschließende Behandlung mit $20 \mu \mathrm{g} / \mathrm{ml}$ Gemcitabin für $8 \mathrm{~h}$. Daten repräsentieren den Mittelwert aus 4 unabhängigen Experimenten; ${ }^{*} \mathrm{p}<0.05, * * \mathrm{p}<0.01$.

B) D) Kernextrakte aus B) unbehandelten Zellen oder Zellen nach Behandlung mit $20 \mu \mathrm{g} / \mathrm{ml}$ Gemcitabin (Ge bzw. Gemz) für 8h bzw. D) nach Transfektion mit Nrf2-siRNA oder Kontroll-siRNA mit oder ohne anschließende Behandlung mit $20 \mu \mathrm{g} / \mathrm{ml}$ Gemcitabin für $8 \mathrm{~h}$ wurden im Westernblot auf den Gehalt von ATF3 und $\Delta$ Zip2 Proteine untersucht. Lamin A/C dient als Ladekontrolle. In D) dient die Untersuchung auf Nrf2 Proteine als Kontrolle für die erfolgreiche Nrf2-siRNA Transfektion. Daten repräsentieren den Mittelwert von 3 unabhängigen Experimenten. 


\subsection{Einfluss von ATF3 und $\Delta$ Zip2 auf die Gemcitabin-induzierte}

\section{Apoptose}

Um die Wirkung von ATF3 und $\triangle$ Zip2 auf die Gemcitabin-induzierte Apoptose zu untersuchen, wurden Panc1, H6c7 und T3M4 mit ATF3- und $\Delta$ Zip2-Plasmiden transfiziert und anschließend mit Gemcitabin behandelt. Die daraus resultierende Überexpression von $\Delta$ Zip2 bewirkte eine starke Hemmung der Gemcitabin-induzierten Apoptose in H6c7 und T3M4, während in Panc1 nur eine moderate Hemmung zu erkennen ist (Abb. 6A).

Im Gegensatz dazu verstärkte eine Überexpression von ATF3 die Gemcitabin-induzierte Apoptose, was besonders in Panc1 deutlich wurde. In diesem Zusammenhang wurde auch $\Delta$ Zip, eine weitere Variante von ATF3, untersucht. Eine Überexpression von $\Delta$ Zip hatte kaum einen Effekt auf die Empfindlichkeit von Panc1 gegenüber Gemcitabin, hemmte jedoch die Gemcitabin-induzierte Apoptose in H6c7 und T3M4. Wurden $\Delta$ Zip und ATF3 gemeinsam in Panc1 überexprimiert, so konnte eine Aufhebung der ATF3 Wirkung, also eine Hemmung der Gemcitabin-induzierten Apoptose, beobachtet werden. Daraus lässt sich schließen, dass eine Überexpression von $\Delta$ Zip2 hauptsächlich Zellen, die endogen eine niedrige $\Delta$ Zip2 Expression aufweisen (wie H6c7 und T3M4), vor einer Gemcitabin-induzierten Apoptose schützt. Demgegenüber beeinflusst eine Überexpression von $\Delta$ Zip vornehmlich nur solche Zellen, die endogen hohe Mengen an ATF3 exprimieren. Panc1 besitzen endogen einen hohen $\Delta$ Zip2 Spiegel, sodass sich ein Effekt durch eine zusätzliche $\Delta$ Zip2 Überexpression kaum mehr bemerkbar macht und ein Effekt durch eine Überexpression mit $\Delta$ Zip nur auftritt, wenn gleichzeitig ATF3 überexprimiert wurde. Um diese These zu bestärken, wurden ATF3 und $\Delta$ Zip2 Knockdown Versuche unternommen und deren Einflüsse auf die Apoptoseantwort nach Gemcitabin Behandlung untersucht. In Abbildung 6B ist zu erkennen, dass ein Knockdown von ATF3 in T3M4 und H6c7 die Gemcitabin-induzierte Apoptose signifikant reduziert. In Panc1 ist dieser Effekt nicht zu verzeichnen. Ein Knockdown von $\Delta$ Zip2 hingegen führt zu einer signifikanten Erhöhung der Sensitivität von Pancl gegenüber Gemcitabin.

Da bereits eine Verbindung zwischen Nrf2-Aktivierung und $\Delta$ Zip2 Expression nachgewiesen werden konnte (siehe Kapitel 4.1), wurde nachfolgend der Einfluss eines Knockdowns von $\Delta$ Zip2 unter Bedingungen einer Nrf2 Aktivierung untersucht. Die Abbildung 6B zeigt, dass die tBHQ-induzierte Resistenz vor Gemcitabin-induzierter Apoptose durch den Knockdown von $\Delta$ Zip2 aufgehoben war, während der Knockdown von ATF3 kaum Effekte zeigte. Dies unterstützt die Beobachtung, dass die Expression von $\Delta$ Zip2 und darüber der Schutz vor 
Chemotherapeutika wie Gemcitabin zum großen Teil von Nrf2 kontrolliert wird, und dass dies ein Mechansimus der zytoprotektiven Wirkung von Nrf2 darstellt.

Im Gegensatz dazu war unter Behandlung mit TGF- $\beta 1$ als wesentlicher Induktor der Expression von ATF3 nach dessen Knockdown eine stärkere Resistenz gegenüber Gemcitabin in allen drei Zelllinien festzustellen, was den Apoptose sensitivierenden Effekt von ATF3 - hier wesentlich unter Kontrolle durch TGF- $\beta 1$ - untermauert.

A)
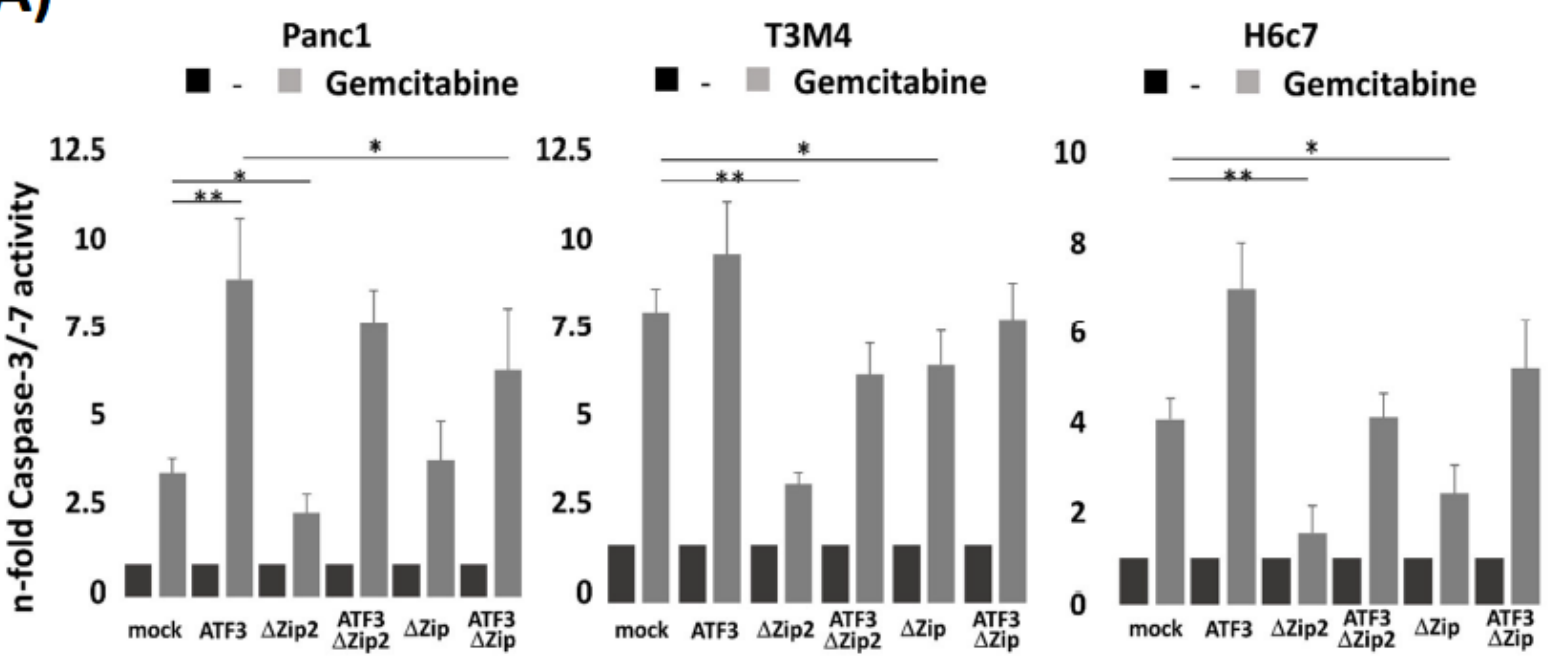

B)

control siRNA $\square$ Zip2 siRNA $\quad$ ATF3 siRNA

Panc1

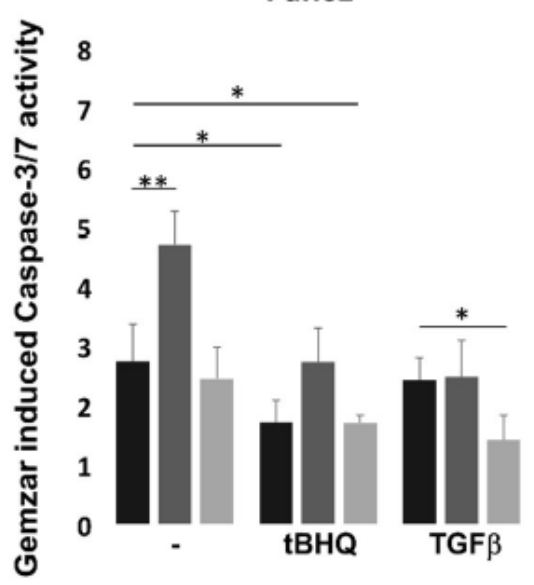

T3M4

12.5

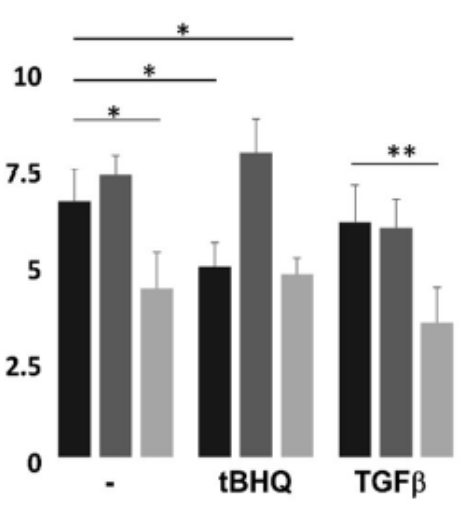

H6c7

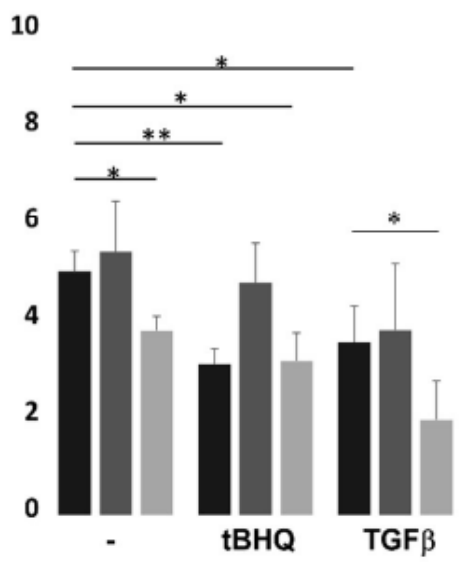

Abbildung 6. Apoptoseverhalten von Panc1, T3M4 und H6c7 unter Gemcitabin in Abhängigkeit von ATF3, $\Delta$ Zip2 und $\Delta$ Zip

A) B) Aktivität von Caspase-3/-7 (normiert an den zellulären Proteingehalt) in Zellen A) nach Transfektion mit ATF3-, $\Delta$ Zip2-, $\Delta$ Zip- oder Kontroll-cDNA (mock) mit oder ohne anschließender Behandlung mit 20 $\mu \mathrm{g} / \mathrm{ml}$ Gemcitabin für 24h bzw. B) nach Transfektion mit ATF3-, $\triangle$ Zip2- oder Kontroll-siRNA mit oder ohne anschießender Behandlung mit 50 $\mu \mathrm{M}$ tBHQ oder 10ng/ml TGF- $\beta 1$ für $16 \mathrm{~h}$ und darauffolgend eine Behandlung mit $20 \mu \mathrm{g} / \mathrm{ml}$ Gemcitabin für 24h. Die Daten repräsentieren den Mittelwert aus vier unabhängigen Experimenten. $* \mathrm{p}<0.05, * * \mathrm{p}<0.01$. 


\subsection{Einfluss von ATF3 und $\triangle \mathrm{Zip} 2$ auf die TRAIL-induzierte Apoptose}

In einem Überexpressionsversuch mit ATF3, $\Delta$ Zip2 und $\Delta$ Zip in Panc1 und T3M4 wurde die Apoptose-Aktivität unter der Behandlung mit TRAIL untersucht. In Panc1, die endogen eine geringe Expression von ATF3 aufweisen, zeigte sich bei einer Überexpression von ATF3 eine deutliche Sensitivierung der Zellen gegenüber TRAIL-induzierter Apoptose (Abb. 7A). Bei T3M4, die bereits eine hohe ATF3 Basalexpression besitzen, konnte hingegen nur eine moderate Veränderung der Apoptosebereitschaft beobachtet werden (Abb. 7A).

Nach Transfektion von $\Delta$ Zip2 in Panc1 kam es zu einer leichten und in T3M4 zu einer deutlichen Reduktion der Sensitivität gegenüber TRAIL-induzierter Apoptose (Abb. 7A). Unter Überexpression von $\Delta$ Zip in Panc1 waren hingegen kaum Veränderungen bzgl. der TRAILinduzierten Apoptose zu erkennen, während in T3M4 eine mäßige Desensitivierung gegenüber TRAIL erreicht wurde (Abb. 7A). Wie in den Versuchen zur Gemcitabin-induzierten Apoptose, zeigte sich auch hier bei der Koexpression von $\triangle$ Zip und ATF3 eine Reduktion der ATF3 Wirkung, wobei dies in Panc1 viel deutlicher ausgeprägt war als in T3M4. Im Vergleich dazu war bei einer kombinierten Transfektion von ATF3 mit $\Delta$ Zip2 in beiden Zelllinien eine fast vollständige Aufhebung der Wirkung von ATF3 zu beobachten.

Des Weiteren wurden Versuche mit Knockdown von ATF3 und $\triangle$ Zip2 mit Einsatz von tBHQ oder TGF- $\beta 1$ durchgeführt und die Auswirkungen auf TRAIL-induzierte Apoptose untersucht. Die Sensitivität gegenüber TRAIL verringerte sich in beiden Zelllinien nach einer Behandlung mit tBHQ, die besonders in Panc1 sichtbar wurde. Durch ein Knockdown von $\triangle$ Zip2 fiel die durch tBHQ hervorgerufene Resistenz vor TRAIL-induzierter Apoptose weg, während ein Knockdown von ATF3 unter tBHQ kaum Effekte brachte (Abb. 7B). Zudem konnte eine verringerte Sensitivität gegenüber TRAIL in beiden Zelllinien bei einem Knockdown von ATF3 und unter der Verwendung von TGF- $\beta 1$ beobachtet werden. Bei einem Knockdown von $\Delta$ Zip2 und einer Behandlung mit TGF- $\beta 1$ zeigte sich hingegen eine leichte Erhöhung der Sensitivität. 
A)
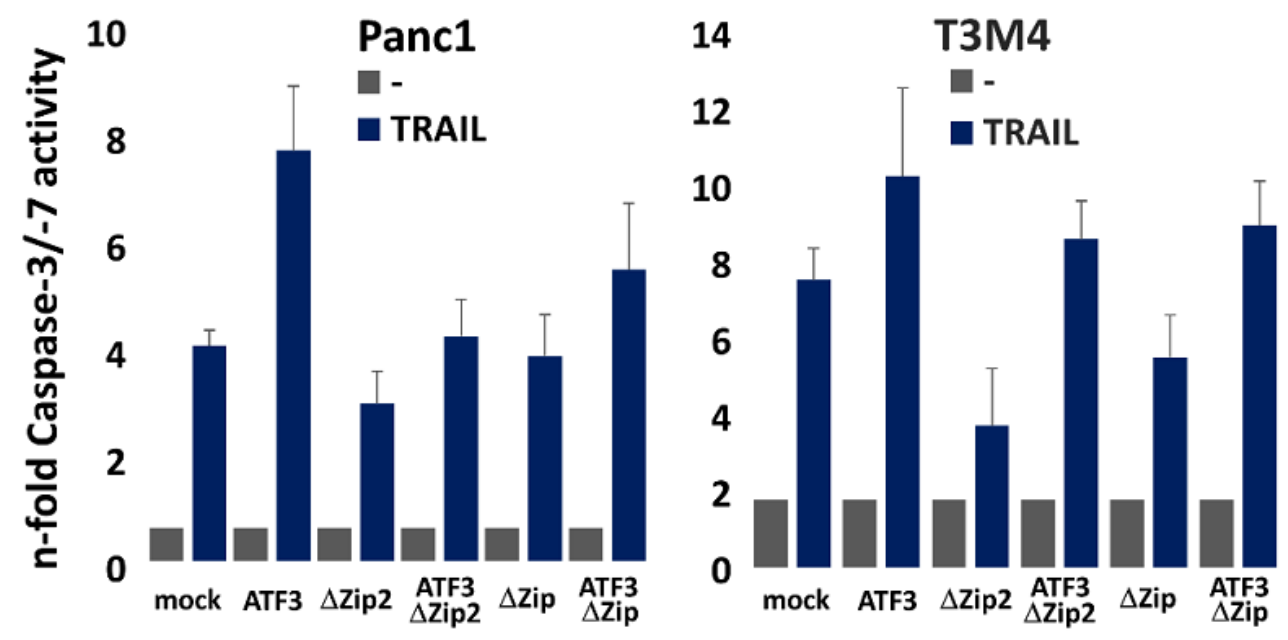

B)
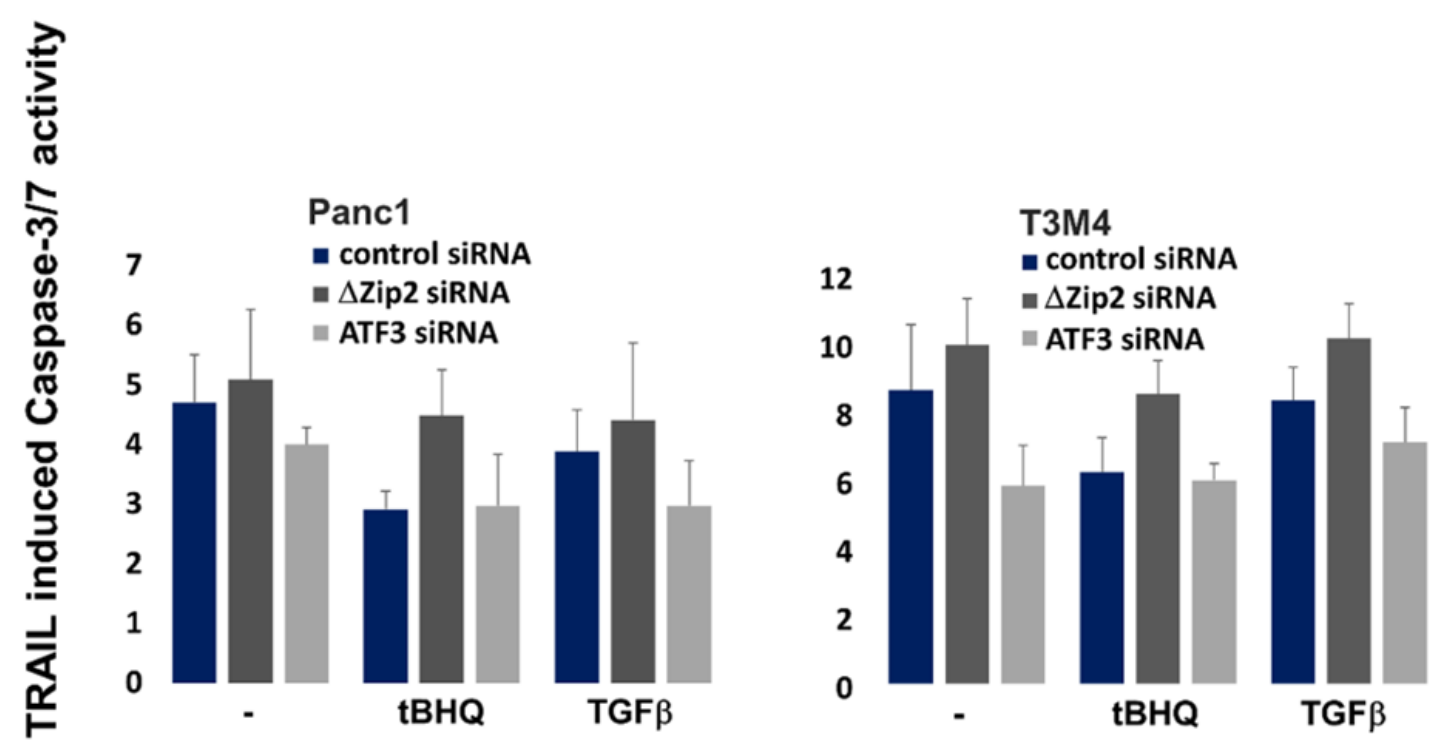

Abbildung 7. Apoptoseverhalten von T3M4 und Panc1 Zellen gegenüber TRAIL in Abhängigkeit von einer Überexpression von ATF3, $\Delta$ Zip2, $\Delta$ Zip

A) B) Aktivität von Caspase-3/-7 (normiert an den zellulären Proteingehalt) in Zellen A) nach Transfektion mit ATF3-, $\Delta$ Zip2-, $\Delta$ Zip- oder Kontroll-cDNA (mock) mit oder ohne anschließender Behandlung mit 0,5mg/ml TRAIL für 8h bzw. B) nach Transfektion mit ATF3-, $\triangle$ Zip2- oder Kontroll-siRNA mit oder ohne anschließender Behandlung mit $50 \mu \mathrm{M}$ tBHQ oder $10 \mathrm{ng} / \mathrm{ml} \mathrm{TGF-} 31$ für $16 \mathrm{~h}$ und darauffolgend eine Behandlung mit 0,5mg/ml TRAIL für 8h. Die Daten repräsentieren die Mittelwerte aus drei unabhängigen Experimenten. 


\subsection{Veränderungen im Zellzyklus und koloniales Wachstum unter}

\section{ATF3 und $\triangle$ Zip2}

Um die Auswirkungen von ATF3 und $\Delta$ Zip2 bezüglich Zellzyklus und koloniales Wachstum $\mathrm{zu}$ verstehen, wurden Knockdown Versuche unter Behandlung mit tBHQ oder TGF- $\beta 1$ und anschließender PI-Färbung mit durchflusszytometrischer Auswertung durchgeführt. In Panc1, T3M4 und H6c7 führte ein Knockdown von $\triangle \mathrm{Zip} 2 \mathrm{zu}$ einer verminderten tBHQ-induzierten Beschleunigung des Zellzyklus (Abb. 8A). Dies konnte besonders in Panc1 beobachtet werden, dessen Anzahl von G1-Phase Zellen durch tBHQ von $60 \pm 6.9 \%$ auf $38.8 \pm 7.1 \%$ sank und diese Reduzierung nach einem Knockdown von $\Delta$ Zip2 weniger stark manifestierte (von $65.8 \pm 5.8 \%$ auf 54.2 \pm 7.1\%). In T3M4 und H6c7 sank die tBHQ-induzierte Reduzierung der G1-Phase Zellen von $63.0 \pm 5.6 \%$ auf $57.1 \pm 2.8 \%$ bzw. $70.8 \pm 4.1 \%$ auf $61.3 \pm 5.2 \%$ und nach Knockdown nur noch von $67.4 \pm 3.6 \%$ zu $66.1 \pm 3.5 \%$ bzw. $72.2 \pm 5.4 \%$ zu $69.3 \pm 6.2 \%$. Im Gegensatz dazu waren in allen drei Zelllinien unter TGF- $\beta 1$ Behandlung ein deutlicher Anstieg der Anzahl von G1Phase Zellen zu verzeichnen, der durch einen Knockdown von $\Delta$ Zip2 unverändert blieb. Dies lässt darauf schließen, dass $\Delta$ Zip2 keinen Einfluss auf die Verlangsamung des Zellzyklus durch TGF- $\beta 1$ in Panc1, T3M4 und H6c7 hat. Mit einem Knockdown von ATF3 ließ sich die Wirkung von TGF- $\beta 1$ auf den Zellzyklus aufheben, denn die Anzahl von G1-Phase Zellen in Panc1 erhöhte sich nach einer Behandlung mit TGF- $\beta 1$ auf $72.3 \pm 4.8 \%$, während sich die Anzahl nach Einsatz von ATF3-siRNA auf $64.3 \pm 5.1 \%$ reduzierte. In T3M4 reduzierte sich die Anzahl von $76.7 \pm 4.7 \%$ auf $66.1 \pm 3.9 \%$ und in $\mathrm{H} 6 \mathrm{c} 7$ von $78.2 \pm 2.8 \%$ auf $68.4 \pm 5.1 \%$. 
A)
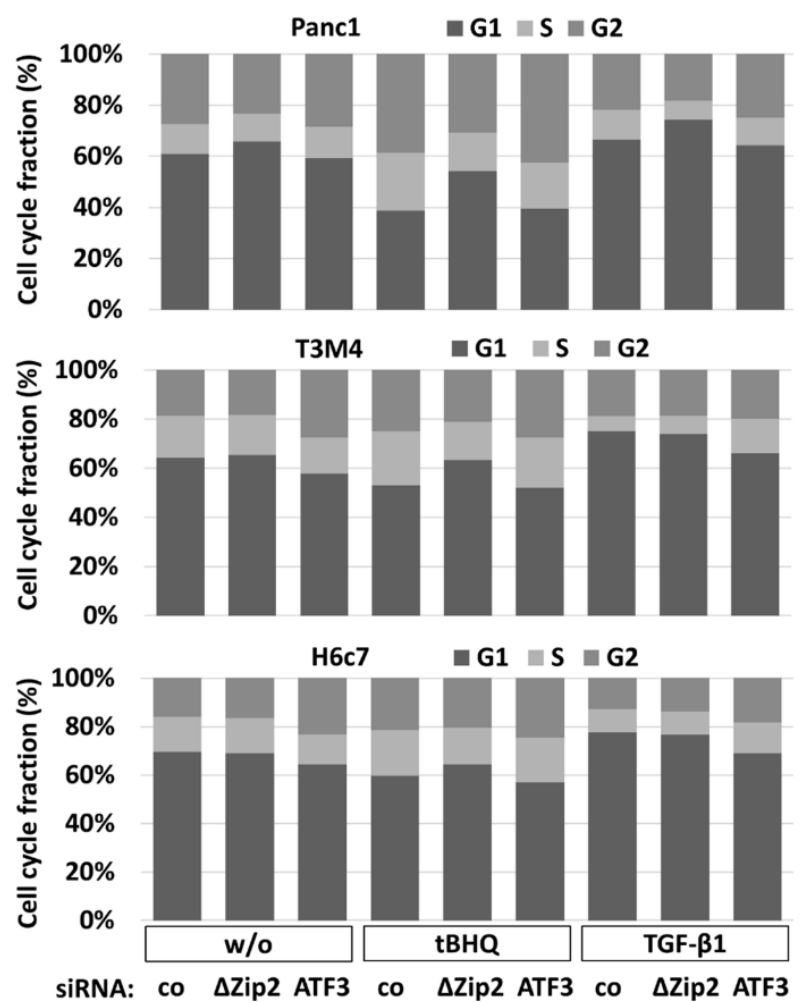

B)
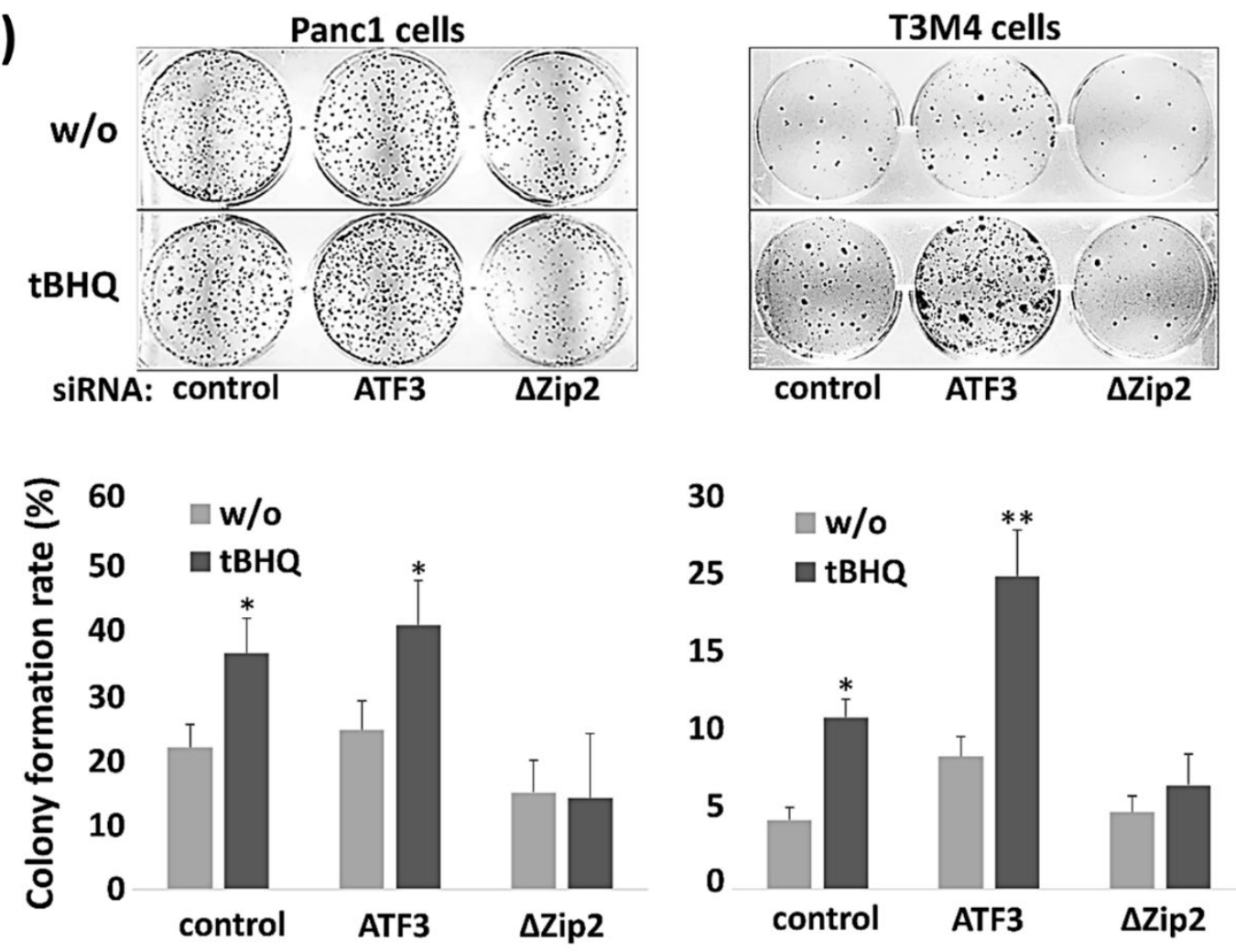

Abbildung 8. Auswirkungen von ATF3 und $\Delta$ Zip2 auf Zellzyklus und Koloniales Wachstum

A) Analyse des Zellzyklus nach Transfektion mit ATF3-, $\Delta$ Zip2- oder Kontroll-siRNA mit oder ohne Behandlung mit $50 \mu \mathrm{M}$ tBHQ oder 10ng/ml TGF- $\beta 1$. Die Daten repräsentieren den Mittelwert aus sechs unabhängigen 
Experimenten.

B) Färbung der Zellen mit Kristallviolett nach Transfektion mit ATF3-, $\Delta$ Zip2- oder Kontroll-siRNA mit oder ohne anschließende Behandlung mit 50 $\mu \mathrm{M}$ tBHQ. Für die Auswertung wurden Fotos geschossen und Kolonien $>0.25 \mathrm{~mm}$ gezählt. Die Daten repräsentieren den Mittelwert aus vier unabhängigen Versuchen. ${ }^{*} \mathrm{p}<0.05$

Die divergente Wirkung von ATF3 und $\triangle$ Zip2 auf das koloniale Wachstum wurde in einem Colony-Formation-Assay mit Knockdown von ATF3 und $\triangle$ Zip2 und Einsatz von tBHQ in Panc1 und T3M4 Zellen überprüft. Die Ergebnisse sind in Abbildung 8B dargestellt.

Es zeigte sich sowohl in Panc1 als auch T3M4 nach tBHQ Behandlung eine größere Anzahl an Kolonien, die sich innerhalb von 10 Tagen gebildet hatten, was als Steigerung des kolonialen Wachstums zu deuten ist. Der Knockdown von ATF3 erhöhte die basale Koloniebildungsrate von Panc1 sowie den fördernden Effekt von tBHQ nur gering, während beides in T3M4 gegenüber der Kontrolle (control siRNA) signifikant erhöht war. Der Knockdown von $\Delta$ Zip2 hingegen verminderte die Koloniebildungsrate unbehandelter Panc1 Zellen ebenso wie die steigernde Wirkung von tBHQ hierauf. In T3M4 bewirkte der Knockdown von $\triangle$ Zip2 vor allem eine Aufhebung des steigernden Effektes von tBHQ auf die Koloniebildung, jedoch keine Wirkung auf die Koloniebildungsrate in Abwesenheit des Nrf2-Aktivators.

\subsection{Koexpression von $\triangle \mathrm{Zip} 2$ und Nrf2 in PDAC- und CP-Gewebe}

Zum klinischen Nachweis des Zusammenhanges von Nrf2-Aktivierung und $\Delta$ Zip2 Expression einerseits und von ATF3 Expression andererseits wurden immunhistochemische Färbungen anhand Formalin fixierter und in Paraffin eingebetteter (FFPE) Gewebe von PDAC und CPPatienten durchgeführt. Dazu wurden monoklonale Antikörper, die selektiv $\Delta$ Zip2, ATF3 und aktiviertes Nrf2 (Phospho-Ser40-Nrf2) detektieren, eingesetzt. Insbesondere die erstmalige Verfügbarkeit des $\Delta$ Zip2 Antikörpers (über eigenes custom designing bei der Firma Abmart) eröffnete die Möglichkeit, eine vergleichende ATF3 und $\triangle$ Zip2 Expressionsanalyse durchzuführen, um so die nach wie vor unklare Rolle von ATF3 in der Tumorgenese zu erhellen. In einer ersten Serie von 20 PDAC Patienten - alle mit T3N1M0 Befund (11) - wurden die FFPE-Gewebsschnitte entsprechend immunhistochemisch angefärbt. Wie in Abbildung 9A an Präparaten von 6 PDAC Patienten zu sehen, zeigen Areale mit einer intensiven Färbung für PNrf2 eine signifikant hohe Expression von $\Delta$ Zip2. In diesen Regionen war die ATF3-Färbung deutlich schwächer und beinahe reziprok zum intensiven P-Nrf2/DZip2 Expressionsmuster. So waren Areale mit niedriger oder ohne Nrf2 Aktivität deutlich stärker gegen ATF3 anfärbbar, jedoch negativ für $\Delta \mathrm{Zip} 2$. 
Wie zuvor erwähnt, kann sich auf Boden einer chronischen Pankreatitis (CP) ein PDAC entwickeln, so dass Gewebe von Patienten mit CP für unsere Untersuchung ebenfalls von Bedeutung waren. Abbildung 9B zeigt, dass duktale Strukturen mit atypischen und aberranten Epithelien, entsprechend als PanIN klassifiziert, für die P-Nrf2 und $\Delta$ Zip2 Färbung positiv waren. In epithelialen Regionen mit geringer P-Nrf2 Expression ist hingegen keine $\Delta$ Zip2 Färbung auszumachen. Demgegenüber ist die Expression von ATF3 im Epithel der PanIN Läsionen zumeist durchweg nachweisbar, wobei in der Gegenüberstellung P-Nrf2 und $\Delta$ Zip2 positiver und negativer Areale keine Unterschiede bezüglich der ATF3 Expression bestanden. Dies weist daraufhin, dass bereits im entzündlichen Geschehen einer CP es zur Nrf2 vermittelten Stressadaptation kommt, verbunden mit der erhöhten Expression der $\Delta$ Zip2 Färbung. Im Laufe der Progression zum Karzinom zeigt sich im malignen Epithel eine stärker ausgeprägte Reziprozität von $\triangle$ Zip2 und ATF3 Expression, was auch auf eine zunehmende Heterogenität der malignen Zellen hindeutet. Gerade die Verfügbarkeit des $\Delta$ Zip2 Antiköpers erlaubt diese Differenzierung bezüglich der Expression beider ATF3 Varianten. 


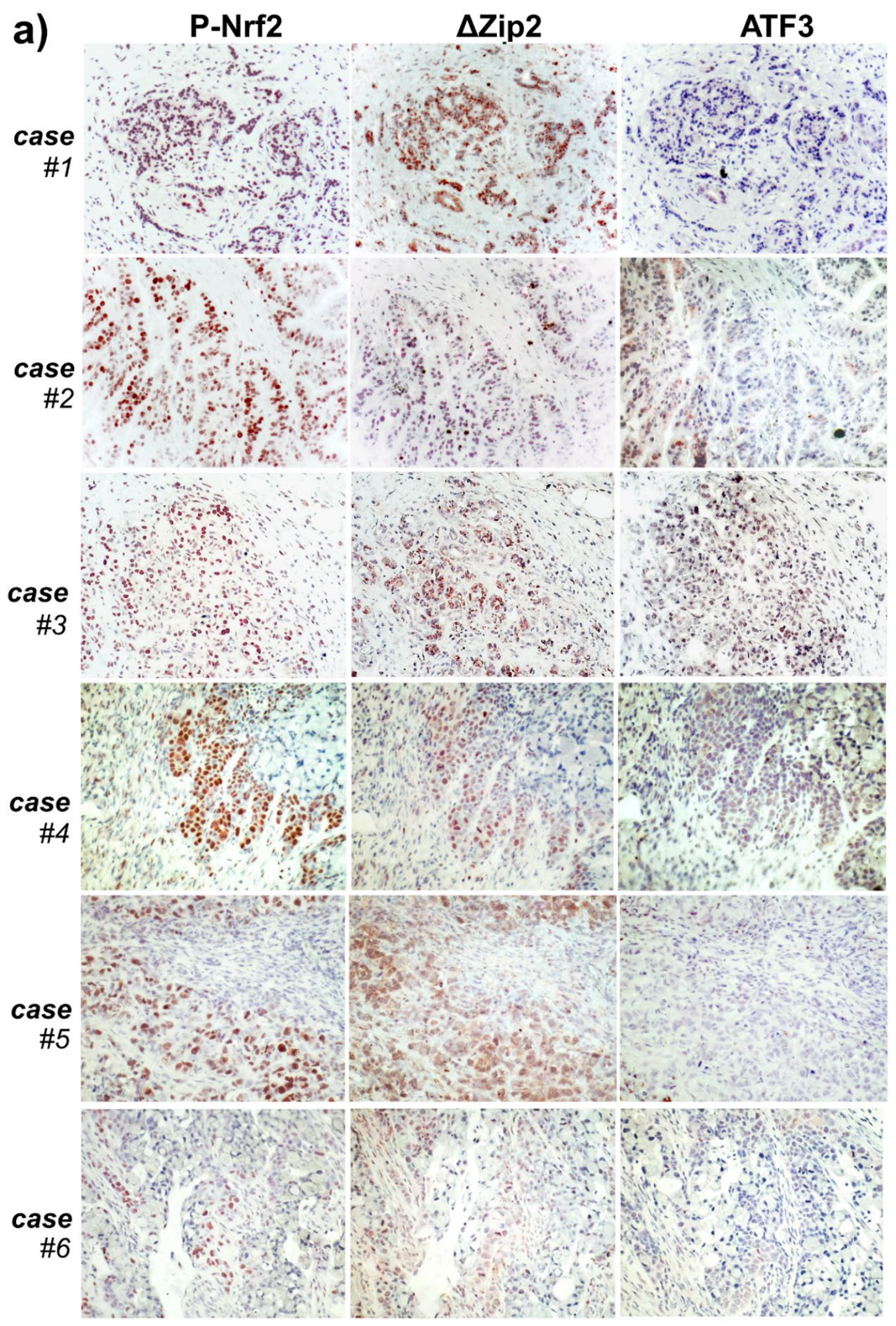




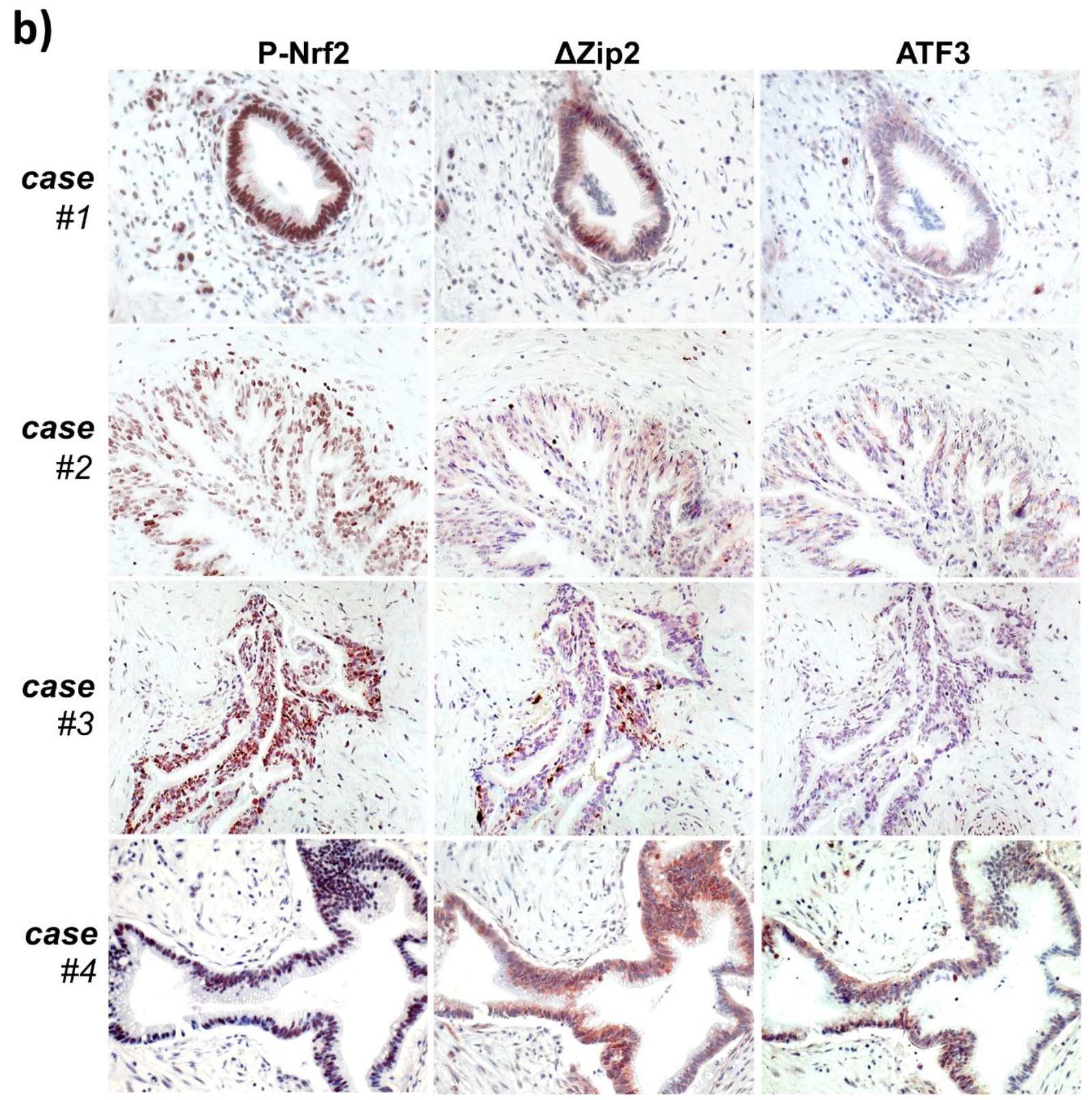

Abbildung 9. Kolokalisation von aktiviertem Nrf2 mit $\triangle Z$ Zip2 in PDAC- und CP-Geweben Unter Einsatz von spezifischen Antikörpern gegen aktiviertes Nrf2 (p-Nrf2), $\Delta$ Zip2 und ATF3 wurden Gewebe von A) vier PDAC Patienten im G3 Stadium und B) drei CP Patienten mit PanIN1/2 Läsionen immunhistochemisch aufgearbeitet. Darstellung in 200x Vergrößerung. 


\section{Diskussion}

Der Transkriptionsfaktor ATF3 - Mitglied der AP1 Familie von Leucine Zipper Porteinen spielt eine wichtige Rolle bei verschiedenen zellulären Stressantworten (u.a. unter UV- $/ \gamma$ Bestrahlung, Hyperthermie, ROS-Exposition). Des Weiteren zeigt ATF3 dichotome Effekte in der Karzinogenese, was auf seinen komplexen Wechselbeziehungen mit anderen pro- und antitumorigenen Signalwegen beruht sowie deren Abhängigkeit vom zellulären Kontext. Dies betrifft vor allem die Interaktion von Tumorzellen mit dem Tumorstroma, das wesentlich durch Fibroblasten, Endothel- und Immunzellen determiniert wird (70), (9). Gerade beim Pankreaskarzinom ist das Tumorstroma sehr prominent und kann bis mehr als $80 \%$ der gesamten Tumormasse ausmachen.

Die Wechselwirkungen dieses Stromas mit den Tumorzellen bzw. auch bereits mit den prämalignen Vorläuferzellen, wie sie vornehmlich in PanIN Läsionen zu finden sind, beinhalten entsprechend eine Vielzahl von Stimuli, die z.B. von einem entzündlichen Kontext herrühren. Hierzu zählen Zytokine, wie TGF- $\beta 1$ oder Stressoren wie ROS, die in komplexer Weise auf die malignen bzw. prämalignen Epithelzellen einwirken. Diesbezüglich konnte bereits eine Wechselwirkung von TGF- $\beta 1$ und dem ROS-induzierten Transkriptionsfaktor Nrf2 nachgewiesen werden, die sich im duktalen Epithel des Pankreas als Adaptationsprozess an den stromalen inflammatorischen Stress nicht nur beim PDAC sondern auch schon während einer CP manifestiert (45), (46). So sind EMT assoziierte Veränderungen durch TGF- $\beta 1$ und Nrf2 in synergistischer Weise festzustellen sowie differentielle Wirkungen bezüglich Zellwachstum und Zellüberleben (45), (46). In der vorliegenden Arbeit konnte nun nachgewiesen werden, dass die differentielle Wirkung TGF- $\beta 1$ und Nrf2 auf das Zellwachstum wesentlich aus der Induktion von unterschiedlichen ATF3 Varianten resultiert (51), (55), (49). Diese Vorgänge betreffen dabei vornehmlich die Expression der full length Variante von ATF3 und der Splicingvariante $\Delta$ Zip2.

\subsection{Bedeutung der Promotor Rekrutierung für die unterschiedliche}

\section{Ausprägung des ATF3-Gens}

Die Entstehung von ATF3 und $\Delta$ Zip2 beruht auf der Rekrutierung unterschiedlicher Promotoren am ATF3 Gen, was zur Folge hat, das unterschiedliche Primärtranskripte entstehen, aus denen durch differentielles Splicing das proapoptotische full length ATF3 Transkript und das antiapoptotische $\Delta$ Zip2 Transkript hervorgehen. Während die Transkription vom distalen Promotor (Abb. 3a) ausschließlich zur Generierung der ATF3 kodierenden mRNA führt (49), 
geht aus der über den proximalen Promotor (Abb. 3b) initiierten Transkription ATF3 und vornehmlich die $\Delta$ Zip2 mRNA hervor (48), (50). Es wurde bereits beschrieben, dass der distale Promotor in Krebszellen konstitutiv aktiv ist und für eine erhöhte Basalexpression von ATF3 sorgt. Vermutlich ist der distale Promotor durch hohe H3-Acetylierung und K4-Trimethylierung besser für durch Wachstumsfaktoren und Seren wie z.B. durch TGF- $\beta 1$ (Abb. 3a) ausgelöste Signalwege zugänglich (50), (71). Der proximale Promotor hingegen unterliegt einer strikten Kontrolle und benötigt für seine Aktivierung Signale aus der zellulären Antwort gegenüber genotoxischen, proinflammatorischen und oxidativen Stress, woran insbesondere Nrf2 und seine Interaktion mit zwei Bindungsstellen (AREs) an den Positionen -3541 bis -3533 und -2975 bis -2967 beteiligt ist (53), (52). Über diesen Mechanismus wird der proximale Promotor des ATF3 Gens durch den Nrf2 Aktivator tBHQ effizient induziert, wie dies in den PDAC Zelllinien der Fall ist (Abb. 3b).

In der Aktivierbarkeit der beiden ATF3 Promotoren spiegelt sich entsprechend auch das Mengenverhältnis der basalen ATF3 und $\Delta$ Zip2 Expression wider. Panc1 Zellen besitzen basal eine deutlich geringere Konzentration von ATF3 als T3M4 Zellen, während die basale Menge von $\triangle$ Zip2 in Panc1 Zellen deutlich höher ist als in T3M4 oder H6c7 Zellen. Dies korreliert mit der stärkeren Basalaktivität von Nrf2 in Panc1 Zellen (40). Somit ist in Panc1 Zellen das ATF3/DZip2 Verhältnis deutlich geringer als in T3M4 oder H6c7 Zellen. Entsprechend bewirkt in den Zelllinien, in denen bereits eine höhere Expression von ATF3 vorliegt, eine Nrf2Aktivierung kaum Effekte am distalen Promotor. Stattdessen führt es zur Aktivierung des proximalen Promotors und damit zur Expression von $\Delta$ Zip2 (Abb. 3b). In der Konsequenz erniedrigt sich in T3M4 und H6c7 Zellen das ATF3/DZip2 Verhältnis. In Panc1 mit geringem ATF3 Spiegel und geringen basalen Aktivität des distalen Promotors, konnten beide Promotoren durch tBHQ induziert werden, wobei der proximale Promotor stärker aktiviert und somit $\triangle$ Zip2 auch unter Nrf2 Aktivierung deutlich stärker exprimiert wurde als ATF3. Hierdurch war insgesamt das ATF3/DZip2 Verhältnis noch weiter erniedrigt. In Anwesenheit von TGF- $\beta 1$, der den distalen Promotor stärker aktiviert und entsprechend mehr ATF3 Expression hervorruft, manifestiert sich die ATF3 Promotoraktivierung durch tBHQ vermehrt auf Ebene des proximalen Promotors und bewirkt somit eine verstärkte Expression von $\Delta$ Zip2. 


\subsection{Effekte von ATF3 und $\triangle$ Zip2 auf den Phänotyp von malignen und prämalignen Pankreasgangepithelzellen}

Die Auswirkungen einer verstärkten Expression von $\Delta$ Zip2 manifestieren sich unter anderem in einer verminderten Apoptoserate in allen drei Zelllinien und einer gesteigerten Zellzyklusund Kolonieformationsrate. Dies zeigte sich entsprechend unter der Nrf2-Aktivierung durch tBHQ. Im Gegensatz dazu kommt unter erhöhter ATF3 Expression dessen hemmender Effekt auf das Zellwachstum sowie die Apoptose steigernde Wirkung zum Ausdruck. Dies zeigt sich in Panc1 deutlich stärker ausgeprägt als in T3M4 Zellen, die bereits eine weitaus höhere ATF3 Basalexpression aufweist.

Eine auf das Zellüberleben supprimierende Wirkung von ATF3 wurde bereits in diversen transgenen Mausmodellen mit ATF3 Expression beobachtet. Hierbei korrelierte die Expression von ATF3 in verschiedenen Geweben der Mäuse mit einer Dysfunktion. So ist beispielsweise eine ATF3 Expression im Pankreas der Mäuse mit einem Defekt der endokrinen pankreatischen Funktion und der Manifestation eines insulinabhängigen Diabetes mellitus assoziiert (72). Des Weiteren konnte ein vermindertes Auftreten diverser Tumore wie Mammakarzinom und Tumore des oberen Gastrointestinaltraktes beobachtet werden (73). Umgekehrt waren jedoch ATF3 knock-out Mäuse durch vermehrtes Auftreten von Tumoren charakterisiert. So sind hier insbesondere durch p53-vermittelnde tumorsupprimierende Wirkungen im Darm und in der Leber in erheblicher Weise durch eine ATF3-Defizienz kompromittiert (74). In einem pankreatischen ATF3 knock-out Modell der Maus zeigten sich zudem eine erhöhte Inzidenz von Pankreatitis und PDAC (75). Allerdings kommt bei Mäusen die $\triangle$ Zip2 Variante nicht vor, so dass die Rolle von ATF3 in humanen Zellen komplexerer Natur sein dürfte. Dies erklärt, dass im Vergleich zu den Mausmodellen mit veränderter ATF3 Expression, die Datenlage bzgl. ATF3 in humanen Tumorzellen bzw. in Geweben von Tumorpatienten uneinheitlich ist. Möglicherweise beruht dies auf der vielfältigen Wirkung von $\Delta$ Zip2, die sowohl unabhängig als auch abhängig von ATF3 erfolgen. Bei einer gemeinsamen Überexpression von ATF3 und $\triangle$ Zip2 ist so z.B. eine Aufhebung der durch ATF3 verursachenden Sensitivierung gegenüber Apoptose zu verzeichnen (Abb. 5).

Inzwischen wurde in einem Tumor-Xenotransplantationsversuch mit SCID Mäusen nach einer subkutanen Inokulation von Panc1 Tumorzellen mit Überexpression von ATF3 bzw. Überexpression von $\Delta$ Zip2 das Wachstumsverhalten und die Resistenz gegenüber Gemcitabin untersucht (76). Innerhalb von drei Wochen nach Tumorzellinokulation von Panc1 mit überexprimierten $\Delta$ Zip2 konnte ein Tumor mit einer Größe von $3.8 \pm 3.9 \mathrm{~mm}^{2}$ nachgewiesen 
werden. Nach sieben Wochen war eine Größenzunahme auf mehr als das 8-fache $(30.6 \pm 5.8$ $\mathrm{mm}^{2}$ ) zu erkennen. Im Vergleich dazu waren in den Mäusen mit Kontrollplasmid (mock) transfizierte Panc1 erst fünf Wochen nach Inokulation ein Tumor nachzuweisen $\left(5.6 \pm 3.4 \mathrm{~mm}^{2}\right)$ und in der siebten Woche erreichte der Tumor das 7-fache seiner Größe $\left(38.4 \pm 11.9 \mathrm{~mm}^{2}\right)$. Panc 1 mit ATF3-Überexpression zeigten ein wesentlich langsameres Tumorwachstum und erreichten Größen von $4.1 \pm 3.3 \mathrm{~mm}^{2}$ und $9.3 \pm 6.9 \mathrm{~mm}^{2}$ erst nach sechs und sieben Wochen.

Die bisherigen Beobachtungen verdeutlichen die divergenten Eigenschaften von $\Delta$ Zip2 und ATF3 und lassen vermuten, dass $\triangle$ Zip2 direkt mit ATF3 interagiert und wie $\Delta$ Zip die Aufhebung der durch ATF3 bewirkenden Hemmung von Genen wie z.B. CyclinD bzw. die Hemmung von durch ATF3-induzierten Genen, verursacht (47). Ähnliche Beobachtungen zu der Nrf2/ATF3-Interaktion wurden in Astrozyten unter oxidativem Stress (53) und Spermatozyten unter Einfluss von Zigarettenrauch (77) gemacht.

Ein weiterer Effekt der direkten Interferenz von $\triangle$ Zip2 mit ATF3 betrifft die Expression der Apoptose und Wachstums regulierenden Gene GADD34 (58) und CHOP/GADD153 (59). Diese beiden Gene sind an der ER-Stressantwort und der Zellzykluskontrolle beteiligt (78), (79) und entfalten proapoptotische Wirkung, u.a. unter Einfluss von Zytostatika (80). Unter ATF3 Expression erhöht sich die GADD34 und CHOP Expression - Ausdruck einer transaktivierenden Wirkung von ATF3 - und, ähnlich wie $\Delta$ Zip, hebt die Überexpression von $\triangle$ Zip2 den induzierenden Effekt von ATF3 auf. Allerdings gibt es auch Hinweise darauf, dass $\Delta$ Zip2 unabhängig von ATF3 agiert. Denn eine gesteigerte $\Delta$ Zip2 Expression führt zu einer erhöhten Expression von protumorigenen und antiapoptotischen cIAP Genen, während ATF3 diese Expression nicht beeinflusst und bei einem Knockdown von ATF3 die basale und tBHQinduzierte Expression von cIAP1 und cIAP2 kaum ansteigt. Dagegen sorgt ein Knockdown von $\triangle$ Zip2 in allen drei Zelllinien - also auch in Abwesenheit von basaler ATF3 Expression wie in Panc1 Zellen - für eine reduzierte Nrf2-abhängige Apoptose Resistenz und eine reduzierte Expression beider cIAP Proteine. Es kann daher angenommen werden, dass ATF3 nicht an der Regulation der cIAP1 und cIAP2 Expression beteiligt ist und der Einfluss von $\triangle$ Zip2 diesbezüglich ATF3 unabhängig erfolgt. Im Einklang hiermit haben Untersuchungen auf das Verhalten von $\Delta$ Zip zeigen können, dass eine $\Delta$ Zip Überexpression und dessen ATF3 inhibierende Wirkung zu keiner Erhöhung von cIAP1 und cIAP2 führt.

Auf Grundlage der genannten Ergebnisse wird die Existenz eines ATF3-unabhängigen Signalweges des $\Delta$ Zip2 vermutet. Somit würde eine Addition der direkten $\Delta$ Zip2/ATF3Interaktion mit dem ATF3-unabhängigen Signalweges den starken Einfluss von $\Delta$ Zip2 auf den zellulären Phänotyp erklären. Die genauen Mechanismen des ATF3-unabhängigen Signalweges 
von $\Delta$ Zip2 sind noch unklar. Ursächlich dafür ist vermutlich die Struktur des $\Delta$ Zip2, bei der die C-Terminale Zip Domäne durch eine aus 21 Aminosäuren, für diese Variante spezifische Sequenz, ersetzt worden ist (48), (81). Bisher gibt es keinerlei Ähnlichkeiten dieser Cterminalen Region mit anderen Proteinsequenzen. Interessanterweise zeigt $\Delta$ Zip2 keinen Effekt auf die Expression von cIAP1 oder cIAP2 auf Ebene ihrer mRNAs, sondern nur auf Ebene ihrer Proteine. Der Mechanismus dieses offenbar posttranslationalen Effekts durch $\Delta$ Zip2 ist noch unbekannt. In Betracht zu ziehen wäre hier in erster Linie ein durch $\Delta$ Zip2 veränderter Turnover von cIAP1 und cIAP2 durch das Ubiquitin-Proteasom-System (82), (83). Möglicherweise interferiert die C-terminale Region von $\triangle$ Zip2 mit der cIAP stabilisierenden Ubiquitinase USP19 oder mit den IAP Regulator SMAC und seiner induzierenden Wirkung auf die cIAP Autoubiquitinierung. Weiterführende Versuche sind gegenwärtig mit der Klärung dieses Sachverhaltes befasst.

\subsection{Resistenzentwicklung gegenüber Chemotherapeutika am Beispiel von Gemcitabin in Abhängigkeit von ATF3 und $\triangle$ Zip2}

Wie bereits erwähnt zeigt ATF3 proapoptotische und wachstumshemmende Wirkungen auf Krebszellen. Diese werden durch die Expression von Genen wie z.B. CHOP/GADD153 und GADD34 realisiert (58), (59), wodurch u.a. die Sensitivität der Zelle gegenüber Chemotherapeutika verstärkt wird (80). Die Erhöhung der Chemosensitivität wurde an Panc1, T3M4 und H6c7 unter Behandlung mit Gemcitabin gezeigt. Das ist von großer Bedeutung, da sich Gemcitabin als Therapeutikum der Wahl bei metastasierten Pankreaskarzinom mit Resistenzentwicklungen auseinandersetzen muss. An der Resistenzentwicklung scheint Nrf2 maßgeblich beteiligt zu sein. Gemcitabin provoziert die Entstehung von ROS, was wiederum DNA Schäden verursacht. Als Reaktion darauf wird u.a. der Transkriptionsfaktor Nrf2 aktiv und stimuliert die Bildung von Enzymen, die z.B. Glutathion katalysieren (GSH), um den zytotoxischen Effekt zu minimieren (intrinsische Resistenz) und das Überleben der Zelle zu sichern. Dass $\Delta$ Zip2 an diesem Prozess der Resistenzbildung beteiligt ist, konnte nun nachgewiesen werden. Über die Induktion von Nrf2 wird vermehrt $\Delta$ Zip2 gebildet (Abb. 5B), was die Apoptose verhindert (Abb. 5A). Unter der Behandlung mit tBHQ wird in Panc1 auch vermehrt $\Delta$ Zip2 exprimiert (Abb. 2A, B) und eine geringe Apoptoseaktivität beobachtet (Abb. 5A). Eine Hemmung von Nrf2 bzw. GSH führt in diesem Kontext zu einer Erhöhung von Glutathion und dementsprechend zu einer Sensitivierung der Zellen gegenüber Gemcitabin in 
vivo und in vitro (84). Ergebnisse aus dem nachfolgend durchgeführten TumorXenotransplantationsversuch mit SCID Mäusen und ATF3 bzw. $\Delta$ Zip2 überexprimierten Panc1 Zellen (76) belegen ebenfalls die Resistenzentwicklung durch $\Delta$ Zip2. So zeigte sich bei parentalen Panc1 Tumoren nach Behandlung mit Gemcitabin eine Zunahme der Tumorgröße um 51\% (in Relation zur Ausgangsgröße des Tumors vor Behandlung) wohingegen bei $\Delta$ Zip2 überexprimierten Panc1 Tumoren die Größenzunahme immerhin $84 \%$ betrug. Im Gegensatz dazu reagierten die Panc1 Tumoren mit ATF3 Überexpression sehr viel stärker auf die Gemcitabin Behandlung, wobei sich deren Wachstum auf unter 20\% verminderte.

In T3M4 konnte im Vergleich zu Panc1 keine Gemcitabin Resistenz festgestellt werden. Dies lässt sich darauf zurückführen, dass Gemcitabin in T3M4 statt $\triangle$ Zip2 ATF3 induziert (Abb. 4B), was die Apoptoseaktivität erhöht (Abb. 5A). Ein Knockdown von ATF3 führt hierbei zu einer geringen Apoptoseaktivität. Folglich sind T3M4 Zellen sensitiv und Panc1 resistent gegenüber einer Gemcitabin Therapie (48), (84).

Eine kürzlich publizierte Studie konnte zeigen, dass Gemcitabin vor allem in Panc1 Zellen eine sogenannte integrated stress response auslöst (85), in deren Verlauf vor allem Nrf2 aktiviert und antiapoptotische Gene induziert werden. Dies wird somit - wie in dieser Arbeit gezeigt durch eine in Panc1 Zellen besonders sichtbare Expressionssteigerung von $\Delta$ Zip2 vermittelt. Ähnliche Beobachtungen konnten in Bezug auf die Anwendung mit TRAIL gemacht werden. T3M4 reagiert dabei wiederum sensitiver als Panc1 auf TRAIL-induzierte Apoptose, was auf den höheren basalen Gehalt von ATF3 in T3M4 zurückzuführen ist, verbunden mit seiner sensitivierenden Wirkung gegenüber diesem Todesliganden (Abb. 6). Auch hier vermag die durch $\triangle$ Zip2 selektiv - d.h. ATF3 unabhängig - erfolgende Induktion der cIAP Expression die Protektion vor Apoptose zusätzlich zur direkten ATF3 Interferenz zu verstärken.

\subsection{Rolle von $\triangle$ Zip2 in der entzündlichen Karzinogenese des Pankreas und seine Beteiligung am Crosstalk zwischen TGF- $\beta 1$ und Nrf2}

Die immunhistochemische Analyse von PDAC Geweben in dieser Arbeit konnte die Überexpression von $\Delta$ Zip2 erstmalig in Tumorgewebe überhaupt zeigen. Bislang erfolgte Untersuchungen an humanen Tumorgeweben bedienten sich Antikörpern, die keine Differenzierung zwischen den ATF3 Varianten zuließen. Entweder wurden Antikörper verwendet, die den N-terminalen Abschnitt des ATF3 Proteins detektierten und damit auch mit 
allen Splicevarianten kreuzreagierten, oder aber Antikörper gegen den C-terminalen Abschnitt von ATF3, die damit weder $\Delta$ Zip2 noch $\Delta$ Zip Proteine nachweisen können.

Durch den von unserer Arbeitsgruppe per Auftragssynthese generierten monoklonalen Antikörper gegen den exklusiven, 19 Reste umfassenden C-Terminus des $\Delta$ Zip2 Proteins konnte nun erstmals diese ATF3-Variante gezielt detektiert werden. Anhand des Vergleiches mit einem C-terminal reagierenden ATF3 Antikörpers und dem $\triangle$ Zip2 Antikörper war eine weitgehend reziproke Expression im PDAC Gewebe $\mathrm{zu}$ detektieren. Während die Gewebsareale mit gesteigerter Nrf2-Aktivierung - dargestellt anhand des Nachweises von Ser40 phosphorylierten Nrf2 - überwiegend positiv für $\Delta$ Zip2 Expression sind, zeigen Areale mit niedriger Nrf2 Aktivierung keinerlei $\Delta$ Zip2 Expression wohl aber eine nachweisbare ATF3 Expression. Interessanterweise war die enge Verbindung zwischen gesteigerte Nrf2Aktivierung im Gewebe anhand des Nachweises von Ser-40 phosphorylierten Nrf2 und $\Delta$ Zip2 Expression nicht nur in PDAC Gewebe nachweisbar, sondern auch bereits in PanIN Strukturen die im pankreatischen Gewebe von CP-Patienten auffindbar sind. Dies belegt die Rolle der Nrf2-induzierten epithelialen Stressadaptation im Verlaufe der inflammatorischen Karzinogenese und hier ist die ATF3-Splicevariante $\Delta$ Zip2 essentiell beteiligt.

Diese immunhistochemischen Befunde wurden inzwischen mittels Transkriptionsanalyse anhand eines 40 Patienten umfassenden Kollektivs mit PDAC (T3N1M0) validiert (76). Dabei korreliert die Höhe der Nrf2 Aktivität mit der Anzahl der Amplifikationen von NQO1 und GCLC. In 20 von 37 PDAC Proben zeigten sich hohe Konzentrationen von NQO1 und GCLC. Von diesen 20 waren in 14 Proben eine erhöhte Expression von $\Delta$ Zip2 entsprechend den hohen NQO1 und GCLC Level zu detektieren. 13 von 17 PDAC Proben zeigten niedrige NQO1 und GCLC Amplifikationen und dementsprechend auch eine niedrige $\Delta$ Zip2 Expression. Bei fehlender NQO1 und GCLC Amplifikationen konnte eine ATF3 Expression nachgewiesen werden. Die Koexpression von NQO1 und $\Delta$ Zip2 verhielt sich unabhängig von der Expression von epithelialen Tumormarkern.

Wie bereits gezeigt wurde (45), (46) ist insbesondere der Crosstalk zwischen Nrf2 und TGF- $\beta 1$ an der inflammatorischen Karzinogenese im Pankreas beteiligt. Entsprechend manifestiert sich die differentielle Expression von ATF3 und $\triangle$ Zip2 ganz wesentlich in diesem Kontext (Abb. 10). So gehen von TGF- $\beta 1$ zum einen EMT fördernde Effekte aus, die wesentlich von ATF3 in seiner full length Variante vermittelt werden (86), (87). Zum anderen beeinflusst TGF- $\beta 1$ in differentieller Weise das Zellwachstum und -überleben. Während in nichtmalignen Zellen ein Zellzyklus inhibierender Effekt von TGF- $\beta 1$ dominiert, ist dies in Tumorzellen aufgrund einer veränderten Signalvermittlung vor allem in Richtung stärkerer Apoptoseprotektion verschoben. 
Dies könnte teilweise auf der Interferenz von $\Delta$ Zip2 - z.B. resultierend aus der Aktivierung von Nrf2 - mit ATF3 beruhen. Hierdurch, wie auch über Interferenz mit der anderen Splicevariante $\Delta$ Zip, wird die Induktion der Expression der proapoptotischen Gene GADD34 und CHOP/GADD153 (78), (79) durch das TGF-ß1 induzierte ATF3 aufgehoben. Zusätzlich verleiht die durch $\Delta$ Zip2, nicht jedoch $\Delta$ Zip, bewirkte Erhöhung der cIAP Expression eine deutliche Erhöhung des Apoptoseschutzes. Dies manifestiert sich entsprechend auch in der Chemosensitivität von PDAC Zellen, die einerseits über die Induktion von ATF3 durch TGF$\beta 1$ erhöht ist, andererseits aber durch Nrf2 und dessen induzierende Wirkung auf $\Delta$ Zip2 vermindert wird.

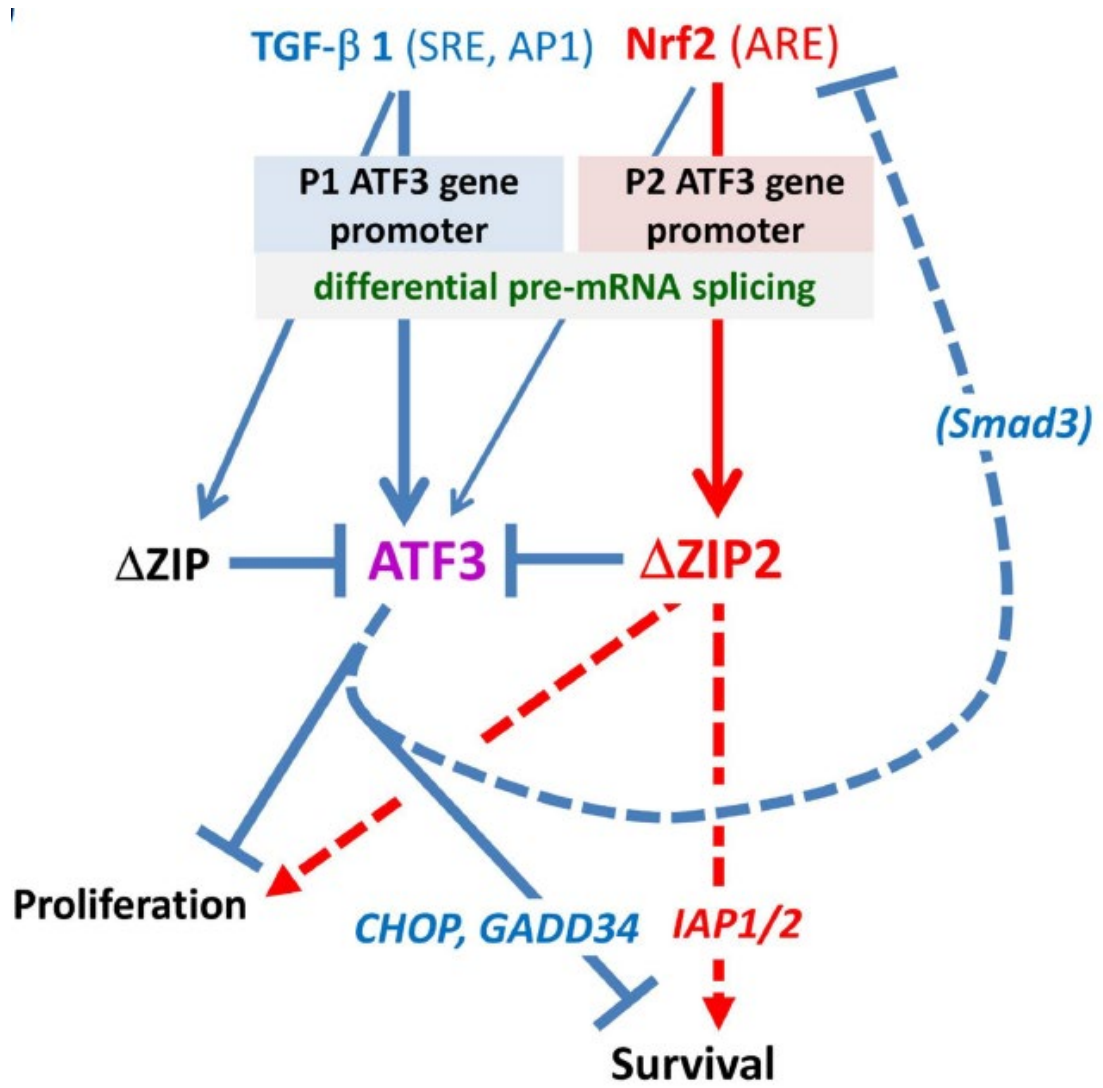

\footnotetext{
Abbildung 10. Hypothetisches Modell über die Induktion von ATF3 und seiner Varianten durch Nrf2 und TGF-ß1 und ihre Auswirkungen auf den Phänotyp.

Die differentielle Induktion der ATF3 Varianten kann durch die Rekrutierung von unterschiedlichen transkriptionellen Startsequenzen (,Promotor I“ und „Promotor II“, Abb.1) ermöglicht werden. Vermutlich spielen auch epigenetische Effekte eine Rolle. Nrf2 induziert $\triangle$ Zip2 stärker als ATF3 und fördert dadurch das Zellüberleben und Zellproliferation. Dahingegen induziert TGF- $\beta 1$ ATF3 und hemmt damit das Zellüberleben bzw. Zellproliferation. $\triangle$ Zip und $\triangle$ Zip2 wirken beide hemmend auf ATF3, wobei erstere stärker hemmt (aus Kha et al. 2018).
} 
Auf der Grundlage dieses komplexen Wechselspiels kann somit abgeleitet werden, dass die Nrf2-abhängige $\Delta$ Zip2 Expression einen wichtigen Bestandteil des malignen Geschehens schon in der Frühphase des PDAC darstellt, und dieses als möglicher Marker in der Früherkennung des PDAC dienen kann. Eine Modulation von Nrf2, z.B. mittels Nrf2 Inhibitoren, oder von $\triangle$ Zip2, z.B. durch Exon editing im ATF3 Gen mittels Genscheren (CRIPR, TALEN), könnte daher neuen Präventions- oder Therapieansätzen beim PDAC zugutekommen.

\section{Zusammenfassung}

Das duktale Pankreasadenokarzinom (PDAC) geht noch immer mit einer infausten Prognose einher, was mitunter an den unzureichenden diagnostischen und therapeutischen Möglichkeiten liegt. Trotz gewisser Fortschritte in der chirurgischen und konventionellen Therapie hat sich das 5-Jahres-Überleben von 1-3\% kaum verändert. Die chirurgische Resektion bleibt weiterhin die effektivste Therapie. Adjuvante Chemo- und Radiotherapien können nur einen geringen Überlebensvorteil erzielen.

Die Pathophysiologie ist bislang noch nicht vollständig geklärt. Ein Risikofaktor stellt die Chronische Pankreatitis dar, bei der persistierende Entzündungsreaktionen z.B. durch oxidativen Stress, genetische und molekulare Alterationen induzieren, die eine Tumorentwicklung begünstigen. Der Transkriptionsfaktor Nrf2 wurde als Schlüsselfaktor im Rahmen der entzündlichen Karzinogenese identifiziert. Interaktionen von Nrf2 mit anderen Transkriptionsfaktoren, darunter ATF3, die ebenfalls zur Tumorentstehung beitragen können, wurden bereits beschrieben.

In der vorliegenden Arbeit wurden die Transkriptionsfaktoren ATF3 und Splicing Varianten in Abhängigkeit von Nrf2 anhand von PDAC Zellen Panc1 und T3M4 und prämalignen duktalen Pankreasepithelzellen H6c7 analysiert. Protein- und molekularbiochemische Methoden ergaben eine deutliche Induktion der Splicing Variante $\Delta$ Zip2 unter Nrf2-aktivierenden Bedingungen (tBHQ). Diese Nrf2-abhängige Expression von $\Delta$ Zip2 führte in weiteren Untersuchungen zu einer Zunahme von antiapoptotischen Proteine (cIAP1 und cIAP2), einer reduzierten Apoptosebereitschaft, einer gesteigerten Proliferationsrate und einer Resistenzentwicklung gegenüber Gemcitabin-induzierte Apoptose. Zudem konnten mit Immunhistochemie bereits in chronisch entzündlichen Pankreasgeweben eine erhöhte Aktivität von Nrf2 und $\Delta$ Zip2 nachgewiesen werden, die die Entstehung eines PDAC auf Boden einer Chronischen Pankreatitis erklären können. Untersuchungen mit ATF3 zeigten, dass TGF- $\beta 1$ und Oltipraz als starke ATF3 Induktoren fungieren können. Die Folgen einer Expression von 
ATF3 sind ein Anstieg von proapoptotischen Proteine (CHOP/GADD34), eine erhöhte Apoptoserate, eine reduzierte Proliferationsbereitschaft und eine Sensitivierung der Tumorzellen gegenüber Gemcitabin-induzierte Apoptose.

Basierend auf den erhobenen Befunden, ist es vorstellbar, dass Nrf2 und $\Delta$ Zip2 als mögliche Marker in der Früherkennung des PDAC dienen und eine Modulation von Nrf2, $\triangle$ Zip2 oder ATF3 neue Präventions- oder Therapieansätze gegen PDAC darstellen können.

\subsection{Summary}

Ductal pancreatic adenocarcinoma (PDAC) is still associated with a poor prognosis, which is partly due to inefficient diagnostic and therapeutic options. The 5-year survival of $1-3 \%$ has barely changed in the last few years. Surgery remains to be the most effective therapy. Adjuvant chemo- and radiotherapy can only provide a small benefit without a constant improvement for the outcome.

The pathophysiology is still not fully understood. A risk factor is chronic pancreatitis, in which persistent inflammation caused by e.g. oxidative stress, induces genetic and molecular alterations that leads to tumor development. The transcription factor Nrf2 was identified as an important key factor for the malignancy of tumor cells by its mediated cell protection against oxidative stress. Interactions of Nrf2 with other transcription factors, including ATF3, which may also contribute to tumorigenesis, have been described.

In the present work, the transcription factor ATF3 and its splicing variants were analyzed in relation to Nrf2 in PDAC cells (Panc1 and T3M4) and premalignant ductal pancreatic cells (H6c7). With the use of protein and molecular biochemical methods, an induction of the splicing variant $\Delta$ Zip2 under Nrf2-activating conditions (tBHQ) was proved. This Nrf2-dependent expression of $\Delta \mathrm{Zip} 2$ led to an increase level of anti-apoptotic proteins (cIAP1 und cIAP2), reduced apoptosis, increased proliferation and promoted resistance to gemcitabine-induced apoptosis. In addition, immunohistochemistry showed that chronic inflammatory pancreatic tissues already have an increased activity of Nrf2 and $\Delta$ Zip2, which may explain the development of PDAC from chronic pancreatitis. In further studies with ATF3 it was observed, that TGF- $\beta 1$ and Oltipraz can act as strong inducers of ATF3 and that ATF3 Expression is associated with an increased level of pro-apoptotic proteins (CHOP/GADD34), increased apoptosis, reduced proliferation and high vulnerability of tumor cells to gemcitabine-induced apoptosis. 
Based on our findings, it is conceivable that Nrf2 and $\Delta$ Zip2 serve as potential markers in the early detection of PDAC, and modulation of Nrf2, $\triangle \mathrm{Zip} 2$ or ATF3 may represent new prevention or treatment strategies against PDAC. 


\section{Literaturverzeichnis}

1. Howe, G.R., Jain, M., Burch, J.D., Miller, A.B. Cigarette smoking and cancer of the pancreas: evidence from a population-based case-control study in Toronto, Canada. International Journal of Cancer. 1991, 47 (3), S. 323-328.

2. Whitcomb, D.C., Applebaum, S., Martin, S.P. Hereditary pancreatitis and pancreatic carcinoma. Annals of the New York Academy of Sciences. 1999, 880, S. 201-209.

3. Farrow, B., Evers, B.M. Inflammation and the development of pancreatic cancer. Surg. Oncol. 2002, 10, S. 153-69.

4. DeNicola, G. M., Karreth, F. A., Humpton, T. J., Gopinathan, A., Wei, C., Frese, K., Mangal, D., Yu, K. H., Yeo, C. J., Calhoun, E. S., Scrimieri, F., Winter, J. M., Hruban, R. H., Iacobuzio-Donahue, C., Kern, S. E., Blair, I. A., Tuveson, D. A. Oncogene-induced Nrf2 transcription promotes ROS detoxification and tumorigenesis. Nature. 2011, 475 (7354), S. 106-109.

5. Hruban, R.H., Wilentz, R.E., Kern, S.E. Genetic progression in the pancreatic ducts. American Journal of Pathology. Jun 2000, S. 156(6):1821-5.

6. Kang, K.W., Lee, S.J., Kim, S.G. Molecular mechanism of nrf2 activation by oxidative stress. Antioxid Redox Signal. 2005, 7, S. 1664-1673.

7. Kaspar, J.W., Niture, S.K., Jaiswal, A.K. Nrf2:INrf2 (Keap1) signaling in oxidative stress. Free Radic Biol Med. 2009, 47, S. 1304-1309.

8. Erkan, M. The role of pancreatic stellate cells in pancreatic cancer. Pancreatology. 2013, 13, S. 106-109.

9. Kleeff, J., P. Beckhove, I. Esposito, S. Herzig, P.E. Huber, J.M. Löhr, H. Friess. Pancreatic cancer microenvironment. Int. J. Cancer. 2007, 121, S. 699-705.

10. Sipos, B., Frank, S., Gress, T., Hahn, S., Klöppel, G. Pancreatic intraepithelial neoplasia revisited and updated. Pancreatology. 2009, 9, S. 45-54.

11. Helm, O., Mennrich, R., Petrick, D., Goebel, L., Freitag-Wolf, S., Röder, C., Kalthoff, H., Röcken, C., Sipos, B., Kabelitz, D., Schäfer, H., Oberg, H.H., Wesch, D., Sebens, S. Comparative characterization of stroma cells and ductal epithelium in chronic pancreatitis and pancreatic ductal adenocarcinoma. PLoS One. 5. May 2014, eCollection 2014, S. 9(5): e94357.

12. Moi, P., Chan, K., Asunis, I., Cao, A., Kann, Y.W. Isolation of NF-E2-related factor 2 (Nrf2), a NF-E2-like basic leucine zipper transcriptional activator that binds to the tandem NF-E2/AP1 repeat of the beta-globin locus control region. Proc Natl Acad Sci USA. 1994, 91, S. 9926-9930.

13. Lau, A., Villeneuve, N.F., Sun, Z., Wong, P.K., Zhang, D.D. Dual roles of Nrf2 in cancer. Pharmacol Res. 2008, 58, S. 262-270.

14. Itoh, K., Wakabayashi, N., Katoh, Y., Ishii, T., Igarashi, K., Engel, J.D., Yamamoto, M. Keap1 represses nuclear activation of antioxidant responsive elements by Nrf2 through binding to the amino-terminal Neh2 domain. Genes Dev. 1999, 13, S. 76-86. 
15. Nioi, P., Nguyen, T., Sherratt, P.J., Pickett, C.B. The carboxy-terminal Neh3 domain of Nrf2 is required for transcriptional activation. Mol Cell Biol. 2005, 25, S. 10895-10906.

16. Katoh, Y., Itoh, K., Yoshida, E., Miyagishi, M., Fukamizu, A., Yamamoto, M. Two domains of Nrf2 cooperatively bind CBP, a CREB binding protein, and synergistically activate transcription. Genes Cells. 2001, 6, S. 857-868.

17. Villamena, F.A. Molecular Basis of Oxidative Stress: Chemistry, Mechanisms, and Disease Pathogenesis. New York : John Wiley \& S, 2013. S. 269-281.

18. Luo, Y., Eggler, A.L., Liu, D., Liu, G., Mesecar, A.D., Van Breemen, R.B. Sites of alkylation of human keap1 by natural chemoprevention agents. J Am Soc Mass Spectrom. 2007, 18, S. 2226-2232.

19. Zhang, D.D., Hannink, M. Distinct cysteine residues in Keap1 are required for Keap1dependent ubiquitination of Nrf2 and for stabilization of Nrf2 by chemopreventive agents and oxidative stress. Mol cell Biol. 2003, 23, S. 8137-8151.

20. Stewart, D., Killeen, E., Naquin, R., Alam, S., Alam, J. Degradation of transcription factor Nrf2 via the ubiquitin-proteasome pathway and stabilization by cadmium. J Biol Chem. 2003, 278, S. 2396-2402.

21. McMahon, M., Itoh, K., Yamamoto, M., Hayes, J.D. Keap1-dependent proteasomal degradation of transcription factor Nrf2 contributes to the negative regulation of antioxidant response element-driven gene expression. J Biol Chem. 2003, 278, S. 21592-21600.

22. Jeong, W.S., Jun, M., Kong, A.N. Nrf2: a potential molecular target for cancer chemoprevention by natural compounds. Antioxid Redox Signal. 2006, 8, S. 99-106.

23. Zhang, D.D. Mechanistic studies of the Nrf2-Keap1 signaling pathway. Drug Metab Rev. 2006, 38, S. 769-789.

24. Ishii, T., Itoh, K., Takahashi, S., Sato, H., Yanagawa, T., Katoh, Y., Bannai S., Yamamoto M. Transcription factor Nrf2 coordinately regulates a group of oxidative stressinducible genes in macrophages. J Biol Chem. 2000, 275, S. 16023-16029.

25. Hayes, J. D., Dinkova-Kostova, A. T. The Nrf2 regulatory network provides an interface between redox and intermediary metabolism. Trends in biochemical sciences. 39, 2014, Bd. 4, S. 199-218.

26. Kensler, T.W., Curphey, T.J., Maxiutenko, Y., Roebuck, B.D. Chemoprotection by organosulfur inducers of phase 2 enzymes: dithiolethiones and dithiins. Drug Metab Drug Interact. 2000, 17, S. 3-22.

27. Morimitsu, Y., Nakagawa, Y., Hayashi, K., Fujii, H., Kumagai, T., Nakamura, Y., Osawa, T., Horio, F., Itoh, K., Iida, K., Yamamoto, M., Uchida, K. A sulforaphane analogue that potently activates the Nrf2-dependent detoxification pathway. J Biol Chem. 2002, 277(5), S. 3456-3463.

28. Balogun, E., Hoque, M., Gong, P., Killeen, E., Green, C.J., Foresti, R., Alam, J., Motterlini, R. Curcumin activates the haem oxygenase-1 gene via regulation of Nrf2 and the antioxidant-responsive element. Biochem J. 2003, 371, S. 887-895.

29. Ramos-Gomez, M., Kwak, M.K., Dolan, P.M., Itoh, K., Yamamoto, M., Talalay, P., Kensler, T.W. Sensitivity to carcinogenesis is increased and chemoprotective efficacy of 
enzyme inducers is lost in nrf2 transcription factor-deficient mice. Proc Natl Acad Sci USA. 2001, 98, S. 3410-3415.

30. Kensler, T.W., Ng, D., Carmella, S.G., Chen, M., Jacobson, L.P., Muñoz, A., Egner, P.A., Chen, J.G., Qian, G.S., Chen, T.Y., Fahey, J.W., Talalay, P., Groopman, J.D., Yuan, J.M., Hecht, S.S. Modulation of the metabolism of airborne pollutants by glucoraphanin-rich and sulforaphane-rich broccoli sprout beverages in Qidong, China. Carcinogenesis. 2012, 33(1), S. 101-7.

31. Sporn, M. B., Liby, K. T. NRF2 and cancer: the good, the bad and the importance of context. Nature reviews. Cancer. 2012, Bd. 12, 8, S. 564-571.

32. Eftekharzadeh, B., Maghsoudi, N., Khodagholi, F. Stabilization of transcription factor Nrf2 by tBHQ prevents oxidative stress-induced amyloid $\beta$ formation in NT2N neu-rons. Biochemie. 2010, 92 (3), S. 245-253.

33. Pinkus, R., Weiner, L.M., Daniel, V. Role of Oxidants and Antioxidants in the Induction of AP-1, NF-кB, and Glutathione S-Transferase Gene Expression. J Biol Chem. 1996, 271(23), S. 13422-9.

34. Heiss, E., Herhaus, C., Klimo, K., Bartsch, H., Gerhauser, C. Nuclear factor kappa B is a molecular target for sulforaphane-mediated anti-inflammatory mechanisms. The Journal of biological chemistry. 2001, 276 (34), S. 32008-32015.

35. Xu, C., Huang, M.-T., Shen, G., Yuan, X., Lin, W., Khor, T. O., Conney, A. H., Kong, A. N. Inhibition of 7,12-dimethylbenz(a)anthracene-induced skin tumorigenesis in C57BL/6 mice by sulforaphane is mediated by nuclear factor E2-related factor 2. Cancer research. 2006, 66 (16), S. 8293-8296.

36. Kensler, T. W., Egner, P. A., Agyeman, A. S., Visvanathan, K., Groopman, J. D., Chen, J.-G., Chen, T. Y., Fahey, J. W., Talalay, P. Keap1-nrf2 signaling: a target for cancer prevention by sulforaphane. Topics in current chemistry. 2013, 329, S. 163-177.

37. Cornblatt, B. S., Ye, L., Dinkova-Kostova, A. T., Erb, M., Fahey, J. W., Singh, N. K., Chen, M. S., Stierer, T., Garrett-Mayer, E., Argani, P., Davidson, N. E., Talalay, P., Kensler, T. W., Visvanathan, K. Preclinical and clinical evaluation of sulforaphane for chemoprevention in the breast. Carcinogenesis. 2007, 28 (7), S. 1485-1490.

38. Egner, P. A., Chen, J. G., Wang, J. B., Wu, Y., Sun, Y., Lu, J. H., Zhu, J., Zhang, Y. H., Chen, Y. S., Friesen, M. D., Jacobson, L. P., Muñoz, A., Ng, D., Qian, G. S., Zhu, Y. R., Chen, T. Y., Botting, N. P., Zhang, Q., Fahey, J. W., Talalay, P., Groopman, J.D., Kensler, T.W. Bioavailability of Sulforaphane from two broccoli sprout beverages: results of a short-term, cross-over clinical trial in Qidong, China. Cancer prevention research (Philadelphia, Pa.). 2011, 4 (3), S. 384-395.

39. Ikeda, H., Nishi, S., Sakai, M. Transcription factor Nrf2/MafK regulates rat placental glutathione S-transferase gene during hepatocarcinogenesis. Biochem J. 2004, 380, S. 515 521.

40. Arlt, A., Sebens, S., Krebs, S., Geismann, C., Grossmann, M., Kruse, M.L., Schreiber, S., Schäfer, H. Inhibition of the Nrf2 transcription factor by the alkaloid trigonelline renders pancreatic cancer cells more susceptible to apoptosis through decreased proteasomal gene expression and proteasome activity. Oncogene. 2013, 32 (40), S. 4825-35. 
41. Wang, X.J., Sun, Z., Villeneuve, N.F., Zhang, S., Zhao, F., Li, Y., Chen ,W., Yi, X., Zheng, W., Wondrak, G.T., Wong, P.K., Zhang, D.D. Nrf2 enhances resistance of cancer cells to chemotherapeutic drugs, the dark side of Nrf2. Carcinogenesis. 2008, 29, S. 1235 1243 .

42. Hayashi, A., Suzuki, H., Itoh, K., Yamamoto, M., Sugiyama, Y. Transcription factor $\mathrm{Nrf} 2$ is required for the constitutive and inducible expression of multidrug resistanceassociated protein 1 in mouse embryo fibroblasts. Biochem Biophys Res Commun. 2003, 310(3), S. 824-9.

43. Vollrath, V., Wielandt, A.M., Iruretagoyena, M., Chianale, J. Role of Nrf2 in the regulation of the Mrp2 (ABCC2) gene. Biochem J. 2006, 395(3), S. 599-609.

44. Meijerman, I., Beijnen, J.H., Schellens, J.H. Combined action and regulation of phase II enzymes and multidrug resistance proteins in multidrug resistance in cancer. Cancer Treat Rev. 2008.

45. Arfmann-Knübel, S., Struck, B., Genrich, G., Helm, O., Sipos, B., Sebens, S., Schäfer, H. The crosstalk between Nrf2 and TGF- 1 in the epithelial-mesenchymal transition of pancreatic duct epithelial cells. PLos One. 2015, doi: 10.1371/journal.pone. 0132978.

46. Genrich, G., Kruppa, M., Lenk, L., Helm, O., Broich, A., Freitag-Wolf, S., Röcken, C., Sipos, B., Schäfer, H., Sebens, S. The anti-oxidative transcription factor Nuclear factor E2 related factor-2 (Nrf2) counteracts TGF- $\beta 1$ mediated growth inhibition of pancreatic ductal epithelial cells -Nrf2 as determinant of pro-tumorigenic functions of TGF- $\beta 1$. BMC Cancer. 25. Feb 2016, S. 16:155.

47. Chen, B.P., Liang, G., Whelan, J., Hai, T. ATF3 and ATF3 delta Zip. Transcriptional repression versus activation by alternatively spliced isoforms. J Biol Chem. 1994, 269 (22), S. 15819-26.

48. Hashimoto, Y., Zhang, C., Kawauchi, J., Imoto, I., Adachi, M.T., Inazawa, J., Amagasa, T., Hai, T., Kitajima, S. An alternatively spliced isoform of transcriptional repressor ATF3 and its induction by stress stimuli. Nucleic Acids Res. 2002, 30 (11), S. 2398406.

49. Hai, T., Wolfgang, C.D., Marsee, D.K., Allen, A.E., Sivaprasad, U. ATF3 and stress responses. Gene Expr. 1999, 7 (4-6), S. 321-35.

50. Miyazaki, K., Inoue, S., Yamada, K., Watanabe, M., Liu, Q., Watanabe, T., Adachi, M.T., Tanaka, Y., Kitajima, S. Differential usage of alternate promoters of the human stress response gene ATF3 in stress response and cancer cells. Nucleic Acids Res. 2009, 37 (5), S. $1438-51$.

51. Yin, X., Dewille, J.W., Hai, T. A potential dichotomous role of ATF3, an adaptiveresponse gene, in cancer development. Oncogene. 2008, 27 (15), S. 2118-27.

52. Dziunycz, P.J., Lefort, K., Wu, X., Freiberger, S.N., Neu, J., Djerbi, N., IotzowaWeiss, G., French, L.E., Dotto, G.P., Hofbauer, G.F.L. The oncogene ATF3 is potentiated by cyclosporine A and ultraviolet light A. J Invest Dermatol. 2014, 134(7), S. 1998-2004.

53. Kim, K.H., Jeong, J.Y., Surh, Y.J., Kim, K.W. Expression of stress-response ATF3 is mediated by Nrf2 in astrocytes. Nucleic Acids Res. 2010, 38(1), S. 48-59. 
54. Mallano, T., Palumbo-Zerr, K., Zerr, P., Ramming, A., Zeller, B., Beyer, C., Dees, C., Huang, J., Hai, T., Distler, O., Schett, G., Distler, J.H. Activating transcription factor 3 regulates canonical TGF $\beta$ signalling in systemic sclerosis. Ann Rheum Dis. 2015.

55. Thompson, M.R., Xu, D., Williams, B.R. ATF3 transcription factor and its emerging roles in immunity and cancer. $J$ Mol Med (Berl). 2009, 11, S. 1053-1060.

56. Yan, C., Wang, H., Boyd, D.D. ATF3 Represses 72-kDa Type IV Collagenase (MMP-2) Expression by Antagonizing p53-dependent trans-Activation of the Collagenase Promoter. $J$ Biol Chem. 2002, 277(13), S. 10804-12.

57. Brown, S.L., Sekhar, K.R., Rachakonda, G., Sasi, S., Freeman, M.L. Activating transcription factor 3 is a novel repressor of the nuclear factor erythroid-derived 2-related factor 2 (Nrf2)-regulated stress pathway. Cancer Res. 2008, 68 (2), S. 364-8.

58. Jiang, H.Y., Wek, S.A., McGrath, B.C., Lu, D., Hai, T., Harding, H.P., Wang, X., Ron, D., Cavener, D.R., Wek, R.C. Activating transcription factor 3 is integral to the eukaryotic initiation factor 2 kinase stress response. Mol Cell Biol. 2004, 24(3), S. 1365-77.

59. Weng, S., Zhou, L., Deng, Q., Wang, J., Yu, Y., Zhu, J., Yuan, Y. Niclosamide induced cell apoptosis via upregulation of ATF3 and activation of PERK in Hepatocellular carcinoma cells. BMC Gastroenterol. 2016, 16.

60. Pelzer, A.E., Bektic, J., Haag, P., Berger, A.P., Pycha, A., Schäfer, G., Rogatsch, H., Horninger, W., Bartsch, G., Klocker, H. The expression of transcription factor activating transcription factor 3 in the human prostate and its regulation by androgen in prostate cancer. J Urol. 2006, 175(4), S. 1517-1522.

61. Janz, M., Hummel, M., Truss, M., Wollert-Wulf, B., Mathas, S., Jöhrens, K., Hagemeier, C., Bommert, K., Stein, H., Dörken, B., Bargou, R.C. Classical Hodgkin lymphoma is characterized by high constitutive expression of activating transcription factor 3 (ATF3), which promotes viability of Hodgkin/Reed-Sternberg cells. Blood. 2006, 107(6):., S. 2536-2539.

62. Ishiguro, T., Nagawa, H., Naito, M., Tsuruo, T. Inhibitory effect of ATF3 antisense oligonucleotide on ectopic growth of HT29 human colon cancer cells. Jpn J Cancer Res. 2000, 91(8):, S. 833-836.

63. Wang, A., et al. The transcription factor ATF3 acts as an oncogene in mouse mammary tumorigenesis. BMC Cancer. 2008, 8:268.

64. Wang, A., Arantes, S., Conti, C., McArthur, M., Aldaz, C.M., MacLeod, M.C. Epidermal hyperplasia and oral carcinoma in mice overexpressing the transcription factor ATF3 in basal epithelial cells. Mol Carcinog. 2007, 46, S. 476-487.

65. Syed, V., Mukherjee, K., Lyons-Weiler, J., Lau, K.M., Mashima, T., Tsuruo, T., Ho, S.M. Identification of ATF-3, caveolin-1, DLC-1, and NM23-H2 as putative antitumorigenic, progesterone-regulated genes for ovarian cancer cells by gene profiling. Oncogene. 2005, 24(10), S. 1774-1787.

66. Wang, Z., et al. Loss of ATF3 promotes Akt activation and prostate cancer development in a Pten knockout mouse model. 2015, 34(38), S. 4975-4984.

67. Rao, J., Qian, X., Li, G., Pan, X., Zhang, C., Zhang, F., Zhai, Y., Wang, X., Lu, L. ATF3-mediated NRF2/HO-1 signaling regulates TLR4 innate immune responses in mouse liver ischemia/reperfusion injury. Am J Transplant. 2015, 15(1), S. 76-87. 
68. Bakin, A.V., Stourman, N.V., Sekhar, K.R., Rinehart, C., Yan, X., Meredith, M.J., Arteaga, C.L., Freeman, M.L. Smad3-ATF3 signaling mediates TGF-beta suppression of genes encoding Phase II detoxifying proteins. Free Radic Biol Med. 2005, 38(3), S. 375-87.

69. Hunt, D., Raivich, G., Anderson, P.N. Activating transcription factor 3 and the nervous system. Front Mol Neurosci. 2012, 14;5:7.

70. Müerköster, S., Wegehenkel, K., Arlt, A., Witt, W., Sipos, B., Kruse, M.-L., Sebens, T., Kloppel, G., Kalthoff, H., Folsch, U.R., Schafer, H. Tumor stroma interactions induce chemoresistance in pancreatic ductal carcinoma cells involving increased secretion and paracrine effects of nitric oxide and IL-1 . Cancer Res. 2004, 64, S. 1331-7.

71. Kimura, K., Wakamatsu, A., Suzuki, Y., Ota, T., Nishikawa, T., Yamashita, R., Yamamoto, J., Sekine, M., Tsuritani, K., Wakaguri, H., et al. Diversification of transcriptional modulation: large scale identification and characterization of putative alternative promoters of human genes. Genome Res. 2006, 16(1), S. 55-65.

72. Allen-Jennings, A.E., Hartman, M. G., Kociba, G.J., Hau, T. The roles of ATF3 in glucose homeostasis: a transgenic mouse model with liver dysfunction and defects in endocrine pancreas. J Biol Chem. 2001, 276, S. 29507-29514.

73. Xie, J.J., Xie, Y.M., Chen, B., Pan, F., Guo, J.C., Zhao, Q., Shen, J.H., Wu, Z.Y., Wu, J.Y., Xu, L.Y., Li, E.M. ATF3 functions as a novel tumor suppressor with prognostic significance in esophageal squamous cell carcinoma. Oncotarget. 30. Sep 2014, S. 5(18):8569-82.

74. Wang, Z., He, Y., Deng, W., Lang, L., Yang, H., Jin, B., Kolhe, R., Ding, H.F., Zhang, J., Hai, T., Yan, C. Atf3 deficiency promotes genome instability and spontaneous tumorigenesis in mice. Oncogene. 4. Jan 2018, S. 37(1):18-27.

75. Fazio, E.N., Young, C.C., Toma, J., Levy, M., Berger, K.R., Johnson, C.L., Mehmood, R., Swan, P., Chu, A., Cregan, S.P., Dilworth, F.J., Howlett, C.J., Pin, C.L. Activating transcription factor 3 promotes loss of the acinar cell phenotype in response to ceruleininduced pancreatitis in mice. Mol Biol Cell. 1. Sep 2017, S. 28(18):2347-2359.

76. Kha, M.-L., Hesse, L., Deisinger, F., Sipos, B., Röcken, C., Arlt, A., Sebens, S., Helm, O., Schäfer, H. The antioxidant transcription factor Nrf2 modulates the stress response and phenotype of malignant as well as premalignant pancreatic ductal epithelial cells by inducing expression of the ATF3 splicing variant $\Delta$ Zip2. Oncogene. 2018, doi.org/10.1038/s41388018-0518-3.

77. Esakky, P., Hansen, D.A., Drury, A.M., Moley, K.H. Cigarette smoke-induced cell cycle arrest in spermatocytes [GC-2spd(ts)] is mediated through crosstalk between Ahr-Nrf2 pathway and MAPK signaling. J Mol Cell Biol. 2015, 7(1):, S. 73-87.

78. Hiss, D.C., Gabriels, G.A. Implications of endoplasmic reticulum stress, the unfolded protein response and apoptosis for molecular cancer therapy. Part I: targeting p53, Mdm2, GADD153/CHOP, GRP78/BiP and heat shock proteins. Expert Opin Drug Discov. 2009, 4(8):, S. 799-821.

79. Sano, R., Reed, J.C. ER stress-induced cell death mechanisms. Biochim Biophys Acta. 2013, 1833(12), S. 3460-3470. 
80. O'Brien, A., Barber, J.E., Reid, S., Niknejad, N., Dimitroulakos, J. Enhancement of cisplatin cytotoxicity by disulfiram involves activating transcription factor 3. Anticancer Res. 2012, 32(7), S. 2679-2688.

81. Pan, Y., Chen, H., Siu, F., Kilberg, M. S. Amino acid deprivation and endoplasmic reticulum stress induce expression of multiple activating transcription factor-3 mRNA species that, when overexpressed in HepG2 cells, modulate transcription by the human asparagine synthetase promoter. J. Biol. Chem. 2003, 278, S. 38402-38412.

82. Dueber, E.C., Schoeffler, A.J., Lingel, A., Elliott, J.M., Fedorova, A.V., Giannetti, A.M., Zobel, K., Maurer, B., Varfolomeev, E., Wu, P., Wallweber, H.J., Hymowitz, S.G., Deshayes, K., Vucic, D., Fairbrother, W.J. Antagonists induce a conformational change in cIAP1 that promotes autoubiquitination. Science. 2011, 334(6054), S. 376-80.

83. Mei, Y., Hahn, A.A., Hu, S., Yang, X. The USP19 deubiquitinase regulates the stability of c-IAP1 and c-IAP2. J Biol Chem. 2011, 286(41), S. 35380-7.

84. Ju, H.Q., Gocho, T, Aguilar, M., Wu, M., Zhuang, Z.N., Fu, J., Yanaga, K., Huang, P., Chiao, P.J. Mechanisms of overcoming intrinsic resistance to gemcitabine in pancreatic ductal adenocarcinoma through the redox modulation. Mol. Cancer Ther. 2015, Bd. 14, S. 788-798.

85. Palam, L.R., Gore, J., Craven, K.E., Wilson, J.L., Korc, M. Integrated stress response is critical for gemcitabine resistance in pancreatic ductal adenocarcinoma. Cell Death Dis. 15. Oct 2015.

86. Yin, X., Wolford, C.C., Chang, Y.S., McConoughey, S.J., Ramsey, S.A., Aderem, A., Hai, T. ATF3, an adaptive-response gene, enhances TGF \{beta $\}$ signaling and cancer-initiating cell features in breast cancer cells. J Cell Sci. 15. Oct 2010, S. 123(Pt 20):3558-65.

87. Jiang, X., Kim, K.J., Ha, T., Lee, S.H. Potential Dual Role of Activating Transcription Factor 3 in Colorectal Cancer. Anticancer Res. Feb 2016, S. 36(2):509-16. 


\section{Veröffentlichungen}

Teile dieser Arbeit wurden auf folgendem Kongress vorgestellt:

Kha, M.-L.; Hesse, L.; Bauer, I., Witt-Ramdohr, M.; Schäfer, H. (2015): Variantenspezifische Wirkung des Transkriptionsfaktors ATF3 in Zusammenhang mit Nrf2-abhängiger Stressantwort in Pankreaskarzinomzellen. Präsentiert auf der Jahrestagung der Deutschen Gesellschaft für Gastroenterologie, Verdauungs- und Stoffwechselkrankheiten (DGVS) in Leipzig. Z Gastroenterol; 53 - KG223; DOI: 10.1055/s-0035-1559249.

Weiterhin wurden Teile dieser Arbeit in folgender Fachzeitschrift veröffentlicht:

Kha, M.-L.; Hesse, L.; Deisinger, F.; Sipos, B.; Röcken, C.; Arlt, A.; Sebens, S.; Helm, O.; Schäfer, H. (2018): The antioxidant transcription factor Nrf2 modulates the stress response and phenotype of malignant as well as premalignant pancreatic ductal epithelial cells by inducing expression of the ATF3 splicing variant $\Delta$ Zip2. Oncogene; doi.org/10.1038/s41388018-0518-3. 


\section{Danksagung}

Im Folgenden möchte ich mich bei den Personen bedanken, die mich bei der erfolgreichen Anfertigung dieser Arbeit unterstützt haben.

Mit Beginn meines Interesses an die medizinische Wissenschaft war die Suche nach einer geeigneten Arbeitsgruppe nicht einfach. Es war nicht selbstverständlich, dass man Engagement, Ehrgeiz, Spaß und Freude an der Forschung, sowie kollegialen und freundschaftlichen Umgang vereint antrifft. Eine Arbeitsgruppe mit solchen Eigenschaften habe ich in der AG Schäfer gefunden. Allen voran gebührt mein größter Dank meinem Doktorvater Herrn Prof. Dr. rer. nat. Heiner Schäfer und Frau Prof. Dr. rer. nat. Susanne Sebens, die mir insgesamt eine sehr positive Erfahrung in der medizinischen Forschung ermöglicht haben. Als Doktorvater leistete Prof. rer. nat. Heiner Schäfer mit seiner engagierten, motivierenden Persönlichkeit und seiner zuverlässigen Betreuung einen wesentlichen Beitrag zum Gelingen meiner Forschungsarbeit, wofür ich mich herzlich bedanken möchte.

Allen Mitgliedern der Arbeitsgruppe von Herrn Prof. Schäfer sowie den Mitarbeitern der Arbeitsgruppen von Prof. Arlt und Prof. Sebens möchte ich ebenfalls danken. Insbesondere gilt mein Dank Iris Kosmol und Maike Witt-Ramdohr für die ausgezeichnete Einarbeitungszeit und die stetige Hilfsbereitschaft in praktisch-technischen Angelegenheiten. Weiterhin danke ich Florian Deisinger, Kristina Diehl und Lisa Hesse für Hilfestellungen und Rat jeglicher Art und darüber hinaus natürlich auch für die gewonnene Freundschaft und die schöne Zeit im und außerhalb des Labors.

Zudem geht ein Dank an Herrn Prof. Dr. med. Stefan Schreiber, Direktor der Klinik für Innere Medizin I des Universitätsklinikums Schleswig-Holstein, Campus Kiel, für die Bereitstellung des Arbeitsplatzes.

Des Weiteren möchte ich mich bei meiner besten Freundin Despina Papadopoulos für die motivierenden und inspirierenden Worte und den stetigen Rückhalt in den letzten 10 Jahren bedanken. Ohne dich wäre ich nicht so weit gekommen.

Zum Schluss geht noch ein großer Dank an die Studienstiftung des deutschen Volkes für die finanzielle und ideelle Förderung während meines Medizinstudiums. 


\section{Erklärung}

Hiermit erkläre ich, dass die vorliegende Dissertation mit dem Thema „Variantenspezifische Wirkung des Transkriptionsfaktors ATF3 in Zusammenhang mit Nrf2-abhängiger Stressantwort in Pankreaskarzinomzellen“ abgesehen von der wissenschaftlichen Beratung meines Doktorvaters und der Betreuung im Labor für Molekulare Gastroenterologie und Hepatologie am Universitätsklinikum Schleswig-Holstein, Campus Kiel, von mir selbstständig und ohne fremde Hilfe angefertigt wurde. Ich versichere, dass in dieser Arbeit keine anderen als die angegebenen Quellen und Hilfsmittel verwendet sowie die wörtlich oder inhaltlich übernommenen Stellen als solche kenntlich gemacht wurden. Die Promotionsordnung der Medizinischen Fakultät der Christian-Albrechts-Universität Kiel in der jeweils gültigen Fassung war mir dabei bekannt und die Regeln guter wissenschaftlicher Praxis der Deutschen Forschungsgemeinschaft wurden eingehalten.

Weiterhin bestätige ich, dass ich bisher noch keinen Promotionsversuch unternommen habe und die Arbeit weder in gleicher noch in ähnlicher Form an anderer Stelle im Rahmen eines Prüfungsverfahrens einer anderen Prüfungsbehörde vorgelegen hat.

Kiel, den 15.Oktober 2018

My-Lan Kha, Verfasserin 